NBER WORKING PAPER SERIES

\title{
THE COSTS OF SOVEREIGN DEFAULT: EVIDENCE FROM ARGENTINA
}

\author{
Benjamin Hébert \\ Jesse Schreger \\ Working Paper 22270 \\ http://www.nber.org/papers/w22270
NATIONAL BUREAU OF ECONOMIC RESEARCH
1050 Massachusetts Avenue
Cambridge, MA 02138 \\ May 2016
}

We thank Laura Alfaro, Joaquin Blaum, Luigi Bocola, John Campbell, John Cochrane, Jeff Frieden, Gita Gopinath, Ed Glaeser, Paul Goldsmith-Pinkham, Réka Juhász, Eduardo Levy Yeyati, Matteo Maggiori, Mikkel Plagborg-Møller, Monika Piazzesi, Ken Rogoff, Martin Schneider, Alex Roth, Mary Bryce Millet Steinberg, Chris Tonetti, Christoph Trebesch, and Victoria Vanasco for helpful conversations. We thank John Leahy and three anonymous referees for comments that helped improve the paper. We thank Vivian Yue, Andreas Stathopoulos, and Graciela Kaminsky for excellent discussions. We thank Brent Neiman for feedback and for generously sharing data. We thank various seminar and conference audiences. We thank Stephen King, Vivek Anand, and Tom Adney of Markit for useful discussions about the data. Christine Rivera provided excellent research assistance. All errors are our own. The views expressed herein are those of the authors and do not necessarily reflect the views of the National Bureau of Economic Research.

At least one co-author has disclosed a financial relationship of potential relevance for this research. Further information is available online at http://www.nber.org/papers/w22270.ack

NBER working papers are circulated for discussion and comment purposes. They have not been peer-reviewed or been subject to the review by the NBER Board of Directors that accompanies official NBER publications.

(C) 2016 by Benjamin Hébert and Jesse Schreger. All rights reserved. Short sections of text, not to exceed two paragraphs, may be quoted without explicit permission provided that full credit, including $(\odot$ notice, is given to the source. 
The Costs of Sovereign Default: Evidence from Argentina

Benjamin Hébert and Jesse Schreger

NBER Working Paper No. 22270

May 2016

JEL No. F3,F4,G15

\section{ABSTRACT}

We estimate the causal effect of sovereign default on the equity returns of Argentine firms. We identify this effect by exploiting changes in the probability of Argentine sovereign default induced by legal rulings in the case of Republic of Argentina v. NML Capital. We find that a $10 \%$ increase in the probability of default causes a $6 \%$ decline in the value of Argentine equities and a $1 \%$ depreciation of a measure of the exchange rate. We examine the channels through which a sovereign default may affect the economy.

\section{Benjamin Hébert}

Stanford Graduate School of Business

655 Knight Way

Stanford, CA 94305

bhebert@stanford.edu

Jesse Schreger

Harvard Business School

Soldiers Field

Boston, MA 02163

and NBER

jschreger@hbs.edu

A Code Repository is available at https://github.com/bhebert/CostOfSovereignDefault 


\section{Introduction}

A fundamental question in international macroeconomics is why governments repay their debt to foreign creditors, given the limited recourse available to those creditors. The seminal paper of Eaton and Gersovitz (1981) argues that reputational concerns are sufficient to ensure that sovereigns repay their debt. In a famous critique, Bulow and Rogoff (1989b) demonstrate that reputation alone cannot sustain sovereign borrowing in equilibrium, without some other type of default cost or punishment. The size and features of this cost also play a key role in quantitative models of sovereign debt, beginning with Aguiar and Gopinath (2006) and Arellano (2008). Numerous empirical papers have been written trying to find the source and measure the size of these costs. The fundamental identification challenge is that governments usually default in response to deteriorating economic conditions, which makes it hard to determine if the default itself caused further harm to the economy.

The case of Republic of Argentina v. NML Capital provides a natural experiment to identify the causal effect of sovereign default. Following Argentina's sovereign default in 2001, NML Capital, a hedge fund, purchased some of the defaulted bonds and refused to join other creditors in restructurings of the debt that occurred in 2005 and 2010. Instead, because the defaulted debt was issued under New York law, NML sued the Argentine government in U.S. courts to receive full payment. To compel the Argentine government to repay the defaulted debt, the U.S. courts blocked Argentina's ability to pay its restructured creditors, unless NML and the other holdout creditors also received payments. The Argentine government resisted paying the holdouts, even though the required payments would be small relative to the Argentine economy. As a result, legal rulings in favor of NML raised the probability that Argentina would default on its restructured bonds, while rulings in favor of Argentina lowered this probability.

We argue that these legal rulings are exogenous shocks to the risk-neutral probability of default ${ }^{1}$ that allow us to identify the causal effect of sovereign default on the market value of Argentine firms. Our key identifying assumption is that the information revealed to market participants by these legal rulings affects firms' stock returns only through the effect on the sovereign's risk-neutral probability of default. This assumption requires that the judges in U.S. courts making these rulings do not have private information about

\footnotetext{
${ }^{1}$ In our context, the "risk-neutral probability of default" is the probability that a risk-neutral agent would have to assign to Argentina defaulting within the next five years to be indifferent between buying and selling a credit default swap on Argentina. The actual, or physical, default probability could differ from the risk-neutral probability if market participants are risk-averse with respect to Argentine default. Computing the risk-neutral probability of default from credit default swap prices involves several assumptions (see appendix section A.4).
} 
the Argentine economy. This assumption also requires that the firms we study are not directly affected by the rulings. Consistent with this assumption, Argentine firms are legally separate from the federal government of Argentina and are not subject to attachment of their assets by creditors of the sovereign. We discuss other potential challenges to our identifying assumption in more detail in section 6 .

We use credit default swaps (CDS) to measure the change in the risk-neutral probability of default. Compiling rulings from the United States District Court for the Southern District of New York, the Second Court of Appeals, and United States Supreme Court, we isolate fifteen rulings that potentially changed the risk-neutral probability of default. We identify the effect of changes in this default probability on equity returns through heteroskedasticity, following Rigobon (2003) and Rigobon and Sack (2004). ${ }^{2}$ We describe this procedure and our identification assumptions in detail in section 4 . We find that, for every $10 \%$ increase in the 5-year cumulative risk-neutral default probability around these rulings, the U.S. dollar value of a value-weighted index of Argentine American Depository Receipts $\left(\mathrm{ADRs}^{3}\right.$ ) falls roughly 6\%. Between January 3, 2011, when our data starts, and July 30, 2014, when Argentina defaulted, the risk-neutral 5year default probability increased from roughly $40 \%$ to $100 \%$. Linearly extrapolating our estimate of the causal effect on log returns implies that this episode reduced the value of the Argentine firms in the index by $30 \%$. We also find that a $10 \%$ increase in the 5-year cumulative risk-neutral default probability causes a $1 \%$ depreciation in our preferred measure of the Argentine unofficial exchange rate. ${ }^{4}$ The most direct interpretation of the risk-neutral default probability changes and stock returns we study is that they reflect changes in the actual probability of default and the expected value of the stream of dividends paid by the firms. However, alternative interpretations are possible, and we discuss them in section 6.

To better understand how this sovereign default was expected to affect the economy, we examine which types of firms are harmed more or less by an increase in the probability of default. We sort firms along the dimensions suggested by the theoretical sovereign debt literature ${ }^{5}$, as well as on some additional firm characteristics. We find suggestive evidence that foreign-owned firms, exporters, banks ${ }^{6}$, and large firms are

\footnotetext{
${ }^{2}$ In appendix section $\mathrm{D}$, we run a traditional event study, and find similar results.

${ }^{3}$ ADRs are shares in foreign firms that trade on U.S. stock exchanges in U.S. dollars.

${ }^{4}$ We focus on unofficial measures of the exchange rate because Argentina had capital controls during this period. These measures are discussed in section 3.4.

${ }^{5}$ Bulow and Rogoff (1989a), Mendoza and Yue (2012), and Cole and Kehoe (1998) motivate us to study exporting firms, importing firms, and foreign-owned firms, respectively. Numerous authors (e.g. Gennaioli et al. (2014), Acharya et al. (2014a), Bolton and Jeanne (2011), Bocola (2013) and Perez (2014)) have offered explanations for why banks would be particularly harmed by sovereign default.

${ }^{6}$ Our point estimates are negative and economically significant for banks, consistent with the theoretical literature, but our standard errors are too large to reject the hypothesis of no differential effects.
} 
hurt more by increases in the probability of sovereign default than would be expected, given their "beta" to the Argentine market and exchange rate.

This paper contributes to a large empirical literature examining the costs of sovereign default, surveyed by Borensztein and Panizza (2009) and Tomz and Wright (2013). Using quarterly time series, Levy Yeyati and Panizza (2011) find that output generally falls in anticipation of a sovereign default and that the default itself tends to mark the beginning of the recovery. Rose (2005) documents that bilateral trade between creditor countries and debtor countries falls after a default. Acharya et al. (2014b) examine the effect of the European sovereign debt crisis on syndicated loan supply and firm behavior. Arteta and Hale (2008) observe that during a sovereign default, external credit to the private sector is reduced. Schumacher et al. (2014) study sovereign debt litigation across a range of countries over the past forty years. Using cross-country panel data, Gornemann (2014) finds a persistent drop in output following a sovereign default. Methodologically, our paper uses a natural experiment to estimate the causal effect of sovereign default. Fuchs-Schundeln and Hassan (2015) survey the literature on natural experiments in macroeconomics. Our cross-sectional analysis is methodologically related to Bernanke and Kuttner (2005) and Gorodnichenko and Weber (2013).

This paper is also related to the literature on quantitative models of sovereign debt, initiated by Aguiar and Gopinath (2006) and Arellano (2008). This literature attempts to simultaneously explain sovereign default decisions, debt levels, credit spreads, and business cycle facts for emerging market countries. In many of these papers, the magnitude of the exogenous output cost of default is one of the key parameters that determines the equilibrium quantity of debt issued and the incidence of default. This literature also emphasizes the cyclical properties of the output cost (Arellano (2008), Chatterjee and Eyigungor (2012)) necessary to explain the observed facts, and develops theories to explain the source of these costs (Mendoza and Yue (2012), Bocola (2013), Perez (2014), Gornemann (2014)). Our evidence speaks to both the size and source of these costs, but further work is needed to relate our findings to this class of models.

This paper is structured as follows: Section 2 discusses the case of Republic of Argentina v. NML Capital. Section 3 describes the data and presents summary statistics. Section 4 presents our estimation framework and results. Section 5 discusses the firm characteristics that are associated with larger responses to changes in the probability of default. Section 6 discusses institutional details and alternative interpretations of the results. Section 7 concludes. 


\section{Argentina's Sovereign Debt Saga}

In 2001, Argentina entered a deep recession, with unemployment reaching $14.7 \%$ in the fourth quarter of that year. In December 2001, after borrowing heavily from the IMF, Argentina defaulted on over $\$ 100$ billion in external sovereign debt and devalued the exchange rate by $75 \%{ }^{7}$

The Argentine government then spent three years in failed negotiations with the IMF, the Paris Club, and its private creditors. In January 2005, Argentina presented a unilateral offer to its private creditors, which was accepted by the holders of $\$ 62.3$ billion of the defaulted debt. Despite the existence of the holdout creditors, S\&P declared the end of the Argentine default in June 2005 and upgraded Argentina's long-term sovereign foreign currency credit rating to B-. In 2006, Argentina fully repaid the IMF, and Argentina reached an agreement with the Paris Club creditors in May 2014.

In December 2010, Argentina offered another bond exchange to the remaining holdout creditors. Holdout private creditors who were owed $\$ 12.4$ billion of principal agreed to the exchange. Following this exchange, on December 31, 2010, the remaining holdout creditors were owed an estimated $\$ 11.2$ billion, split between $\$ 6.8$ billion in principal and $\$ 4.4$ billion in accumulated interest. ${ }^{8}$ At this point, Argentina had restructured over $90 \%$ of the original face value of its debt.

Following the 2010 debt exchange, the remaining holdout creditors- termed "vultures" by the Argentine government- continued their legal battle. This litigation eventually culminated in Argentina's 2014 default on its restructured bondholders. The creditors, led by NML Capital, ${ }^{9}$ argued that the Argentine government breached the pari passu clause, which requires equal treatment of all bondholders, by paying the restructured bondholders and refusing to honor the claims of the holdouts.

The case took several years to work its way through the U.S. courts, going from the United States District Court for the Southern District of New York ("Southern District"), to the United States Court of Appeals for the Second Circuit ("Second Circuit"), all the way to the United States Supreme Court. These three courts issued numerous rulings between December 2011, when Judge Thomas P. Griesa of the Southern District first ruled in favor of the holdouts on the pari passu issue, and July 2014, when Argentina defaulted.

\footnotetext{
${ }^{7}$ Data and facts cited in this section are from Global Financial Data, Daseking et al. (2005), Hornbeck (2013), and Thomas and Marsh (2014).

${ }^{8}$ The interest on the defaulted debt has continued to accumulate since 2010 , with the total amount owed reaching $\$ 15$ billion in 2014 (Gelpern (2014a)). However, some of these claims may never be repaid, due to issues related to the statute of limitations (Millian and Bartenstein (2016)).

${ }^{9}$ Elliott Management Corporation, the parent company of NML, has a long history in litigating against defaulting countries. See Gulati and Klee (2001) for a discussion of Elliott's litigation against Peru and Panizza et al. (2009) for a literature review on the law and economics of sovereign default.
} 
Following Griesa's initial ruling in December 2011, years of legal wrangling ensued over what this ruling meant and how it would be enforced. Griesa clarified that Argentina was required to repay the holdouts as long as it continued to the pay the restructured bondholders (using a "ratable" payment formula). Argentina was not willing to comply with this ruling, and continued to pay the restructured bondholders without paying the holdouts. Griesa then ordered the financial intermediaries facilitating Argentina's payments to stop forwarding payments to the restructured bondholders, until Argentina also paid the holdouts. Griesa also ordered Argentina to negotiate with the holdouts, but the holdouts and the courts rejected Argentina's offer of a deal comparable to the 2005 and 2010 bond exchanges. Argentina then twice appealed to the Supreme Court, with the Supreme Court declining to hear either appeal. Following the decline of the second appeal on June 16, 2014, Griesa's orders were implemented, and Argentina had only two weeks before a coupon to the restructured creditors was due. Against court orders, Argentina sent this coupon payment to the bond trustee, Bank of New York Mellon (BNYM), but, as ordered by the court, BNYM did not forward to the payment to the restructured bondholders. Argentina's restructured bonds did not receive a coupon payment on June 30, which began a 30-day grace period. Negotiations failed, and the International Swaps and Derivatives Association (ISDA) declared that a credit event had occurred for credit default swaps referencing Argentina's restructured bonds on August 1, 2014. On September 3, 2014, the auction associated with the settlement of the CDS contracts was held, and it resulted in a recovery rate of 39.5 cents on the dollar. $^{10}$

The cumulative effect of these legal rulings was to change the menu of options available to Argentina. The status quo option, in which Argentina continued to pay its restructured bondholders without paying the holdouts, became infeasible. Instead, Argentina could attempt to settle with the holdouts and avoid defaulting on its restructured bondholders, or it could default on the restructured bondholders.

Argentina effectively chose to default. In the simplest interpretation of these events, making the required payments was not possible, and Argentina was forced to default by the U.S. court system. This was the interpretation offered by a number of commentators in the financial press (e.g. O'Brien (2014)). However, if a settlement was possible, the rulings might have also raised the probability of a settlement. If Argentine firms would be affected by a settlement, through some channel other than the avoidance of a sovereign default, then the exclusion restriction of our experiment would not hold. In section 6, we argue that such

\footnotetext{
${ }^{10}$ The low recovery rate reflects both the decline in the price of Argentina's bonds from 2011 to 2014, and the fact that some (the "cheapest to deliver") of Argentina's bonds had relatively low coupons, and therefore low prices, when they were issued.
} 
channels are not plausible, because the amount of money required for a settlement was small.

As of this writing (May 2016), Argentina has not yet resumed payments on its restructured bonds. However, an end to the default appears imminent (Platt and Mander (2016)). In a closely contested election in the fall of 2015, Argentina elected a new president, whose platform included a promise to settle with the holdout creditors. Argentina reached an agreement with the main litigating holdouts, passed a law allowing payments to the holdouts, and convinced the U.S. courts to lift their injunctions. The settlement is reported as being worth roughly $75 \%$ of the full value of the judgements obtained by the litigating holdouts (Politi and Yuk (2016)), and will cost around $\$ 12.5$ billion if accepted by all of the holdouts (Mander and Moore (2016)). Argentina recently issued $\$ 16.5$ billion of new debt, for the stated purpose of repaying the holdouts, making the restructured bonds current, and increasing Argentina's dollar reserves.

\section{Data and Summary Statistics}

\subsection{Stock Market and CDS Data}

Our dataset consists of daily observations of financial variables from January 3, 2011 to July 29, 2014 (the day before Argentina most recently defaulted). We study the returns of ADRs(U.S. dollar-denominated claims on underlying local equities) issued by Argentine firms and traded in the United States, as well the returns of Argentine peso-denominated equities traded in Argentina. The ADRs trade on the NYSE and NASDAQ, are relatively liquid, and are traded by a wide range of market participants. ${ }^{11}$ However, using only the ADRs limits our analysis to twelve firms that have exchange-traded ADRs. To study the crosssectional patterns of Argentine firms, we also examine the returns of firms traded only in Argentina. The full list of firms included in our analysis, along with select firm characteristics, is available in appendix table 2.

The most commonly cited benchmark for Argentine ADRs is the MSCI Argentina Index, an index of six Argentine ADRs. We also construct our own indices of ADRs, covering different sectors of the Argentine economy. We classify Argentine firms by whether they are a bank, a non-financial firm, or a real estate holding company. The industry classifications are based on the Fama-French 12 industry classification and

\footnotetext{
${ }^{11}$ Edison and Warnock (2004) document that ADRs that trade on the NYSE and NASDAQ are incorporated into U.S. investors' portfolios at float-adjusted market weights; that is, they are not subject to the "home bias" that causes U.S. investors to underweight foreign stocks more generally. In contrast, several market participants have told us that capital controls and related barriers were significant impediments to their participation in local Argentine equity markets during the time period we study.
} 
are listed in appendix table 2. We construct value-weighted indices for the entire market and each of these industries, except real estate. ${ }^{12}$ The value-weighted indices we construct exclude YPF, the large oil company that was nationalized in 2012.

We use credit default swap (CDS) spreads to measure the risk-neutral probability of default. A CDS is a financial contract in which the seller of the swap agrees to insure the buyer against the possibility that a reference entity (in this case, the Republic of Argentina) defaults on a particular set of bonds issued by that entity. Once a third party, the International Swaps and Derivatives Association (ISDA), declares a credit event, an auction occurs to determine the price of the defaulted debt. The CDS seller then pays the buyer the difference between the face and auction value of the debt. In appendix section A.4, we provide details on how Markit, our data provider, imputes risk-neutral default probabilities from the term structure of CDS spreads using the ISDA Standard Model. We focus on the 5-year cumulative default probability, the risk-neutral probability that Argentina defaults within 5 years of the CDS contract initiation. ${ }^{13}$

Because we want to capture the abnormal variation in Argentine CDS and equity returns caused by changes in the probability of default, we would like to account for other global factors that may affect both measures. Controlling for these factors is not necessary, under our identification assumptions, but can reduce the magnitude of our standard errors. To proxy for risk aversion, we use the VIX index, the 30-day implied volatility on the S\&P 500. ${ }^{14}$ We use the S\&P 500 to measure equity returns and we use the MSCI Emerging Markets Asia ETF to proxy for factors affecting emerging markets generally. We use the Asia index to ensure that movements in the index are not directly caused by fluctuations in Argentine markets. To control for aggregate credit market conditions, we use the Markit CDX High Yield and Investment Grade CDS indices. We also control for crude oil prices (West Texas Intermediate). These controls are included in all specifications reported in this paper, although our results are qualitatively similar when using a subset of these factors, or no controls at all. In our discussion, we will assume that the legal rulings we study do not affect these controls; if this assumption were false, our estimates would measure the effect of the legal rulings on firms above and beyond what would be expected, given the effects on our control variables (see

\footnotetext{
${ }^{12}$ We do not include a value-weighted real estate index in the results because there are only two closely-related firms in this sector. We have also constructed equal-weighted indices, and found similar results.

${ }^{13}$ We prefer the 5-year cumulative default probability measure because we believe that shocks which move default probability from (for example) one year ahead to two years ahead, without altering the cumulative default probability over those two years, should have only a minimal impact on stock valuations. Our results are qualitatively robust to using the 1- or 3-year cumulative default probability, and other CDS-based measures, subject to the caveat that the 1- and 3-year cumulative default probabilities are more volatile than the 5-year measure. Tenors longer than five years are not traded frequently. See appendix table 7 for details.

${ }^{14}$ See Longstaff et. al. (2011) for discussion of the relationship between the VIX and sovereign CDS spreads.
} 
section 5 for details).

\subsection{Definition of Events and Non-Events}

We build a list of legal rulings issued by Judge Griesa, the Second Circuit, and the Supreme Court. We have created this list using articles in the financial press (the Wall Street Journal, Bloomberg News, and the Financial Times), LexisNexis searches, and publicly available information from the website of Shearman, a law firm that practices sovereign debt law.

In appendix section J, we list all of these events and links to the relevant source material. Unfortunately, for many of the events, we are unable to determine precisely when the ruling was issued. We employ several methods to determine the timing of rulings. First, we examine news coverage of the rulings, using Bloomberg News, the Financial Times, and LexisNexis searches. Sometimes, contemporaneous news coverage specifically mentions when the ruling was released. Second, we use the date listed in the ruling. Third, many of rulings are released in the PDF electronic format, and have a "creation time" and/or "modification time" listed in the meta-information of the PDF file. In appendix section J, we list the information used to determine the approximate time of each ruling.

For our main analysis, we use two-day event windows. Consider the Supreme Court ruling on Monday, June 16th, 2014. The two-day event window, applied to this event, would use the CDS spread change from the close on Thursday, June 12th to the close on Monday, June 16th. It would use stock returns (for both ADRs and local stocks) from 4pm EDT on Thursday, June 12th to 4pm EDT on Monday, June 16th. ${ }^{15}$

For our two-day event windows, we choose our sample of non-events to be a set of two-day risk-neutral default probability changes and stock returns, non-overlapping, at least two days away from any event, and at least two days away from any of the "excluded events." "Excluded events" are legal rulings that we do not use, but also exclude from our sample of non-events. ${ }^{16}$ For the heteroskedasticity-based identification strategy we employ, removing these legal rulings increases the validity of our identifying assumption that

\footnotetext{
${ }^{15}$ For events occurring outside of daylight savings time in the eastern time zone, the local stocks close at 5pm ART (3pm EST), while the ADRs use 4pm EST. We do not correct for this. For some events, we are certain about the day of the event. For these events, we place the event on the first day of the two-day window; however, our results are robust to placing the event on the second day of the two-day window instead (see appendix section E.1). We also report our results using one-day windows in appendix section E.1.

${ }^{16}$ We exclude three rulings for which we could not find any contemporaneous media coverage. For one ruling, we could not find the ruling itself. One of the rulings was issued on the Friday in October 2012 shortly before "Superstorm Sandy" hit New York, and another the night before Thanksgiving. One of the legal rulings was issued at the beginning of an oral argument, in which Argentina's lawyers may have revealed information about Argentina's intentions. Finally, we exclude the ruling made on July 28th, 2014, because this ruling was made very close to the formal default date, and news articles on that day focused on the last-minute negotiations, not the ruling. Our results are qualitatively similar when we include this ruling.
} 
the variance of shocks induced by legal rulings is higher on event days than non-event days. However, our results are robust to including these days in the set of non-events.

\subsection{Summary of Events and Non-Events}

In figure 3a, we plot the two-day change in the 5-year risk-neutral default probability and the two-day return of value-weighted index over our sample. Small data points in light gray are non-events and the maroon/dark dots cover event windows in which a U.S. court ruling was released. The details on each event can be found in appendix section J. In figure $3 \mathrm{~b}$, we construct the equivalent figure for the MSCI Mexico equity index and the change in Argentina's probability of default. Comparing the figure for the Argentine value-weighted equity index with the figure for the Mexican index, we see that on the non-event days, both stock indices co-move with our Argentine default probability measure. However, on the event days, only the Argentine equity index co-moves with the Argentine default probability measure. This observation suggests that omitted common factors might not be very important on our event days, consistent with the result that our event studies and heteroskedasticity-based identification strategy reach similar conclusions. In appendix section B, we present similar figures for the different sectors of the Argentine economy and measures of the exchange rate.

[Insert figure 3 here]

In the table below, we present summary statistics for the returns of our value-weighted ADR index and the changes in 5-year risk-neutral default probabilities, during the two-day event and non-event windows.

[Insert table 1 here]

\subsection{Exchange Rates}

We also study the effect of sovereign default on exchange rates. However, "the exchange rate" was difficult to measure during this period. Argentina imposed capital controls in 2002, strengthened them in 2011, and then relaxed them at the end of 2015, after our sample ends. During the 2011-2014 period, the official exchange rate diverged from the exchange rates implied by other markets. We will consider three different measures of these parallel exchange rates, known as the Blue Dollar. All of them are based on the rate at which individuals could actually transact, subject to various transaction costs. 
The first unofficial exchange rate that we consider is the one that Argentines could use to buy dollars from black market currency dealers. Dolarblue.net published this rate daily and was the source used by many Argentines as a reference for the exchange rate. This onshore rate is known as the Dolar Blue or the Informal dollar, among many other names. This is our preferred measure of Argentina's market exchange rate.

The other two measures of the unofficial exchange rate we study come directly from market prices and provide a way for onshore currency dealers to secure dollars. Both rely on the fact that even though the Argentine peso was a non-convertible currency, securities can be purchased onshore in pesos and sold offshore in dollars. The first class of instruments for which this can be done are domestic law Argentine government bonds, and the exchange rate associated with this transaction is known as the "blue-chip swap" rate. We can construct a similar measure of the exchange rate, known as the "ADR blue rate," by using equities rather than debt. We describe the construction of both measures in appendix section A.3. ${ }^{17}$

\section{[Insert Figure 1 here]}

In Figure 1, we plot all four of these exchange rates during our sample period. Throughout this period, the official rate is significantly below the unofficial rates. The ADR blue rate and the blue-chip swap rate are virtually indistinguishable (at low frequencies) during this period, and co-move with the Dolar Blue rate.

The three parallel exchange rates we consider are not equivalent to a (hypothetical) freely-floating exchange rate. All three depend on local markets that were difficult for foreigners to access, and were potentially subject to government intervention. We found news articles stating that, during the 2011-14 period, the Argentine government occasionally intervened in local (peso-denominated) bond and stock markets to manage these parallel exchange rates. Moreover, the premium demanded by black market currency dealers for dollars would fluctuate based on the vigor with which the government prosecuted those dealers (Parks and Natarajan (2013)).

\footnotetext{
${ }^{17}$ Auguste et al. (2006) explore how the convertibility of ADRs provides a way around capital controls. Both of our measures rely on Argentine local markets, which are illiquid, and therefore can be quite noisy at high frequencies. Pasquariello (2008) documents that, for countries with convertible currencies, ADR parity does not always hold, and that the violations of ADR parity are more common around financial crises. As a result, we should not necessarily expect our ADR-based measure and the dolar blue to respond identically to the legal rulings.
} 


\subsection{Case Study: Supreme Court Announcement}

For one of our events, we are able to precisely determine when the event occurred. On June 16, 2014, the U.S. Supreme Court denied two appeals and a petition from the Republic of Argentina. The denial of Argentina's petition meant that Judge Griesa could prevent the Bank of New York Mellon, the payment agent on Argentina's restructured bonds, from paying the coupons on those bonds unless Argentina also paid the holdouts. Because Argentina had previously expressed its unwillingness to pay the holdouts, this news meant that Argentina was more likely to default. ${ }^{18}$

The Supreme Court announces multiple orders in a single public session, and simultaneously provides copies of those orders to the press. SCOTUSBlog, a well-known legal website that provides news coverage and analysis of the Supreme Court, had a "live blog" of the announcements on June 16th, 2014. At 9:33am EST, SCOTUSBlog reported that "Both of the Argentine bond cases have been denied. Sotomayor took no part" (Howe (2014)). At 10:09am, the live blog stated that Argentina's petition had been denied. At 10:11am, the live blog provided a link to the ruling. In figure 2, we plot the returns of the Argentine ADRs and the 5-year cumulative default probability, as measured by CDS. The ADRs begin trading in New York at 9:30am. The default probability is constructed from CDS spreads based on the Markit "sameday" data at 9:30am EST and 10:30am EST.

[ Insert figure 2 here]

From 9:30am to 10:30am, the MSCI Argentina Index fell 6\% and five-year cumulative risk-neutral default probability rose by $9.8 \%$. When the Argentine stock market opened, the local stocks associated with the MSCI Argentina Index opened 6.2\% lower than it closed the previous night, implying virtually no change in the ADR-based blue rate.

\section{Framework and Results}

In this section, we estimate the causal effect of sovereign default on equity returns using all of the events in our sample and two-day event windows. The key identification concerns are that stock returns might have an effect on default probabilities, and that unobserved common shocks might affect both the market-implied

\footnotetext{
${ }^{18}$ On the same day, the Supreme Court also allowed the holdouts to pursue discovery against all of Argentina's foreign assets, not just those in the United States.
} 
probability of default and stock returns. In our context, one example of the former issue is that poor earnings by large Argentine firms might harm the fiscal position of the Argentine government. An example of the latter issue is a shock to the market price of risk, which could cause both CDS spreads and stock returns to change.

We consider these issues through the lens of a simultaneous equation model (following Rigobon and Sack (2004)). While our actual implementation uses multiple assets and controls for various market factors, for exposition we discuss the log return of a single asset (the equity index, for example), $r_{t}$, and the change in the risk-neutral probability of default, $\Delta D_{t}$, and ignore constants. ${ }^{19}$ The model we consider is

$$
\begin{aligned}
\Delta D_{t} & =\gamma r_{t}+\kappa_{D} F_{t}+\varepsilon_{t} \\
r_{t} & =\alpha \Delta D_{t}+\kappa F_{t}+\eta_{t}
\end{aligned}
$$

where $F_{t}$ is a single unobserved factor that moves both the probability of default and equity returns, $\varepsilon_{t}$ is a shock to the default probability, $\eta_{t}$ is a shock to the equity market return, and all of these shocks are uncorrelated with each other and over time. The goal is to estimate the parameter $\alpha$, the impact of a change in the probability of default on equity market returns.

Our key identifying assumption is that the information revealed to market participants by the legal rulings affects firms' stock returns only through the effect on the sovereign's risk-neutral probability of default. This assumption is equivalent to asserting that the legal rulings are idiosyncratic default probability shocks $\left(\varepsilon_{t}\right)$ in the framework above. The assumption embeds both the requirement that the legal rulings be exogenous (the $\varepsilon_{t}$ shocks are not correlated with the other shocks) and that the exclusion restriction is satisfied (the $\varepsilon_{t}$ shocks affect returns only by affecting default probabilities).

If one were to simply run the regression in equation 2 using OLS, the coefficient estimate could be biased. There are two potential sources of bias: simultaneity bias (stock returns affect default probabilities) and omitted variable bias (unobserved common factors). ${ }^{20}$ In order for the OLS regression to be unbiased, equity market returns must not affect default probabilities and there must be no omitted common shocks. These assumptions are implausible in our context, but we present OLS results for comparison purposes.

We could rely on more plausible assumptions by adopting an event study framework (see, for instance,

\footnotetext{
${ }^{19}$ In appendix section I, we demonstrate how an equivalent system can be derived in a multi-asset framework.

${ }^{20}$ Rigobon and Sack (2004) discusses these biases in the context of this framework.
} 
Kuttner (2001) or Bernanke and Kuttner (2005)). In this case, the identifying assumption would be that changes to Argentina's risk-neutral probability of default during the event windows (time periods in which a U.S. court makes a legal ruling) are driven exclusively by those legal rulings, or other idiosyncratic default probability shocks $\left(\varepsilon_{t}\right)$. Under this assumption, we could directly estimate equation (2) using OLS on these ruling days. We present these results, and the details of the event studies, in appendix section D.

Our preferred specification uses a heteroskedasticity-based identification strategy, following Rigobon (2003) and Rigobon and Sack (2004). This does not require the complete absence of common and idiosyncratic shocks during event windows. This strategy instead relies on the identifying assumption that the variances of the common shocks $F_{t}$ and equity return shocks $\eta_{t}$ are the same on non-event days and event days, whereas the variance of the shock to the probability of default $\varepsilon_{t}$ is higher on event days than non-event days (because of the effects of the legal rulings, which we have assumed are $\varepsilon_{t}$ shocks). Under this assumption, we can identify the parameter $\alpha$ by comparing the covariance matrices of abnormal returns and abnormal default probability changes on event days and non-event days.

We divide all two-day periods in our sample into two types, events $(E)$ and non-events $(N)$. For each of the two types of two-day windows, $j \in\{E, N\}$, we estimate the covariance matrix of $\left[r_{t}, \Delta D_{t}\right]$, denoted $\Omega_{j}$ :

$$
\Omega_{j}=\left[\begin{array}{cc}
\operatorname{var}_{j}\left(r_{t}\right) & \operatorname{cov}_{j}\left(r_{t}, \Delta D_{t}\right) \\
\operatorname{cov}_{j}\left(r_{t}, \Delta D_{t}\right) & \operatorname{var}_{j}\left(\Delta D_{t}\right)
\end{array}\right]
$$

We can then define the difference in the covariance matrices during events and non-events as $\Delta \Omega=\Omega_{E}-\Omega_{N}$, which simplifies to ${ }^{21}$

$$
\Delta \Omega=\lambda\left[\begin{array}{ll}
\alpha^{2} & \alpha \\
\alpha & 1
\end{array}\right]
$$

where $\lambda=\left(\frac{\sigma_{\varepsilon, E}^{2}-\sigma_{\varepsilon, N}^{2}}{(1-\alpha \gamma)^{2}}\right)$.

The estimator we employ, which we call the CDS-IV estimator, is defined as

$$
\hat{\alpha}_{C I V}=\frac{\Delta \Omega_{1,2}}{\Delta \Omega_{2,2}}=\frac{\operatorname{cov}_{E}\left(\Delta D_{t}, r_{t}\right)-\operatorname{cov}_{N}\left(\Delta D_{t}, r_{t}\right)}{\operatorname{var}_{E}\left(\Delta D_{t}\right)-\operatorname{var}_{N}\left(\Delta D_{t}\right)}
$$

\footnotetext{
${ }^{21}$ Algebraic details can be found in Rigobon (2003).
} 
As shown in Rigobon and Sack (2004), this estimator can be implemented in an instrumental variables framework. While at first glance there may appear to be alternative estimators to estimate $\alpha$ based on $\Delta \Omega$, we believe they are not appropriate given our null hypothesis that $\alpha=0 .^{22}$

The CDS-IV instrument is relevant under the assumption that $\lambda>0$. We can reject the hypothesis that $\lambda=0$ using a test for equality of variances, which is described in appendix section F.1. The relevance of the CDS-IV instrument is also suggested by the weak-identification F-test of Stock and Yogo (2005), also reported in appendix section F.1. In table 2, we present the results of our CDS-IV estimation. The standard errors and confidence intervals use the bootstrap procedure described in appendix section C.

\section{[Insert table 2 ]}

\subsection{Equity Returns}

In the first five columns of Table 2, we report the effects of increases in the probability of default on different classes of Argentine equities. We focus on our preferred CDS-IV specification in the lower panel and report the OLS results in the upper panel for comparison purposes. We find that a $10 \%$ increase in the 5 -year cumulative risk-neutral default probability causes a negative $6.043 \%$ log-return for our value-weighted ADR index. We also find that increases in the cumulative risk-neutral probability of default cause statistically and economically significant declines in the MSCI Argentina Index, value-weighted bank ADR index, valueweighted non-financial ADR index, and the YPF ADR. The MSCI Argentina Index falls by substantially more than our value-weighted index because the MSCI Argentina Index consists mostly of YPF and bank ADRs, which fall by more than the ADRs of non-financial and real estate firms. We linearly extrapolate the $\log$-return to find that an increase in the risk-neutral default probability from $40 \%$ to $100 \%$, which is roughly what Argentina experienced, would cause around a 30\% fall in the value-weighted index, by our estimates. This increase also caused a 39\% fall in the value of banks, a 30\% decline in non-financials, and a $43 \%$ fall for YPF, by our estimates. Linearly extrapolating the log-return, we find that a completely unexpected default (a change from $0 \%$ to $100 \%$ in the risk-neutral default probability) would cause a $45 \%$ fall in the value index. Our results are consistent with the hypothesis that Argentina's default caused significant harm to the value of Argentine firms.

\footnotetext{
22 These issues are discussed in more detail in appendix section F.2.
} 


\subsection{Exchange Rates}

We next discuss our results for the various exchange rate measures we study. The last four columns of Table 2 report our estimate of the effects of increases in the probability of default on the four exchange rate measures. As with equities, we focus on the CDS-IV results and report the OLS results for comparison. Unsurprisingly, given the Argentine government's exchange rate policy, we find no contemporaneous effect of increases in the probability of default on the official exchange rate. We find that a $10 \%$ increase in the risk-neutral probability of default causes a $1 \%$ depreciation in all three measures of the parallel exchange rates. The results for the Dolar Blue (black market exchange rate) are statistically significant; the results for the ADR blue rate and blue-chip swap rate are not.

In appendix figure 3, we display the raw data behind these results. The ADR blue rate and blue-chip swap results are both substantially influenced by a single outlier event (the Supreme Court announcement described in section 3.5), during which they exhibit substantial appreciation, despite a depreciation of the Dolar Blue rate, a fall in the stock market, and an increase in the risk-neutral probability of default. On the day of the Supreme Court ruling, while the value of the ADRs and internationally-traded domestic law bonds fell sharply, the local stocks and domestically traded debt fell even more, implying an appreciation of ADR blue rate and blue-chip swap rate. This could be because local markets became more illiquid on this particular day. Outside of this event, the ADR blue rate and blue-chip swap rate exhibit a consistent pattern of depreciation during events in which the risk-neutral probability of default increases, and appreciation during events in which that default probability decreases.

Our preferred interpretation of these results is that they are consistent with the empirical coincidence of devaluation and default documented by Reinhart (2002), and with models in which a government finds it optimal to simultaneously default and devalue, such as Na et al. (2014). However, we must emphasize that the exchange rates we measure are not the freely convertible exchange rates studied and modeled by those authors.

\subsection{Magnitudes}

In table 3, we present estimates for the magnitude of the losses caused by default. The columns labeled "Estimate (60\%)" and "Estimate (100\%)" report the estimated losses caused by increasing the probability of default by $60 \%$ and $100 \%$, respectively. The $60 \%$ is relevant for Argentina because this is approximately 
the amount the five-year risk neutral default probability increased during the period of our study. The $100 \%$ column is relevant because it is closer to the concept of the cost of default in the literature.

In the first three rows of the table, we present estimates for the firms that have ADRs. The first row estimates are calculated by multiplying the sum of the 2011 market values of all non-YPF firms in the value index by the point estimate for the value index in table 2 , converted from log to arithmetic returns. The second row estimates follow the same procedure, for YPF, and the third row is the sum of the first two rows. The losses for firms with ADRs are comparable to the ultimate cost of the 2016 settlement. In the fourth and fifth rows, we also include the losses experienced by locally traded firms. We assume that these firms experience losses at the same rate as the firms with ADRs. When considering the losses on these two broader classes of firms, the direct reduction in the market value of these firms as a result of default significantly exceeds the face value of all holdout claims.

For the firms with ADRs, including YPF, the average yearly earnings from the first quarter of 2009 through the second quarter of 2011 was roughly $\$ 2.4$ billion. ${ }^{23}$ We estimate that, in response to a completely unanticipated default, the market value of these firms would decline by roughly 8 years of annual earnings. For reference, in the quantitative sovereign debt model of Aguiar and Gopinath (2006), a country loses 2\% of its output upon default, and is "redeemed" with a $10 \%$ chance each quarter. If a firm's ADR dividends followed the same process after a default, the "cashflow news" (Campbell (1990)) associated with default would represent roughly $4-5 \%$ of the firm's annual earnings. Accounting for leverage explains part but not all of the difference (see appendix section G.3). One (speculative) explanation for our results is that default causes very persistent or permanent output losses, or equivalently a decline in growth rates, and this is reflected in firm earnings. This would be consistent with the findings of Gornemann (2014), who uses a panel dataset to estimate the impact of default on growth rates. It would also be consistent with the findings of Aguiar and Gopinath (2007), who argue that emerging market countries experience shocks to their trend growth rate more generally. ${ }^{24}$ However, we must emphasize that this is not the only possible explanation for our results, and that further research on this topic is necessary.

[Insert table 3 here ]

\footnotetext{
${ }^{23}$ We calculate annual earnings from 2009-2011 because of the availability of earnings data in CRSP for all of the firms with ADRs. Unfortunately, that time period coincides with a recession in many developed countries. Using our preferred measure of Argentine real GDP, growth was low but positive over this period.

${ }^{24}$ The view that emerging market countries experience permanent productivity shocks is controversial (see, for example, GarcíaCicco et al. (2010)).
} 


\section{Cross-Sectional Evidence}

In this section, we examine which firm characteristics are associated with larger or smaller responses to the default shocks. The cross-sectional pattern of responses across firms can help shed light on the mechanism by which sovereign default affects the economy.

First, motivated by Bulow and Rogoff (1989a), we examine whether or not firms that are reliant on exports are particularly hurt. Bulow and Rogoff (1989a) argue that in the event of a sovereign default, foreign creditors can interfere with a country's exports. Second, motivated by Mendoza and Yue (2012), we examine whether or not firms that are reliant on imported intermediate goods are particularly hurt by default. Mendoza and Yue (2012) argue that a sovereign default reduces aggregate output because firms cannot secure financing to import goods needed for production, and so are forced to use domestic intermediate goods, which are imperfect substitutes. Third, motivated by Gennaioli et al. (2014), Acharya et al. (2014a), Bolton and Jeanne (2011), Bocola (2013) and Perez (2014), we examine whether financial firms are more adversely affected. While these papers are not explicitly about whether banks are hurt more than other firms, they posit that the aggregate decline in output following a sovereign default occurs because of the default's effect on bank balance sheets. Finally, motivated by Cole and Kehoe (1998), we examine whether foreign-owned firms underperform following an increase in the probability of sovereign default. Cole and Kehoe (1998) argue that "general reputation," rather than a specific reputation for repayment, is lost by defaulting on sovereign debt. This theory would lead us to expect increases in the risk of sovereign default to cause foreign-owned firms to underperform, due to a higher risk that Argentina will act disreputably in other arenas, such as investment protection.

Our empirical approach is similar to several papers in the literature studying the cross-section of firms' responses to identified monetary policy shocks, using an event study for identification, such as Bernanke and Kuttner (2005) and Gorodnichenko and Weber (2013). We test whether certain types of firms experience returns around our legal rulings that are larger or smaller than would be expected, given those firms' betas to the Argentine equity markets and exchange rate. In effect, we are testing whether the ensemble of shocks that generate returns outside of the event windows have a similar cross-sectional pattern of returns to the default probability shock.

Our procedures are motivated by a modified version of the model in equation (2) and equation (1). We derive both models from a single underlying system of equations, presented in appendix section I. The 
modified version of the those equations has the return of the Argentine market index and the exchange rate on the right-hand side. We show that the heteroskedasticity-based estimation procedure identifies the coefficient $\left(\alpha_{i}-\beta_{i}^{T} \alpha_{m}\right)$, where $\alpha_{i}$ is the response of this portfolio to the default shock, $\alpha_{m}$ is the response of the market index and exchange rate to the default shock, and $\beta_{i}$ are the coefficients of a regression of the returns of portfolio $i$ on the market index and ADR blue rate. This coefficient can be interpreted as the excess sensitivity of the portfolio to the default shock, above and beyond what would be expected from the Argentine equity market's and exchange rate's exposures to the default shock, and the sensitivity of the portfolio to the Argentine equity market and exchange rate. In this sense, our approach generalizes the CAPM-inspired analysis of Bernanke and Kuttner (2005).

To increase our sample size of firms, we now use local Argentine stock returns, rather than ADRs. The use of the local stocks and CDS data requires that both the New York and Buenos Aires markets be open, which reduces the size of our sample. However, all but one of the legal rulings remain in our sample.

We study which characteristics of firms are associated with over- or under-performance in response to default shocks. We form zero-cost, long-short portfolios ${ }^{25}$ based on the export intensity of their primary industry (for non-financial firms), the import intensity of individual non-financial firms in 2007 and 2008 using data from Gopinath and Neiman (2014), whether they are a listed subsidiary of a foreign firm, firm size, and whether they have an associated ADR. For the exporter, importer, and firm size portfolios, we group firms based on whether they are above or below the median value in our sample. An import-intensive firm is not the opposite of an export-intensive one; some firms are classified as neither import nor export intensive, whereas others are both import and export intensive.

In these portfolios, we equally weight firms within the "long" and "short" groups. For example, we classify 12 of our 26 non-financial firms ${ }^{26}$ as high export intensity, and 14 of 26 as low export intensity. We equally weight these firms, so that the "long" portfolio has a 1/12 weight on each high export intensity firm, and the short portfolio has a 1/14 weight on each low export intensity firm. We then form the long-short portfolio, and determine whether the portfolio over- or underperforms after a default shock, using the CDSIV estimator and bootstrapped confidence intervals discussed previously. The local equity index that we use as a control is an equal-weighted index of all of the local stocks in our data sample.

\footnotetext{
${ }^{25}$ Because we form long-short portfolios, the nominal exchange rate does not directly impact the portfolio's return, except to the extent that it differentially affects the firms.

${ }^{26}$ We actually have 27 non-financial firms, but one is a technology firm. The technology firm's industry classification did not exist when the input/output table we use to construct the data was generated.
} 
The over- or underperformance of the portfolios is not an ideal test of the theories. For example, if we do not observe that importing firms underperform, it may be because the firms we observe are not the ones who would have difficulties, or because our import-intensive and non-import-intensive firms also differ on some other characteristic that predicts over- or underperformance (essentially an omitted variables problem). The reverse is also true; a significant result does not necessarily validate the theory, but might instead be found because of a correlation across firms between importing and some other firm characteristic.

[Insert table 4 here]

In table 4, we find that firms whose primary industry is export-intensive under-perform given their exposure to the equal-weighted index and exchange rates, and those assets' response to the default probability shock, while the long-short importer portfolio overperforms by a statistically insignificant amount. ${ }^{27}$ We find that foreign subsidiaries, of which there are nine, underperform relative to non-financial firms that are not foreign subsidiaries. This result is consistent with the general reputation theory of Cole and Kehoe (1998), which implies that default makes policy changes more likely and that foreign investors become reluctant to invest. We also find that larger firms (defined as above-median market capitalization in 2011) significantly underperform relative to smaller firms; however, this may reflect the relative illiquidity of smaller firms' stocks, rather than a difference in real outcomes. We do not find that firms with an ADR substantially overor underperform firms without ADRs.

We estimate economically large, but not statistically significant, underperformance for banks. The excessive sensitivity of bank stocks to default risk is consistent with the theories of Gennaioli et al. (2013, 2014), Bocola (2013), and Bolton and Jeanne (2011). However, we find that a "de-levered" portfolio of bank stocks (see appendix section G.3) outperforms a de-levered portfolio of non-financial firms, which suggests that the assets held by these Argentine banks are not substantially impaired by the sovereign default. This result is not necessarily surprising- Argentina did not default on its local law, locally owned debt.

We interpret this cross-sectional analysis as lending modest support to several of the theories in the existing literature that try to understand the costs of sovereign default.

\footnotetext{
${ }^{27}$ We display these results graphically in appendix figure 4.
} 


\section{Identification and Interpretation}

In this section, we discuss challenges to our identification assumption and alternative interpretations of our stock market results, as well as the external validity of our results. We first discuss the exogeneity of our shocks, and then discuss channels through which the rulings might have affected firms, other than by changing the default probability.

We argue that the rulings of the courts are not influenced by news about the Argentine economy. Formally, the interpretation of the laws in question does not depend on the state of the Argentine economy. Substantively, because the amount required to repay the litigating holdouts in full was small relative to the Argentine economy (more on this below), news about the Argentine economy's prospects would not materially change the Argentine government's ability to pay. Moreover, even if the judges were responding to economic fundamentals, under the null hypothesis that default does not affect fundamentals, the judges would have no information advantage over market participants. ${ }^{28}$

It is important that our study avoid announcements by the Argentine government, because such announcements might be responding to news about fundamentals, or affect corporations in ways other than through default. In the case of the Supreme Court decision discussed earlier, the Argentine government did not respond immediately to the ruling (Russo and Porzecanski (2014)). More generally, we include as events only orders by a judge or judges. We exclude orders that were issued during oral arguments, because those events also include opportunities for lawyers representing Argentina to reveal information.

We also argue that the rulings did not directly impact the firms we study, except by changing the probability of default. One potential issue is that the legal rulings might have changed the probability or size of a settlement with the holdouts, and this could affect the firms. To meet the precise demands of the courts, Argentina needed to pay its litigating creditors only $\$ 1.5$ billion. However, the $\$ 1.5$ billion owed to the litigating creditors was only around $10 \%$ of the estimated $\$ 15$ billion holdout debt outstanding (Gelpern (2014a)). Presumably, if Argentina paid NML and its co-litigants in full, the other holdout creditors would have demanded repayment on similar terms; indeed, "me too" claims caused the size of the 2016 settlement with litigating creditors to grow to $\$ 9.3$ billion. Even if we assume that Argentina will eventually need to

\footnotetext{
${ }^{28}$ More subtle interactions between the state of the Argentine economy and the legal rulings might complicate the interpretation of our analysis. For example, if bad news about the Argentine economy causes the market response to the legal rulings to be larger than it otherwise would have been, our estimates will reflect some sort of average effect, where the averaging occurs over states of the economy.
} 
pay the full $\$ 15$ billion, that represented only $3 \%$ of GDP, and $45 \%$ of foreign currency reserves. ${ }^{29}$ As seen in Table 3, the actual repayment was less than half the loss of market value experienced by publicly traded firms. Because only a small fraction of Argentine firms are publicly traded, and there is no reason to expect the tax burden to repay the debt to fall exclusively on these firms, the direct repayment costs could only account for a tiny fraction of the loss of market value experienced by these firms.

This issue is complicated, however, by the presence of a "Rights Upon Future Offers" (RUFO) clause in the restructured bond contracts. If Argentina voluntarily made an offer to the holdouts that was better than what the restructured creditors received, the restructured creditors would be entitled to the better deal, provided the offer occurred before December 31, 2014. Argentina claimed that this RUFO clause meant that it could not pay NML the $\$ 1.5$ billion owed without incurring hundreds of billions in additional liabilities. There is one crucial word in the RUFO that makes the whole matter more complicated: voluntarily. If Argentina offered the holdouts a better deal because U.S. courts would otherwise have blocked its payments to the restructured bondholders, would that offer be voluntary or involuntary? Some observers noted that Argentina's counsel told the Second Circuit Court of Appeals that Argentina "would not voluntarily obey" court rulings to pay the holdouts in full (Cotterill (2013)). In addition, other commenters noted that the RUFO clause appeared to have some loopholes, allowing Argentina to potentially settle with the holdouts without triggering the clause. ${ }^{30}$ Moreover, the restructured bondholders could waive their right to exercise the RUFO clause, because it takes $25 \%$ of exchange bondholders to trigger the clause, and the whole issue could have been rendered moot if the exchange bondholders could be persuaded that waiving the clause was preferable to having their coupon payments blocked. Of course, this possibility assumes Argentina would have paid any amount to the holdouts, a questionable proposition given the domestic politics surrounding the holdouts (Gelpern (2014b)). Notably, when the RUFO clause expired at the end of 2014, no progress in settlement talks between the holdouts and Argentina was reported. Nevertheless, suppose the RUFO clause was binding, and settlement with the holdouts was not possible. In this case, the legal rulings caused Argentina to default, and our identification assumption holds. ${ }^{31}$

\footnotetext{
${ }^{29}$ The CIA World Factbook reports Argentina's 2013 GDP as $\$ 484.6$ billion, and its exchange and gold reserves at $\$ 33.7$ billion as of December 31, 2013. However, the GDP calculation uses the official exchange rate, which may overstate the size of Argentina's economy.

${ }^{30}$ See the comments from Barclay's reported in Cotterill (2013).

${ }^{31}$ If the RUFO clause was binding, and nevertheless a settlement was possible, one would have expected rulings in favor of NML to raise the value of the restructured bonds. In fact, we observe that restructured bond prices decline along with the stock returns. In appendix table 14, we report the effect of increases in the probability of default on the price of the defaulted bonds held by the holdouts, the restructured bonds that Argentina eventually defaulted on in July 2014, and domestic-law dollar debt.
} 
In table 3, we show that the losses to firms were of similar magnitude to the amount owed to all of the holdouts, not just the litigants. To believe that the prospect of a settlement was driving the losses we observe, one would need to believe that the holdouts would be paid in full and that the entirety of the burden of repayment would fall on firms with ADRs, even though those firms are a small part of the economy.

Given our identification strategy, we would be concerned about any effect the rulings had on the value of Argentine firms that did not operate through the rulings' impact on the probability of default. There is no direct effect on Argentine firms because they are legally independent from the Argentine government, and their assets cannot be attached by the holdouts. ${ }^{32}$ In fact, eleven of the twelve ADR firms issued debt internationally between 2002 and 2014, when the federal government of Argentina was excluded from international debt markets. ${ }^{33}$ The ruling affects them only to the extent that it changes the behavior of the Argentine government or other actors. One potential channel not operating through the probability of default is the possibility that the legal rulings changed the law regarding sovereign debt generally. We muster evidence against this in the appendix. ${ }^{34}$ Another possible channel that would violate our exclusion restriction, which we cannot test, is that the rulings act as a sort of coordination device. For instance, the legal rulings could have provoked the government of Argentina into a sequence of actions unrelated to sovereign default, or changed the probability that the Peronist government of Argentina stayed in power, for reasons unrelated to the default. It is important to remember, however, that our costs of default are inclusive of the effects on government policy changes and political fortunes, if these changes occur because of the default. Our exclusion restriction is only violated if these changes are unrelated to sovereign default.

\subsection{Interpreting Returns}

In this subsection, we discuss how to interpret the stock returns and risk-neutral default probability changes we study. First, we argue that U.S. investors' stochastic discount factor is the relevant one for pricing the ADRs and CDS. As shown by Edison and Warnock (2004), the ADRs we study are held by US investors in proportion to their market weight, and are not affected by "home bias." In appendix section H.1, we

\footnotetext{
${ }^{32}$ There was litigation regarding whether the Argentine central bank qualified as independent from a legal perspective, but no such litigation for any of the companies listed in the stock index.

${ }^{33}$ Data from Bloomberg. The twelfth firm, Pampa Energia, issued debt internationally through a subsidiary.

${ }^{34}$ In appendix section G.1, we show that the stock markets of Brazil and Mexico and the risk-neutral default probabilities of more than 30 countries did not respond to these legal rulings (our estimates are close to zero, and relatively precise). This is in contrast to the OLS estimates, which show that those financial variables are correlated with the Argentine risk-neutral probability of default, presumably due to common shocks affecting Latin America or emerging markets more generally. This evidence suggests that, whatever changes to sovereign debt law occurred as the result of these rulings, they did not materially impact other Latin American countries that issue debt in New York.
} 
document that the ADRs we study are held by large, diversified financial institutions (who are also the type of institutions that trade CDS). In appendix table 16, we show that the average turnover of ADRs is significantly higher than the average turnover of the underlying local equities, providing further evidence for the relative importance of foreign investors in pricing Argentine firms.

Second, we argue that the stock returns and risk-neutral default probability changes we study measure Argentina-specific news. The legal shocks are an almost canonical example of idiosyncratic risk, and it is very unlikely that U.S. investors' stochastic discount factor is meaningfully affected by these legal rulings. Consistent with this argument, we find no evidence for an impact of these rulings on other emerging market CDS spreads and stock indices (see appendix section G.1). We also control for the legal rulings' impact on a variety of proxies for the price of risk. Consistent with the previous point, incorporating these controls makes little difference for our estimates.

However, it is possible that these legal rulings create a shortage of Argentina-specific (as opposed to emerging-market specific) expert capital, along the lines of Gabaix and Maggiori (2015). We muster evidence against this by showing that Argentine-listed multinationals, such as Tenaris and Petrobras Brazil are unaffected by the default shocks (see table 11 in the appendix). This expert-specific capital would therefore have to defined more narrowly than firms trading on the Buenos Aires Stock Exchange, and this shortage of expert capital would have to occur within the large financial institutions that own the ADRs we study.

Assuming the the shocks we study are Argentina-specific news, there are two potential (and not exclusive) explanations for these returns. The most direct interpretation is that the returns represent changes in the expected cash flows from the ADRs. Alternatively, the returns could be caused by an increase in the exposure of the dividends of the ADRs to priced risk factors (an increase in "beta", rather than a change in the mean value of the dividends). This would explain a decline in the value of the firms, as valued by the market. If the returns we measure are caused by this discount rate news, then we should expect that our legal rulings predict future returns. We have run our heteroskedasticity-based estimator using two-day-ahead returns, rather than contemporaneous returns, as the outcome variable. We found no significant effects, but our standard errors are too large to rule out economically plausible return predictability. Additionally, for some purposes, it may not matter whether the value of Argentine firms fell because they were expected to be less profitable as a result of the default or because they became riskier as a result of the default.

The issues discussed in this section with regards to stock returns also apply with regards to the riskneutral probability of default, as measured by credit default swaps. The most straightforward interpretation 
of the changes in default probabilities we study is that they are changes in the physical default probability. However, it is theoretically possible that the legal rulings induced changes in the covariance between Argentine default or recovery rates and priced risk factors, and this caused part of the change in risk-neutral probabilities that we observe.

One concern we can muster evidence against is that Argentine CDS markets are thinly traded. According to data from the Depository Trust and Clearing Corporate (DTCC), from the first quarter of 2011 until the second quarter of 2014, the Argentine sovereign was the 15th most commonly traded sovereign CDS and the 48th most commonly single-name CDS overall. In appendix section H.3, we compare the liquidity of Argentine sovereign CDS to the liquidity of CDS on other emerging market governments, major financial institutions, and non-financial corporations.

\subsubsection{Transfer and Convertibility Risk}

Even if we assume that the negative returns we observe represent cashflow news, there is still the question of whether news about these ADRs is representative of Argentina's broader economy. As mentioned previously, the earnings of firms with ADRs are a small fraction of the Argentine economy. Market participants may have anticipated that, conditional on default, it would become difficult for firms to make payments on their ADR dividends. In other words, default might have caused the government to adjust its capital controls.

Ex-post, we know that this did not occur, and we are not aware of any evidence suggesting it was ever likely. However, suppose investors were concerned about this possibility. In this case, we might expect to see a significant difference between firms' local (peso) stock performance and their ADR performance. However, to compare the performance of local stocks and ADRs, we need a measure of the exchange rate that would not be affected by these capital controls. Unfortunately, all of our market exchange rate measures (the ADR blue, the blue-chip swap, and the dolar blue) would likely be affected by changes in the capital control regime. We do not find any evidence that there is a different effect across these three exchange rates. This suggests that, if changes in capital controls conditional on default were anticipated, the anticipated changes would have applied equally to bonds, stocks, and other means by which Argentines can acquire dollars. 


\subsection{External Validity}

Our estimates of the cost of default include the consequences of whatever policies the government is expected to employ, conditional on default. These costs also include the effects of firms, households, and other agents changing their behavior as a result of the default. For the government, these policies could include renegotiating with creditors, finding other means to borrow, balancing budgets via taxes or reduced spending, and taking actions that affect the convertibility of the currency, among other actions. When we refer to the causal of effects of sovereign default, we include the anticipated effects of whatever policies the government is expected to employ as a result of having defaulted. The external validity of our results depends on the extent to which other defaulting countries would behave similarly to Argentina in the aftermath of a default.

One potential cost of default is exclusion from markets. Although the debt exchanges of 2005 and 2010 eventually achieved a participation rate of $91.3 \%$ - above the level generally needed by a sovereign to resolve a default and reenter capital markets- the government of Argentina remained unable to issue international law bonds. Ongoing creditor litigation had resulted in an attachment order, which would allow the holdouts to confiscate the proceeds from any new bond issuance (Hornbeck (2013)). However, prior to these legal rulings, the government of Argentina was able to issue local-law, dollar-denominated bonds, and some of those bonds were purchased by foreigners. Some of these local-law bonds were affected by the legal rulings, and it may have become more difficult for Argentina to borrow as a result of the rulings.

There are several complications arising from Argentina's ambiguous international standing. If the costs of default for Argentina were lower than that of a typical sovereign debtor, because Argentina was already unable to borrow in international markets, then our estimates understate the costs for the typical sovereign. On the other hand, because Argentina chose to default despite an ability to pay, the costs might be higher than is typical. These complications emphasize the uniqueness of Argentina's circumstances.

\section{Conclusion}

For several decades, one of the most important questions in international macroeconomics has been "why do governments repay their debts?" Using an identification strategy that exploits the timing of legal rulings in the case of Republic of Argentina v. NML Capital, we present evidence that a sovereign default significantly reduces the value of domestic firms. We provide suggestive evidence that exporters and foreign-owned firms 
are particularly hurt by sovereign default.

\section{References}

Acharya, Viral, Itamar Drechsler, and Philipp Schnabl, “A Pyrrhic Victory? Bank Bailouts and Sovereign Credit Risk,” The Journal of Finance, 2014, 69 (6), 2689-2739.

Acharya, Viral V., Tim Eisert, Christian Eufinger, and Christian W. Hirsch, "Real Effects of the Sovereign Debt Crisis in Europe: Evidence from Syndicated Loans," 2014.

Aguiar, Mark and Gita Gopinath, "Defaultable debt, Interest Rates and the Current Account," Journal of International Economics, 2006, 69 (1), 64-83.

_ and _ , "Emerging Market Business Cycles: The Cycle Is the Trend," Journal of Political Economy, 2007,115 (1), 69-102.

Arellano, Cristina, "Default Risk and Income Fluctuations in Emerging Economies," American Economic Review, 2008, 98 (3), 690-712.

Arteta, Carlos and Galina Hale, "Sovereign Debt Crises and Credit to the Private Sector," Journal of International Economics, 2008, 74 (1), 53-69.

Auguste, Sebastian, Kathryn M. E. Dominguez, Herman Kamil, and Linda L. Tesar, "Cross-Border Trading as a Mechanism for Implicit Capital Flight: ADRs and the Argentine Crisis," Journal of Monetary Economics, 2006, 53 (7), 1259-1295.

Bernanke, Ben S. and Kenneth N. Kuttner, "What Explains the Stock Market's Reaction to Federal Reserve Policy?," The Journal of Finance, 2005, 60 (3), 1221-1257.

Bocola, Luigi, “The Pass-Through of Sovereign Risk,” Manuscript, University of Pennsylvania, 2013.

Bolton, Patrick and Olivier Jeanne, "Sovereign Default Risk and Bank Fragility in Financially Integrated Economies," IMF Economic Review, 2011, 59 (2), 162-194.

Borensztein, Eduardo and Ugo Panizza, “The Costs of Sovereign Default,” IMF Staff Papers, 2009, 56 (683-741).

Bulow, Jeremy and Kenneth Rogoff, “A Constant Recontracting Model of Sovereign Debt,” The Journal of Political Economy, 1989, 97.

_ and _ , "Sovereign Debt: Is to Forgive to Forget?," The American Economic Review, 1989, pp. 43-50.

Campbell, John Y, “A variance decomposition for stock returns," Technical Report, National Bureau of Economic Research 1990.

Chatterjee, Satyajit and Burcu Eyigungor, "Maturity, indebtedness, and default risk," American Economic Review, 2012,102 (6), 2674-2699.

Cole, Harold L. and Patrick J. Kehoe, "Models of Sovereign Debt: Partial versus General Reputations," International Economic Review, 1998, 39 (1), 55-70.

Cotterill, J., "Raising the RUFO in Argentine bonds," 2013. http://ftalphaville.ft.com/2013/03/06/1411442/ raising-the-rufo-in-argentine-bonds / [Accessed: 10/22/2015].

Daseking, Christina, Atish R. Ghosh, Timothy D. Lane, and Alun H. Thomas, Lessons from the Crisis in Argentina, International monetary fund, 2005.

Eaton, Jonathan and Mark Gersovitz, "Debt with potential repudiation: Theoretical and empirical analysis," The Review of Economic Studies, 1981, pp. 289-309.

Edison, Hali J. and Francis E. Warnock, "US investors' emerging market equity portfolios: a security-level analysis," Review of Economics and Statistics, 2004, 86 (3), 691-704.

Fuchs-Schundeln, Nicola and Tarek A. Hassan, "Natural Experiments in Macroeconomics," Available at SSRN 2583876, 2015.

Gabaix, Xavier and Matteo Maggiori, "International Liquidity and Exchange Rate Dynamics," Quarterly Journal of Economics, 2015, 130 (3), 1369-1420.

García-Cicco, Javier, Roberto Pancrazi, and Martín Uribe, "Real Business Cycles in Emerging Countries?" American Economic Review, 2010, 100 (5), 2510-31.

Gelpern, Anna, "After Argentina," Credit Slips Blog June 2014. http://www.creditslips.org/creditslips/2014/06/ after-argentina.html [Accessed: 4/18/2016].

_ , "Argentina: The RUFO Crazy," Credit Slips Blog July 2014. http://www.creditslips.org/creditslips/2014/07/ argentina-the-rufo-crazy .html [Accessed: 4/18/2016].

Gennaioli, Nicola, Alberto Martin, and Stefano Rossi, "Banks, Government Bonds, and Default: What do the Data Say?,” 2013. _ , _ , and _ , "Sovereign Default, Domestic Banks, and Financial Institutions," The Journal of Finance, 2014, 69 (2), 819-866.

Gopinath, Gita and Brent Neiman, "Trade Adjustment and Productivity in Large Crises," American Economic Review, 2014,104 (3), 793-831. 
Gornemann, Nils, “Sovereign Default, Private Investment, and Economic Growth,” 2014.

Gorodnichenko, Yuriy and Michael Weber, "Are Sticky Prices Costly? Evidence from the Stock Market,” 2013.

Gulati, Mitu and Kenneth N. Klee, "Sovereign Piracy," The Business Lawyer, 2001, pp. 635-651.

Hornbeck, J.F., “Argentina's Defaulted Sovereign Debt: Dealing with the 'Holdouts', Congressional Research Service, 2013.

Howe, Amy, "Live blog of orders and opinions I June 16, 2014," 2014. http://live.scotusblog.com/Event/Live_blog_ of_orders_and_opinions__June_16_2014?Page=0 [Accessed: 10/22/2015].

Kuttner, Kenneth N., "Monetary Policy Surprises and Interest Rates: Evidence from the Fed Funds Futures Market," Journal of Monetary Economics, 2001, 47 (3), 523-544.

Mander, Benedict and Elaine Moore, "Argentina puts an end to long holdouts saga," 2016. http://www.ft.com/intl/cms/ s/0/516ab98a-08a1-11e6-876d-b823056b209b.html [Accessed: 4/29/2016].

Mendoza, Enrique G. and Vivian Z. Yue, "A General Equilibrium Model of Sovereign Default and Business Cycles," Quarterly Journal of Economics, 2012, 127, 889-946.

Millian, Carolina and Ben Bartenstein, "Argentina Settlement Surprise Leaves Some Investors in the Cold," $2016 . \quad$ http://www.bloomberg.com/news/articles/2016-03-24/ argentina-settlement-surprise-leaves-some-investors-in-the-cold [Accessed: 4/22/2016].

Na, Seunghoon, Stephanie Schmitt-Grohé, Martin Uribe, and Vivian Z Yue, "A model of the twin ds: Optimal default and devaluation," Technical Report, National Bureau of Economic Research 2014.

O'Brien, Matt, "Everything you need to know about Argentina's weird default," 2014. http://www. washingtonpost.com/ news/wonkblog/wp/2014/08/03/everything-you-need-to-know-about-argentinas-weird-default/ [Accessed: 10/22/2015].

Panizza, Ugo, Federico Sturzenegger, and Jeromin Zettelmeyer, "The Economics and Law of Sovereign Debt and Default," Journal of Economic Literature, 2009, pp. 651-698.

Parks, Ken and Prabha Natarajan, "Argentina Peso Rises; Intervention Is Cited," 2013. http://www.wsj.com/articles/ SB10001424127887323582904578489470877343446 [Accessed: 4/22/2016].

Pasquariello, Paolo, "The anatomy of financial crises: Evidence from the emerging ADR market," Journal of International Economics, 2008, 76 (2), 193-207.

Perez, Diego J., "Sovereign Debt, Domestic Banks and the Provision Of Public Liquidity," Manuscript, Stanford University, 2014.

Platt, Eric and Benedict Mander, "US appeals court clears way for Argentina bond sale," 2016. http://www.ft.com/cms/s/ 0/5039a628-01a0-11e6-99cb-83242733f755.html [Accessed: 4/18/2016].

Politi, Daniel and Pan Kwan Yuk, "Argentina strikes deal with holdouts," 2016. http://www.ft.com/intl/cms/s/0/ 26f ca102-deff-11e5-b67f-a61732c1d025.html [Accessed: 4/18/2016].

Reinhart, Carmen M., "Default, currency crises, and sovereign credit ratings," The World Bank Economic Review, 2002, 16 (2), 151-170.

Rigobon, Roberto, "Identification through Heteroskedasticity," Review of Economics and Statistics, 2003, 85 (4), $777-792$.

— and Brian Sack, "The Impact of Monetary Policy on Asset Prices," Journal of Monetary Economics, 2004,51 (8), $1553-1575$.

Rose, Andrew K, "One reason countries pay their debts: renegotiation and international trade," Journal of development economics, 2005, 77 (1), 189-206.

Russo, Camila and Katia Porzecanski, "Argentine Bonds Plunge After U.S. Court Rejects Apeeal," 2014. http://www.bloomberg.com/news/articles/2014-06-16/ argentine-bonds-plunge-after-u-s-supreme-court-rejects-appeal [Accessed: 10/22/2015].

Schumacher, Julian, Christoph Trebesch, and Henrik Enderlein, "Sovereign Defaults in Court," Available at SSRN 2189997, 2014.

Stock, James H. and Motohiro Yogo, "Testing for Weak Instruments in Linear IV Regression," Identification and Inference for Econometric Models: Essays in honor of Thomas Rothenberg, 2005, 1.

Thomas, Leigh and Sarah Marsh, "Argentina clinches landmark debt repayment deal with Paris Club," 2014. http://www.reuters.com/article/2014/05/29/us-argentina-debt-parisclub-idUSKBNOE90JI20140529 [Accessed: 10/22/2015].

Tomz, Michael and Mark L. J. Wright, "Empirical Research on Sovereign Debt and Default," Annu. Rev. Econ., 2013, 5 (1), 247-272.

Yeyati, Eduardo Levy and Ugo Panizza, “The elusive costs of sovereign defaults,” Journal of Development Economics, 2011, 94 (1), 95-105. 


\section{Tables and Figures}

Table 1: Summary Statistics

\begin{tabular}{ccc}
\hline Window Type & Event & Non-Event \\
\hline Mean $\Delta D_{t}(\%)$ & -0.09 & -0.01 \\
SD $\Delta D_{t}(\%)$ & 5.06 & 1.79 \\
Mean Equity Log Return $(\%)$ & 0.30 & 0.04 \\
Equity Log Return SD $(\%)$ & 4.02 & 2.77 \\
Cov $\left(\Delta D_{t}, r_{t}\right)$ & -15.27 & -2.21 \\
Number of two-day windows & 15 & 386
\end{tabular}

Notes: This table reports the mean default probability change, the standard deviation of default probability changes, the mean value-weighted index return, the standard deviation of that return, and the covariance of default probability changes and that return during events and non-events. The underlying data is based on the two-day event windows and non-events described in the text. 


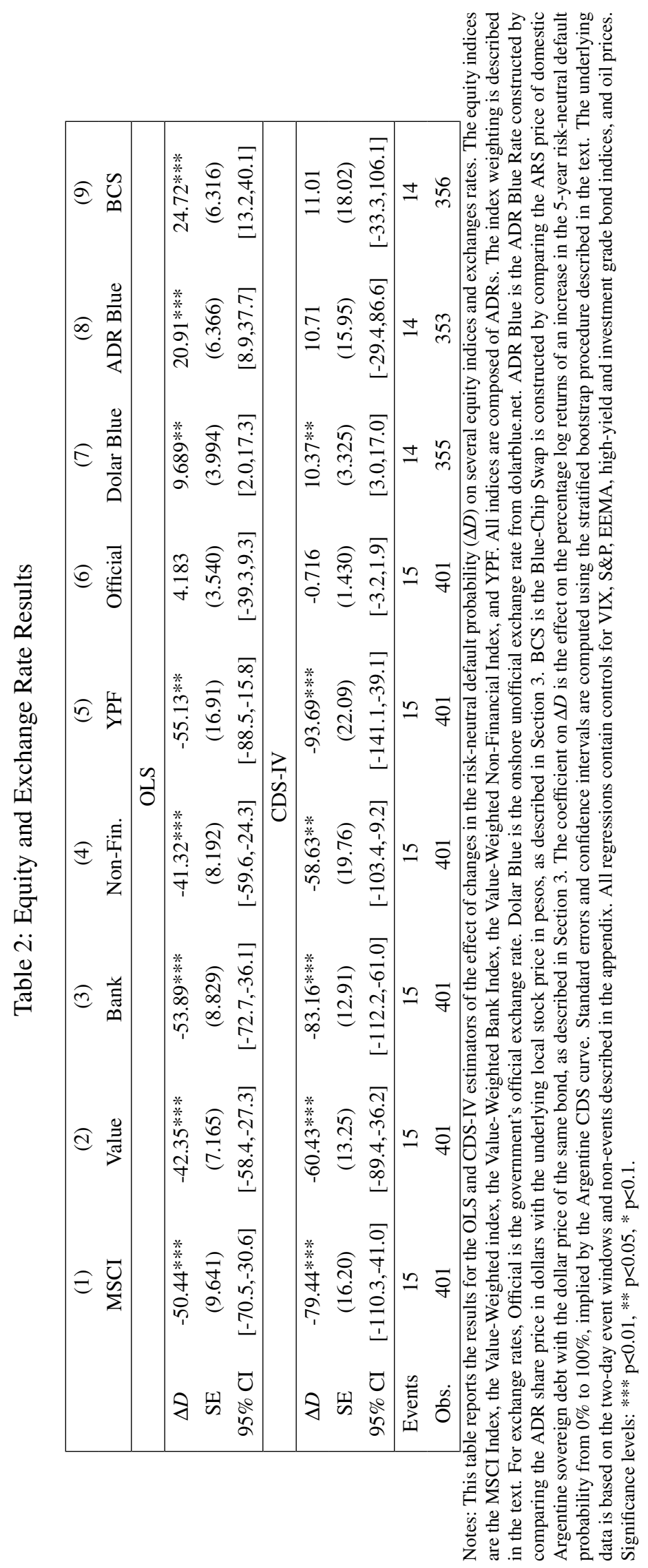


Table 3: Magnitudes

\begin{tabular}{|ccc|}
\hline Measure & Estimate (60\%) & Estimate (100\%) \\
\hline ADRs (ex. YPF) & -4.7 \$B & -7.9 \$B \\
YPF & -6.6 \$B & -11.0 \$B \\
ADRs & -11.3 \$B & -18.9 \$B \\
All equities in dataset & -15.6 \$B & -26.0 \$B \\
All equities & -16.7 \$B & -27.8 \$B \\
\hline Actual Repayment & & 12.5 \$B (Estimated) \\
\hline
\end{tabular}

Notes: The first line, "ADRs (ex.YPF)" reports the imputed loss of market value all firms included in our sample of ADRs experienced, excluding YPF. It is calculated by multiplying the sum of the market values of all the firms in 2011 by point estimate on the Value Index in Table 2 . The second row, "YPF", reports the same calculation for YPF. The third row, "ADRs," is the sum of the first two. The fourth row, "All equities in dataset", is the loss by locally traded firms that are included in the analysis of Section 5. It is computed by extrapolating the losses of the value index to these stocks. The fifth row, "All equities," includes all Argentine firms with listed equities, even those that do not meet the data quality standards to be included in Section 5, and is also computed by extrapolation. "Actual Repayment" is the cost to the government of Argentina of the recently agreed-upon settlement with the major holdouts, extrapolated to cover all holdouts.

Table 4: Cross-Section: Long-Short Portfolios, CDS-IV

\begin{tabular}{ccccccc}
\hline & $(1)$ & $(2)$ & $(3)$ & $(4)$ & $(5)$ & $(6)$ \\
& Foreign & Financial & Exporter & Importer & Size & ADR \\
\hline$\Delta D$ & $-27.96 * * *$ & -34.36 & $-39.47 * * *$ & 2.722 & $-33.72^{* *}$ & -12.81 \\
& $(9.538)$ & $(16.51)$ & $(9.867)$ & $(8.147)$ & $(10.20)$ & $(12.46)$ \\
$95 \%$ CI & {$[-51.0,-10.1]$} & {$[-78.2,13.7]$} & {$[-62.8,-20.6]$} & {$[-17.1,18.4]$} & {$[-56.9,-9.8]$} & {$[-46.9,23.4]$} \\
Index $\beta$ & -0.341 & 0.0198 & -0.682 & -0.124 & -0.396 & 0.0679 \\
FX $\beta$ & -0.0888 & -0.0252 & -0.351 & -0.184 & 0.0497 & 0.139 \\
Events & 14 & 14 & 14 & 14 & 14 & 14 \\
Obs. & 353 & 353 & 353 & 353 & 353 & 353 \\
\hline
\end{tabular}

Notes: This table reports the results for the "CDS-IV" estimator. The column headings denote the outcome variable, a zero-cost long short portfolio. "Foreign" goes long firms with a foreign parent and short domestically owned firms. "Financial" goes long banks and short non-financial firms. "Exporter" goes long export-intensive non-financial firms and short non-export-intensive non-financial firms. "Importer" is defined equivalently for importers. "Size" goes long firms with above-median market capitalization in 2011, and short firms with below-median market cap. "ADR" goes long firms with an American Depository Receipt and short firms without one. The coefficient on $\Delta D$ is the effect on the percentage log returns of an increase in the 5-year risk-neutral default probability from $0 \%$ to $100 \%$, implied by the Argentine CDS curve. Index beta is the coefficient on the equal-weighted index of Argentine local equities, as described in section 5, and FX beta is the beta to the ADR blue rate. Standard errors and confidence intervals are computed using the stratified bootstrap procedure described in the appendix, section C. The underlying data is based on the two-day event windows and non-events described in the text. All regressions contain controls for VIX, S\&P, EEMA, high-yield and investment grade bond indices, and oil prices. Significance levels: $* * * \mathrm{p}<0.01, * * \mathrm{p}<0.05, * \mathrm{p}<0.1$. 
Figure 1: Exchange Rates

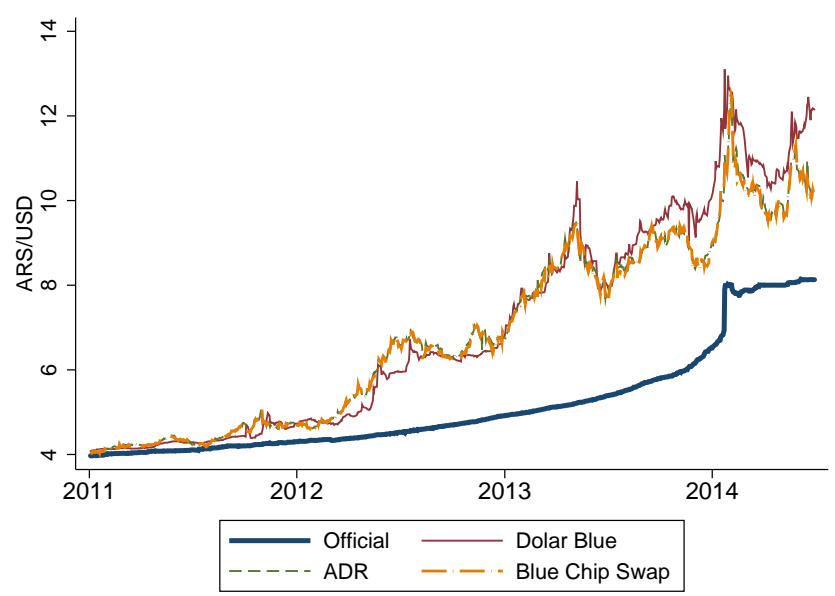

Notes: This figure plots the four versions of the ARS/USD exchange rate. Official is the government's official exchange rate. Dolar Blue is the onshore unofficial exchange rate from dolarblue.net. ADR is the ADR Blue Rate constructed by comparing the ADR share price in dollars with the underlying local stock price in pesos, as described in Section 3. Blue-Chip Swap is constructed by comparing the ARS price of domestic Argentine sovereign debt with the dollar price of the same bond, as described in Section 3.

Figure 2: Event Data from June 16, 2014, 9:30-11:30am EST

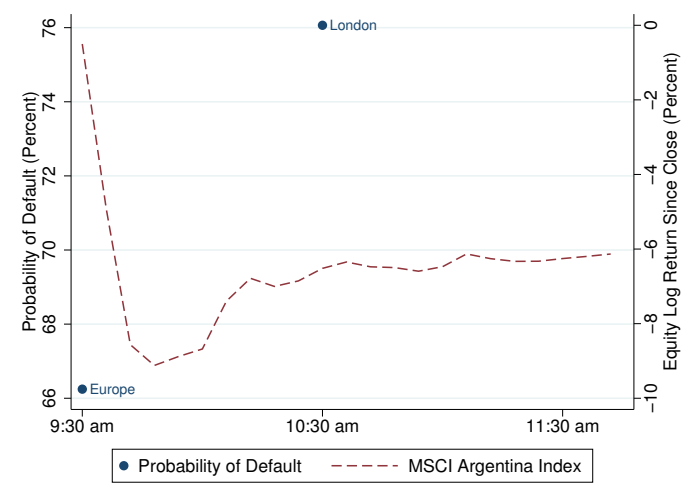

Notes: This figure plots the 5-year risk-neutral probability of default ("Probability of Default (Percent)", left axis), the change in the price of the MSCI Argentina Index against the previous night's close ("Equity Return Since Close (Percent)", right axis). The default probability points are labeled with the name of the reporting market, with European markets reporting at 9:30am EST and London Markets reporting at 10:30am EST. The Supreme Court order was released at 9:33 am EST. 


\section{Figure 3: Equity Returns and Argentine Default Probability}

(a) Argentine Equity Index

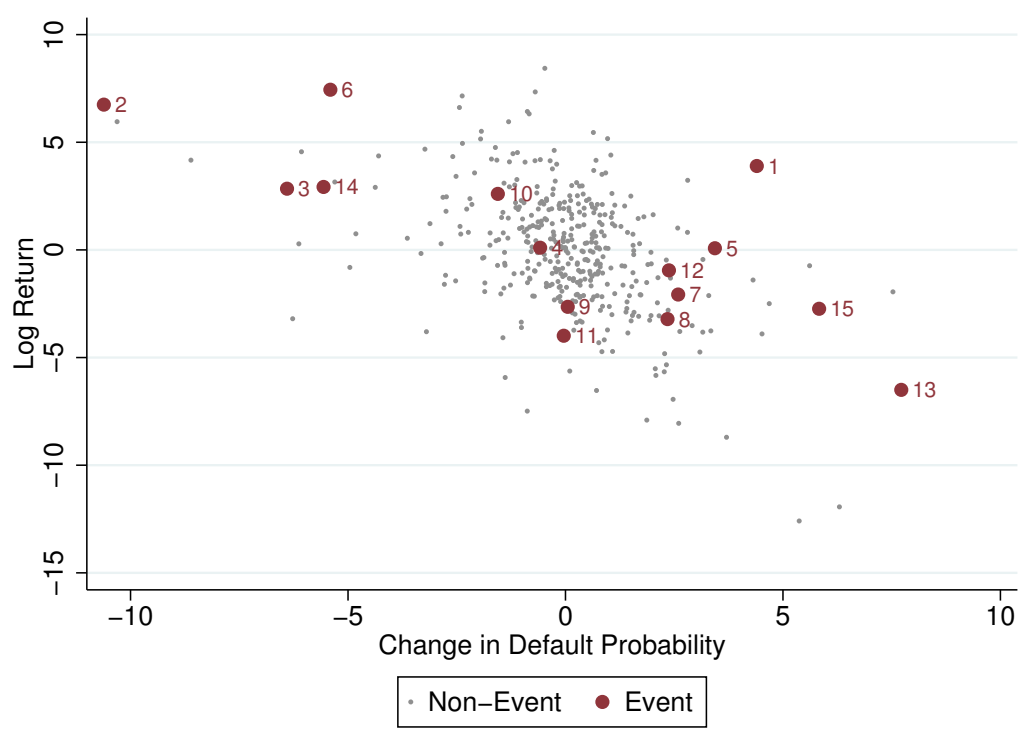

(b) Mexican Equity Index

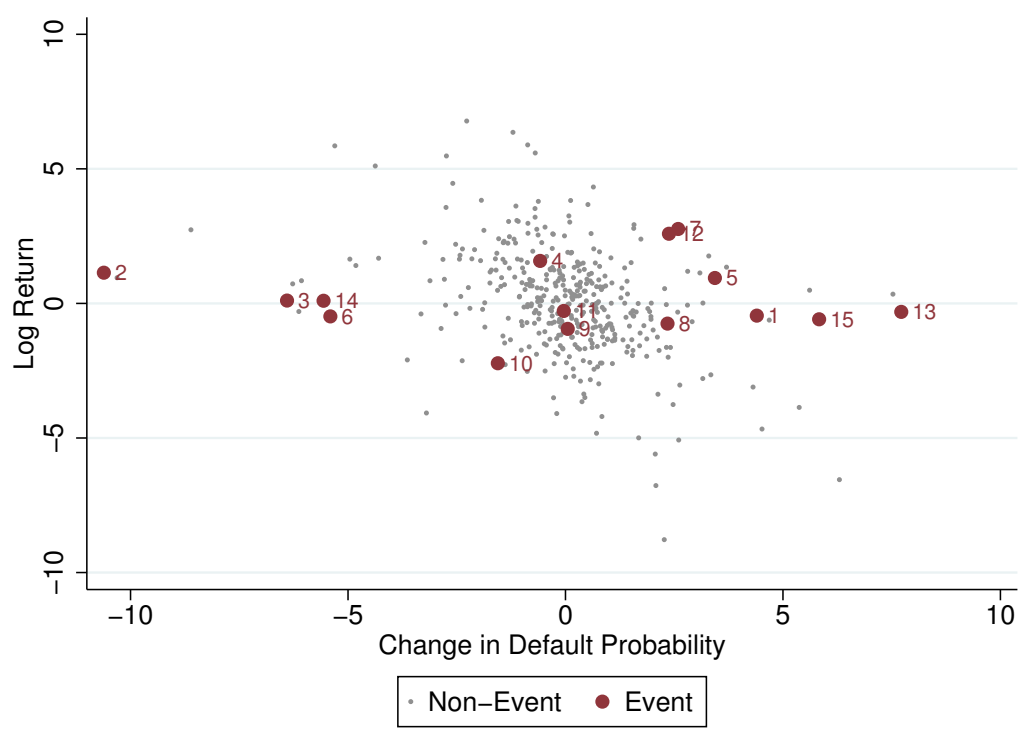

Notes: This figure plots the change in change in the risk-neutral probability of default and returns on the Argentine value-weighted Index (top panel) and MSCI Mexico Index (bottom panel) on event and non-event two-day windows. Each event and non-event window is a two-day event or non-event as described in the text. The numbers next to each maroon/dark/large dot reference an event window in appendix table 18 . The procedure for classifying events and non-events is described in the text. 


\section{Appendix}

\section{A Data Construction Details}

In this section, we provide additional details about our data construction.

\section{A.1 Data Sources}

In the table below, we list the data sources used in the paper. The data source for the credit default swap prices is Markit, a financial information services company. We use Markit's composite end-of-day spread, which we refer to as the "close." The composite end-of-day spread is gathered over a period of several hours from various market makers, and is the spread used by those market makers to value their own trading books. The composite end-of-day spread uses a survey of dealers to estimate the recovery rate. Markit uses a data cleaning process to ensure that the composite end-of-day quotes are reasonable approximations of market prices. Markit provides extensive documentation on their data, including documentation on the "CDS Data Cleaning Process," a "Markit CDS Liquidity User Guide," and other detailed information on the data construction. This very thorough documentation and extensive conversations with Markit give us confidence that this is the most reliable source of CDS pricing available.

We have experimented with alternative providers of CDS data, such as Bloomberg, but found discrepancies between these data sources and Markit. Although the aggregate time series of Markit, Bloomberg, and Datastream appear similar, at a higher frequency it is clear that there are significant issues with the Bloomberg and Datastream data. The primary issue with the Bloomberg data is that the CDS spreads at tenors other than 5 years appear to be unreliable. In particular, Bloomberg's 2, 3, and 4 year CDS spreads have very large daily fluctuations that are completely absent from the 5 year spread and from the Markit data. However, the Bloomberg data for the 5 year spread appears to be reasonable. This explains why the Bloomberg and Markit results that use a 5 year credit triangle approximation, with a $39.5 \%$ recovery rate, are very similar (see appendix table 7). However, while the credit triangle approximation method is a useful first step, it essentially assumes a constant hazard rate over the life of the 5 year CDS. Given that the court case would likely lead to default over the shorter term, as we see in the Markit hazard rates, this assumption is not appropriate.. Given the problems with the shorter tenor Bloomberg CDS, we do not attempt to bootstrap a risk-neutral default probability curve using the ISDA Standard Model.

The Datastream data look very similar to Markit on most days, but there are many dates, including several of our events, for which the Datastream data is missing. For instance, the data in Datastream on the day of the major Supreme Court ruling (June 16, 2014) is missing. We conferred extensively with Datastream support, and they confirmed that their source data is from EIKON, and that on that day, as well as several other of the rulings, EIKON did not receive any CDS quotes. They were unable to explain why there were no prices on these days. Both Bloomberg and Markit have data for these days, and DTCC trading volume data indicates that Argentine CDS were traded during the weeks for Datastream has missing data. When we use the previously mentioned credit triangle approximation with the Datastream data, and discard the days with missing data, we find results that are similar to the full-sample Markit and Bloomberg credit triangle approximation results (see appendix table 7). 
Table 1: Data Sources

\begin{tabular}{|c|c|}
\hline Data & Data Source \\
\hline \hline Prices and returns for ADRs & CRSP \\
\hline Prices and returns for local equities & Bloomberg \\
\hline VIX & CBOE \\
\hline S\&P & Global Financial Data \\
\hline MSCI Emerging Markets Asia ETF & Datastream \\
\hline High Yield and IG Bond Index & Datastream \\
\hline Oil Prices & Global Financial Data \\
\hline Industry Exports & OECD-STAN IO Tables \\
\hline Firm Imports & Gopinath and Neiman (2014) \\
\hline Firm Revenue & Compustat Global \\
\hline Firm Earnings (ADR firms only) & CRSP \\
\hline Market Capitalization & Bloomberg \\
\hline Foreign Ownership & Bloomberg \\
\hline Industry Classification & Fama-French, formatted by Dexin Zhou \\
\hline Bond Prices for BCS construction & Bloomberg \\
\hline Dolar Blue Rate & dolarblue.net \\
\hline Official nominal exchange rate & Datastream \\
\hline CDS spreads/Recovery Rate/Default Probability & Bloomberg, Datastream \\
\hline Alternative CDS Spreads & Bloomberg \\
\hline Argentine Sovereign Bond Prices &
\end{tabular}

\section{A.2 Firm Classifications}

To ensure sufficient data quality, we limit our study of local Argentine equities to firms with a 2011 market capitalization at least 200 million pesos ${ }^{35}$, have returns during at least ten of our event windows, and for which the equity price changes on at least half of all trading days in our sample. We exclude several firms that have neither headquarters or a large fraction of their revenues in Argentina, but are listed on the Argentine exchange for legacy reasons. ${ }^{36}$

We classify firms according to their Fama-French industry classifications. ${ }^{37}$ We sort firms into their corresponding Fama-French industries according the SIC code of their primary industry, available from Datastream. After this initial sort, we only have one firm, Boldt, classified as Business Equipment, and so we combine it with the telecommunications firms. The "Finance" Fama-French 12 industry classification is also too broad for our purposes, as it combines banks, holding companies, and real estate firms. We therefore split the nine firms initially classified as "Finance" according to their Fama-French 49 industry classification. This gives us six banks, two real estate firms, and one "Trading" firm, Sociedad Comercial del Plata. Because Sociedad Comercial del Plata is a diversified holding company, and is the only company in the Fama-French 49 industry classification of "Trading," we rename its industry "Diversified", and do not

\footnotetext{
${ }^{35}$ About $\$ 50 \mathrm{~mm}$ USD at market exchange rates in 2011.

${ }^{36}$ See appendix section G.2, for a discussion of these firms.

${ }^{37}$ Classifications available on Kenneth French's website. We use the versions formatted by Dexin Zhou.
} 
merge it with any other industry classification. After these modifications, our sample includes six banks, two chemical firms, one diversified firm, three energy firms, four manufacturing firms, six non-durables firms, two real estate firms, three telecoms and eight utilities. These industries are listed in table 2.

We also sort firms by their exporter status. Unfortunately, this task is complicated by the fact that publicly available data sources do not comprehensively report firm-level exports. We instead rely on industrylevel measures. We use the OECD STAN Input-Output Tables for Argentina to calculate what share of each industry group's output is exported. The Input-Output Table covers 37 industries, each of which covers at least one two-digit ISIC industry, and some of which, such as "Agriculture, hunting, forestry and fishing", cover up to five two-digit ISICs. After we calculate the share of exports for each of these 37 industries, we classify our 33 firms into one of these industries according to the SIC code of its primary output. The most recent Input-Output Table for Argentina uses data from 1995, so our export analysis assumes that the relative tradability of different products has not changed too much over the past 20 years. ${ }^{38}$ When we construct a zero-cost long-short portfolio, going long exporters and short non-exporters, we will classify firms as exporters if exports accounted for at least $10 \%$ of their primary industries' revenues in our Input-Output table, and non-exporters otherwise. The exporter threshold is set at $10 \%$ because there are no firms with an export share between $3.6 \%$ and $10.1 \%$.

To calculate each firm's import intensity, we use firm level data from Gopinath and Neiman (2014). The most recent available import data is for 2007 and 2008 (through October), and we compute the ratio of imports to firm revenue using data from Compustat Global. Our measure of import intensity is the average ratio of imports to revenue in 2007 and 2008. The importer threshold is set to the median ratio $0.6 \%$.

The next cut of the data divides firms between those that are subsidiaries of foreign corporations and those that are not. We classify firms as foreign-owned if the headquarters of their ultimate parent is any country other than Argentina in Bloomberg (Field ULT_PARENT_CNTRY_DOMICILE). We use the most recent (as of our data construction) version of this variable and cannot account for the possibility that an Argentine firm was only recently purchased by a foreign parent.

The final variable we use to classify our local equities is an indicator for whether or not the firms have an ADR that is traded in the US. This includes some firms with ADRs that trade over-the-counter, and are therefore not included in our analysis of the ADRs.

\footnotetext{
${ }^{38}$ For those firms that report data on revenue from exports, there is a strong correlation between reported exports as a share of sales and the imputed share of exports from the 1995 input-output table.
} 
Table 2: Firms Included in Analysis

\begin{tabular}{|c|c|c|c|c|c|c|c|}
\hline Company & Ticker & Industry & Exports & Imports & Market Cap & Foreign & ADR \\
\hline Aluar & ALUA & Manufacturing & 19.4 & 9.1 & 9443.0 & & \\
\hline IRSA Propiedades Commerciales & APSA & Real Estate & & & 2960.1 & & $\mathrm{Y}$ \\
\hline Hipotecario Naci & BHIP & Banks & & & 3540.0 & & $\mathrm{Y}^{*}$ \\
\hline Banco Macro Bansud & BMA & Banks & & & 9379.2 & & $\mathrm{Y}$ \\
\hline Boldt & BOLT & Telecoms & & 1.8 & 1537.5 & & \\
\hline Banco Patagonia & BPAT & Banks & & & 3488.4 & $\mathrm{Y}$ & $\mathrm{Y}^{*}$ \\
\hline Banco Santander Rio & BRIO & Banks & & & 12786.1 & Y & $\mathrm{Y}$ \\
\hline Carlos Casado & CADO & Real Estate & & & 378.1 & & $\mathrm{Y}^{*}$ \\
\hline Capex & CAPX & Utilities & 0.1 & 0.9 & 1087.8 & & \\
\hline Celulosa & CELU & Chemicals & 11.2 & 1.3 & 760.3 & & \\
\hline Central Puerto Rights & CEPU2 & Utilities & 0.1 & 0.4 & 1814.4 & & \\
\hline Sociedad Comercial Del Plata & COME & Diverse & 1.5 & & 212.3 & & \\
\hline Cresud & CRES & Non-Durables & 14.5 & 0.0 & 3495.9 & & Y \\
\hline Edenor & EDN & Utilities & 0.1 & 0.1 & 1894.5 & & $\mathrm{Y}$ \\
\hline Siderar & ERAR & Manufacturing & 19.4 & 0.0 & 10893.1 & Y & \\
\hline BBVA Banco Frances & FRAN & Banks & & & 7723.6 & Y & Y \\
\hline Gp Finance Galicia & GGAL & Banks & & & 7125.7 & & $\mathrm{Y}$ \\
\hline Solvay Indupa & INDU & Chemicals & 11.2 & 0.6 & 1218.0 & $\mathrm{Y}$ & \\
\hline IRSA & IRSA & Real Estate & & & 3350.5 & & $\mathrm{Y}$ \\
\hline Juan Minetti & JMIN & Manufacturing & 3.6 & 2.1 & 1633.5 & $\mathrm{Y}$ & \\
\hline Ledesma & LEDE & Non-Durables & 14.5 & 1.0 & 4004.0 & & \\
\hline Metrogas & METR & Utilities & 0.1 & 0.0 & 677.3 & & $\mathrm{Y}^{*}$ \\
\hline Mirgor & MIRG & Manufacturing & 10.1 & 11.8 & 512.0 & & $\mathrm{Y}^{*}$ \\
\hline Molinos Rio De La Plata & MOLI & Non-Durables & 19.5 & 0.4 & 8014.4 & & \\
\hline Pampa Energia & PAMP & Utilities & 0.1 & 0.1 & 3417.2 & & $\mathrm{Y}$ \\
\hline Quickfood & PATY & Non-Durables & 19.5 & 0.5 & 641.9 & Y & \\
\hline Petrobras Argentina & PESA & Energy & 25.5 & 3.8 & 8228.4 & $\mathrm{Y}$ & $\mathrm{Y}$ \\
\hline SA San Miguel & SAMI & Non-Durables & 19.5 & 0.6 & 491.1 & & \\
\hline Moli Juan Semino & SEMI & Non-Durables & 19.5 & 0.1 & 325.5 & & \\
\hline Telecom Argentina & TECO2 & Telecoms & 2.7 & 0.3 & 21754.8 & $\mathrm{Y}$ & $\mathrm{Y}$ \\
\hline Transportadores De Gas Del Norte & TGNO4 & Utilities & 0.1 & 3.3 & 540.4 & & \\
\hline Transportadora De Gas Del Sur & TGSU2 & Energy & 25.5 & 0.9 & 2558.3 & & $\mathrm{Y}$ \\
\hline Transener & TRAN & Utilities & 0.1 & 2.1 & 640.3 & & \\
\hline YPF & YPFD & Energy & 14.2 & 2.2 & 74532.8 & & $\mathrm{Y}$ \\
\hline
\end{tabular}

Notes: This table lists the 33 firms used in the analysis of local equities, and one firm (IRSA Propiedades Commerciales) whose ADR is included in our ADR sample, but whose local stock returns do not pass our data quality requirement. Ticker indicates the company's local ticker in Bloomberg. Exports denotes the ratio (in percentage terms) of exports to total output for the firm's primary industry. Exports are calculated by classifying the firm into one of the 37 industries in the OECD STAN Input-Output Table according the SIC code of the firm's primary industry. Imports denotes the ratio (in percentage terms) of imports to firm revenue in 2007 and 2008. The import data is from Gopinath and Neiman (2014). Market Cap. is the firm's average end-of-quarter market capitalization in 2011 from Bloomberg, measured in Argentine pesos. ADR is an indicator for whether the firm currently has an American depository receipt. "Y*" indicates that the firm has an OTC-traded or discontinued ADR and is not included in our sample of ADRs. To be included in our ADR sample, the ADR must be exchange-traded and have existed for our entire sample. Foreign is an indicator for whether the firm is owned by a non-Argentine parent company. 


\section{A.3 Exchange Rate Construction}

The blue-chip swap rate is constructed by dividing the peso price of the government bond by the dollar price of the same bond. The mechanics of this transaction are outlined in Panel A of Figure 1. In Panel B of Figure 1, we demonstrate how to construct an exchange using local equities and ADRs.

We calculate the blue-chip swap rate using the two most liquid available debt instruments, the Bonar $\mathrm{X}$ and the Boden 15. ${ }^{39}$ To calculate this blue-chip swap rate, we search for the bonds on Bloomberg, use $<$ ALLQ $>$ to find the list of all available pricing sources for the bonds, and then download the full available history of closing prices for every data provider in ARS and USD. ${ }^{40}$ Each day, there are around 5 closing price quotes per bond in ARS and USD. We calculate the median price for each bond every day, by currency, and then construct the implicit exchange rate by dividing the median peso price by the median dollar price. This gives us a blue-chip swap rate for each of our two bonds, and we construct the Blue-Chip Swap rate by taking the average of the two. Despite these bonds being classified as domestic debt, many of these instruments have ISINs and are accepted on Euroclear or Clearstream. This makes it relatively easy for foreign investors to use this process to get money on- or offshore, circumventing Argentina's capital controls. ${ }^{41}$ However, it is important to remember that although we calculate the exchange rate using simultaneous prices, an investor implementing this transaction is required to hold the bond for at least 3 days at an Argentine custodian bank, and therefore bears some price risk when acquiring dollars. ${ }^{42}$ Despite being domestic law debt instruments, both of these bonds became entangled in the legal proceedings we focus on in this paper. ${ }^{43}$

For the ADR blue rate, we follow the methodology outlined on dolarblue.net. ${ }^{44}$ We collect daily open and close price data on the ADR and local equity for eight firms from Bloomberg. ${ }^{45}$ We then calculate the daily implicit exchange rate for each firm, drop the high and low price among the eight firms, and construct our measure as the mean of the remaining six equities. The average difference between the maximum and minimum firm-level exchange rate is $3.6 \%$ of the level of the ADR Blue Rate. This difference could reflect differences in the closing times of the NYSE/NASDAQ and Buenos Aires stock exchanges, bidoffer spreads, and other forms of illiquidity. Generally speaking, it is very costly for foreign investors to participate in local Argentine markets, which makes the ADR blue rate arbitrage difficult for them to execute. Together, the ADR Blue Rate and the Blue-Chip Swap rate may be known as the dolar contado con liquidación, dolar fuga, or the dolar gris (Infodolar (2016)).

While the CDS-IV results in Table 2 report similar point estimates of the effect of default on the Dolar Blue, ADR Blue and Blue-Chip Swap Rate, the standard errors and confidence interval for the Dolar Blue are significantly tighter. The reason for this is that the behavior of the ADR Blue rate and Blue-Chip swap rate on the day with the largest increase in the probability of default, the Supreme Court ruling day on June 16,2014 , is a significant outlier. On that day, these measures of the exchange rate significantly appreciated. This is in stark contrast to the Dolar Blue rate, which has a significant depreciation. Mechanically, the reason for the appreciation of the ADR Blue and Blue-Chip Swap rates is that the value of domestically traded securities priced in ARS fell significantly more than those traded by foreign investors in dollars.

\footnotetext{
${ }^{39}$ The ISIN for the Bonar X is ARARGE03F441 and the ISIN for the Boden 15 is ARARGE03F144.

${ }^{40} \mathrm{We}$ drop pricing sources with less than 300 days of data and sources where more than $5 \%$ of the daily observations record no price change.

${ }^{41}$ Indeed, dolarblue.net offers a simple guide for how to buy and sell dollars (Dolarblue.net (2014)).

${ }^{42}$ Chodos and Arsenin (2012).

${ }^{43}$ Excellent coverage of turmoil around the domestic debt was provided by Joseph Coterill of FT Alphaville. See, for instance, Cotterill (2015b) or Cotterill (2015a).

${ }^{44}$ Dolarblue.net (2016)

${ }^{45}$ Grupo Financiero Galicia (ADR Ticker: GGAL, Local Ticker: GGAL), Tenaris (TS, TS), BBVA Banco Frances (BFR, FRAN), Banco Macro (BMA, BMA), Pampa Energia (PAM, PAMP), Petrobras Argentina (PZE, PESA), Petroleo Brasileiro (PBR, APBR), and Telecom Argentina (TEO, TECO2).
} 
Based on conversations with market participants, we believe that the ruling caused a major disruption in local trading. If we expand the window size around this ruling, it ceases to be an outlier, consistent with the trading disruption hypothesis. However, a major speech was made by the President of Argentina in the evening following the ruling, so we cannot be certain that this pattern is due to a disruption in trading. We also find that, if that event is excluded, the effect on the exchange rate approximately doubles and is relatively precisely estimated. The importance of this outlier (Event 13) can be clearly seen in Figure 3.

Figure 1: Blue Rate Construction

(a) Blue-Chip Swap

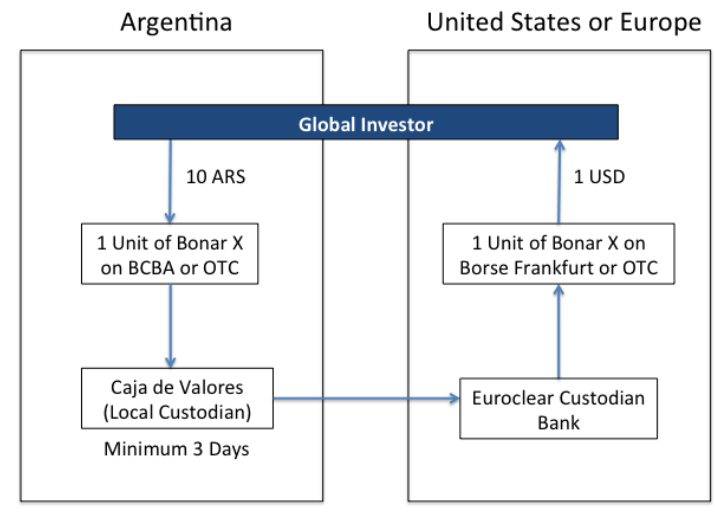

(b) ADR Blue Rate

Panel (a) demonstrates how an investor would convert Argentine pesos into U.S. dollars at an exchange rate of 10 pesos to the dollar, by buying a domestic sovereign bond in ARS and selling the bond offshore in USD. This transaction defines an unofficial exchange rate known as the Blue-Chip Swap rate. Panel (b) demonstrates how an investor would convert Argentine pesos into U.S. dollars at the same exchange rate, by buying shares of Banco Macro onshore and selling an ADR in New York. The transaction defines an unofficial exchange rate known as the ADR Blue Rate.

\section{A.4 Construction of Risk-Neutral Default Probabilities}

We convert CDS spreads into risk-neutral default probabilities to provide a clearer sense of the magnitude of the estimated coefficients. We emphasize that we work with risk-neutral probabilities and do not attempt to convert them to physical probabilities. Pan and Singleton (2008) and Longstaff et al. (2011) impose additional structure to estimate the physical default probabilities.

In our baseline results, we will use the five-year cumulative risk-neutral default probability estimated by Markit using the ISDA standard model. This calculation begins with data from Markit on CDS par spreads and the dealer reported recovery rates, as well as a zero-coupon discounting curve. ${ }^{46}$ The par spread is the coupon payment that a buyer of CDS protections pays to the seller of the contract such that the CDS

\footnotetext{
${ }^{46}$ Details on the discounting curve can be found at http://www.cdsmodel.com/cdsmodel/documentation.html. In the robustness checks where we estimate the risk-neutral default probability rather than using the data provided by Markit, we will use the U.S. zero-coupon Treasury curve calculated in Gürkaynak et al. (2007) as our discount curve. As Longstaff et al. (2011) point out, changing from the Treasury curve to a zero-coupon curve extracted from Libor and swap rates would have very little effect on the results. Our estimation is performed using the Matlab function $c d$ sbootstrap.
} 
contract has zero cost at initiation. Because the seller of a CDS insures the buyer of a CDS against credit losses throughout the duration of the contract, pricing the contract involves calculating the term structure of credit risk on the bond. The recovery rate we use is the average of the recovery rates reported by dealers contributing prices to Markit. In robustness checks, we also consider a case with a constant recovery rate equal to the realized recovery of $39.5 \% .^{47}$

The market standard for pricing CDS is a reduced form model that models time-varying credit risk as a time-varying hazard rate of default. ${ }^{48}$ Because we use the risk-neutral default probabilities calculated by Markit, our exposition will exactly follow Markit (2012). The par spread is the spread that equates the present value of payments from buyer of protection to the seller of protection (Fee Leg) equals the value of the from the seller to the buyer upon default (Contingent Leg). We can write the equation equating the present value of fee leg to the present value of the contingent leg as

$$
S_{n} \sum_{i=1}^{n} \Delta_{t} P_{S(t)} D f_{t}+A D=(1-R) \cdot \sum_{i=1}^{N}\left(P_{S(t-1)}-P_{S(t)}\right) D f_{t}
$$

where

$$
\begin{aligned}
S_{n} & =\text { Spread for protection to period } n \\
\Delta_{t} & =\text { Length of Period } \\
P_{S i} & =\text { Probability of survival to time } i \\
D f_{i} & =\text { Discount factor to time } i \\
R & =\text { Recovery Rate } \\
A D & =\text { Accrual on Default }
\end{aligned}
$$

White (2013) provides a detailed explanation of the calculation of accrual on default and we will omit the details here for brevity. If we assume that the default hazard rate is constant between CDS nodes (tenors for which CDS contracts are traded), the survival probabilities map exactly to the hazard rates. For example, if the shortest tenor CDS traded is 6 months, and the hazard rate of default is $\lambda_{6 m}$ from time 0 to 6 months, then the survival probability is equal to $\exp \left(-\lambda_{6 M} \cdot\left(\frac{1}{2}\right)\right)$. Given a 6 month par spread, a discounting curve to 6 months, and an assumption on the recovery rate, $\lambda_{6 m}$ can be calculated directly from equation 4 . Once this hazard rate, and therefore the survival probability, has been calculated for the 6 month tenor, the hazard rate between the next node of the CDS curve, 6 months and 1 year, can be calculated in the same way. In this way, the hazard rate curve is bootstrapped until we have calculated the hazard rates between every CDS node. We can then use our estimate hazard rates to calculate the risk-neutral default probabilities for various horizons:

$$
\begin{aligned}
\operatorname{Pr}(D \leq 6 M) & =1-\exp \left(-\lambda_{6 M} \cdot\left(\frac{1}{2}\right)\right) \\
\operatorname{Pr}(D \leq 1 Y) & =1-\exp \left(-\lambda_{6 M} \cdot\left(\frac{1}{2}\right)-\lambda_{1 Y} \cdot\left(\frac{1}{2}\right)\right) \\
& \vdots \\
\operatorname{Pr}(D \leq 5 Y) & =1-\exp \left(-\lambda_{6 M} \cdot\left(\frac{1}{2}\right)-\lambda_{1 Y} \cdot\left(\frac{1}{2}\right)-\lambda_{2 Y}-\lambda_{3 Y}-\lambda_{4 Y}-\lambda_{5 Y}\right)
\end{aligned}
$$

The final equation, the probability that the government defaults in the next 5 years, is the measure we use for the default probability in our baseline analysis. For the calculation of the default probabilities of the other

\footnotetext{
${ }^{47}$ See http://www.creditfixings.com/CreditEventAuctions/holdings.jsp?auctionId=9073 for details on the auction to calculate the recovery rate.

${ }^{48}$ White (2013) provides a very thorough discussion of the ISDA standard model.
} 
sovereigns in section G.1, we approximate the default probability by using the credit triangle relationship. As shown in White (2013), if we assume the premium leg were paid instantly and the hazard rate were equal to a constant $\lambda$, then we would have

$$
\begin{aligned}
S & =(1-R) \lambda \\
\lambda & =\frac{S}{1-R} \\
\operatorname{Pr}(D<5 Y) & =1-\exp (-5 \lambda) .
\end{aligned}
$$

In the figure below, we chart the CDS spreads and recovery assumptions that we use to infer hazard rates of default and cumulative default probabilities. In all regressions in the body of the paper, we use Markit's risk-neutral default probability calculations rather than our own calculations.

Figure 2: From CDS Spreads to Default Probabilities

(a) Daily Composite CDS Spreads

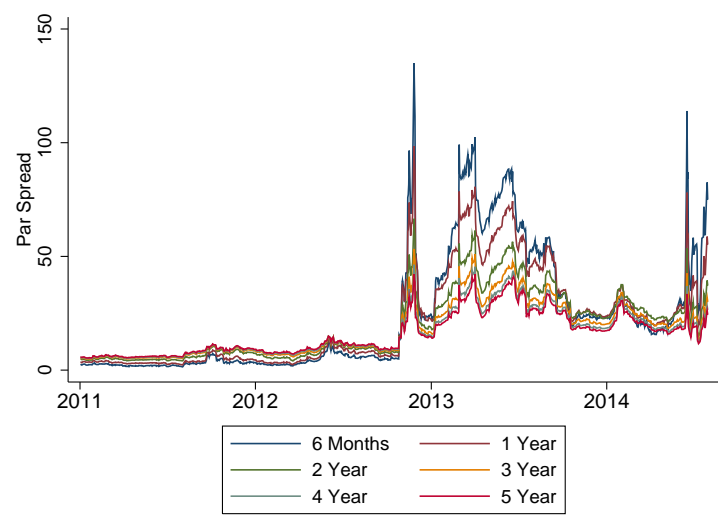

(c) Estimated Hazard Rate

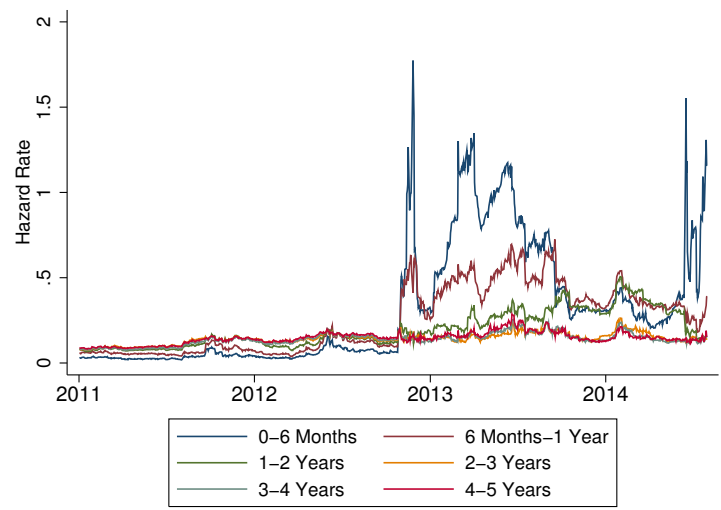

(b) Dealer-Reported Recovery Rate

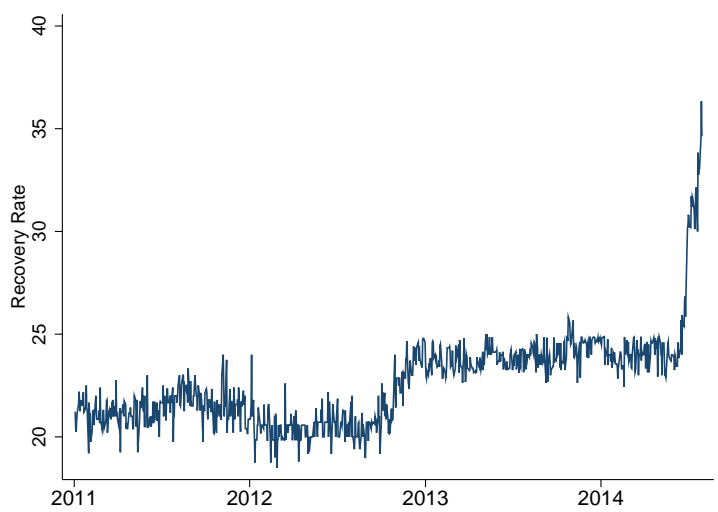

(d) Risk-Neutral Cumulative Default Probability

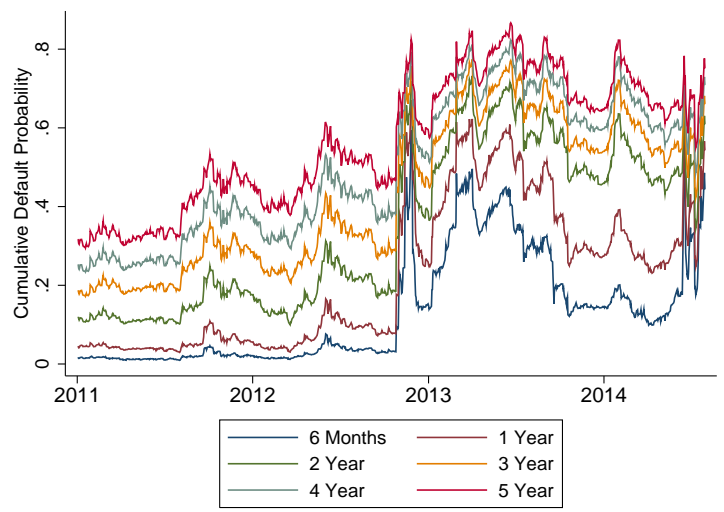

Notes: Panel (a) plots the daily Composite CDS spreads from Markit. Panel (b) plots the the average of all recovery rates of Markit contributors whose CDS curves are used to calculate the Markit CDS End of Day composite curve. Panel (c) plots the default hazard rates estimated using the ISDA Standard model. 0-6 Months indicates the estimated constant hazard rate from initiation to 6 months, 6 Months - 1 Year indicates the implied estimated constant hazard rate from 6 months after initiation to 1 year after initiation, and so on. Panel (d) converts the estimated hazard rates in Panel (c) into cumulative risk-neutral default probabilities. 6 Months indicates the probability the government defaults in the next 6 months, 1 Year indicates the probability of default in the next year, and so on. The data and ISDA Standard model are discussed in Sections 3.1 and A.4. 


\section{B Additional Figures}

Figure 3: Change in Default Probability and other Financial Variables on Event and Non-Event Days
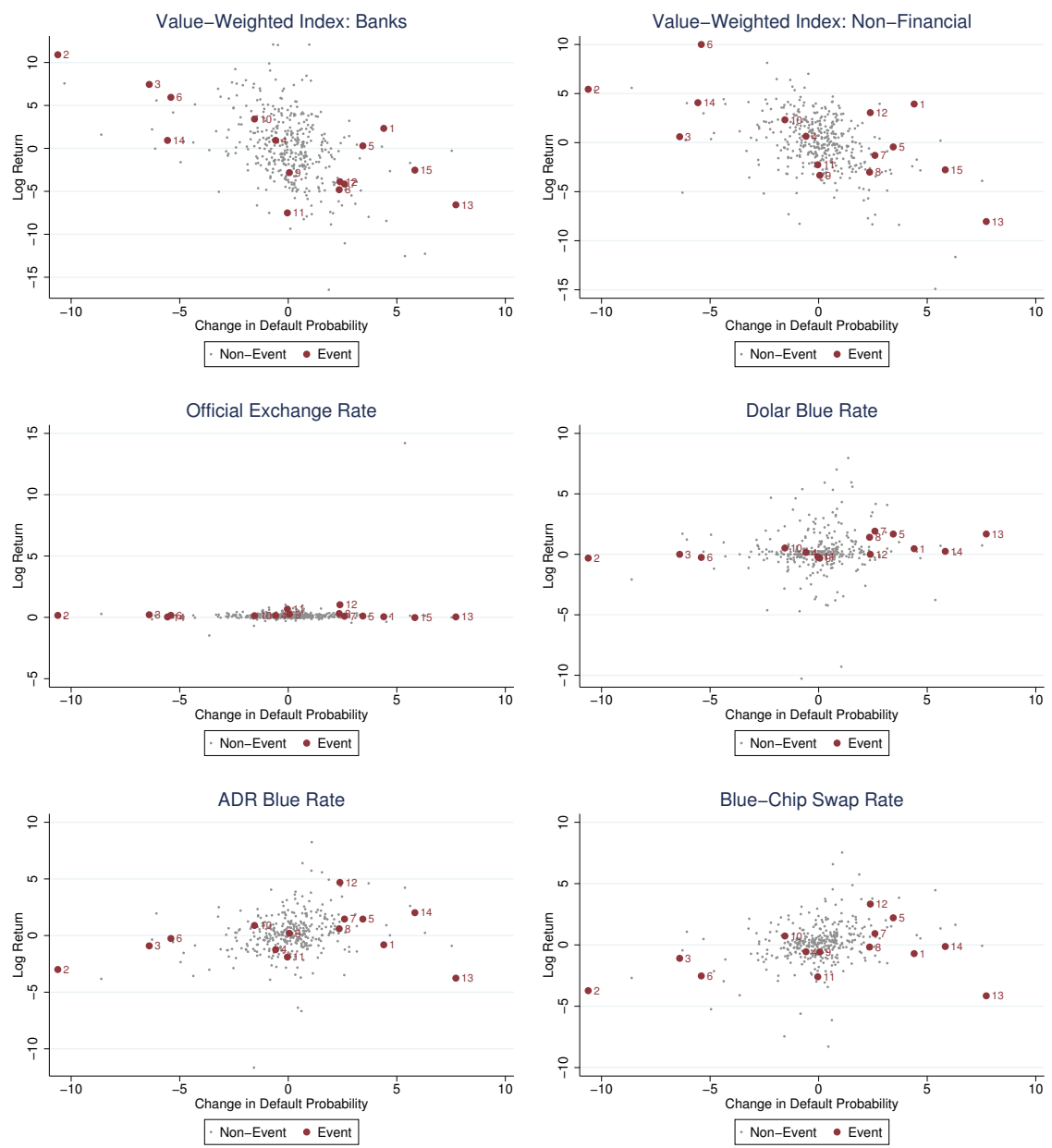

Notes: This figure plots the change in the risk-neutral probability of default and returns on the Value-Weighted Bank and NonFinancial Index and four measures of the exchange rate, on event and non-event days. Official is the government's official exchange rate. Dolar Blue is the onshore unofficial exchange rate from dolarblue.net. ADR Blue is the ADR Blue Rate constructed by comparing the ADR share price in dollars with the underlying local stock price in pesos, as described in Section 3. Blue-Chip Swap is constructed by comparing the ARS price of domestic Argentine sovereign debt with the dollar price of the same bond, as described in Section 3. Each event and non-event day is a two-day event or non-event as described in the text. The numbers next to each large dark maroon dot references each event-day in the table below figure $3 \mathrm{a}$. The procedure for classifying events and non-events is described in the text. 
Figure 4: Estimated Response to Default Shocks: Long-Short

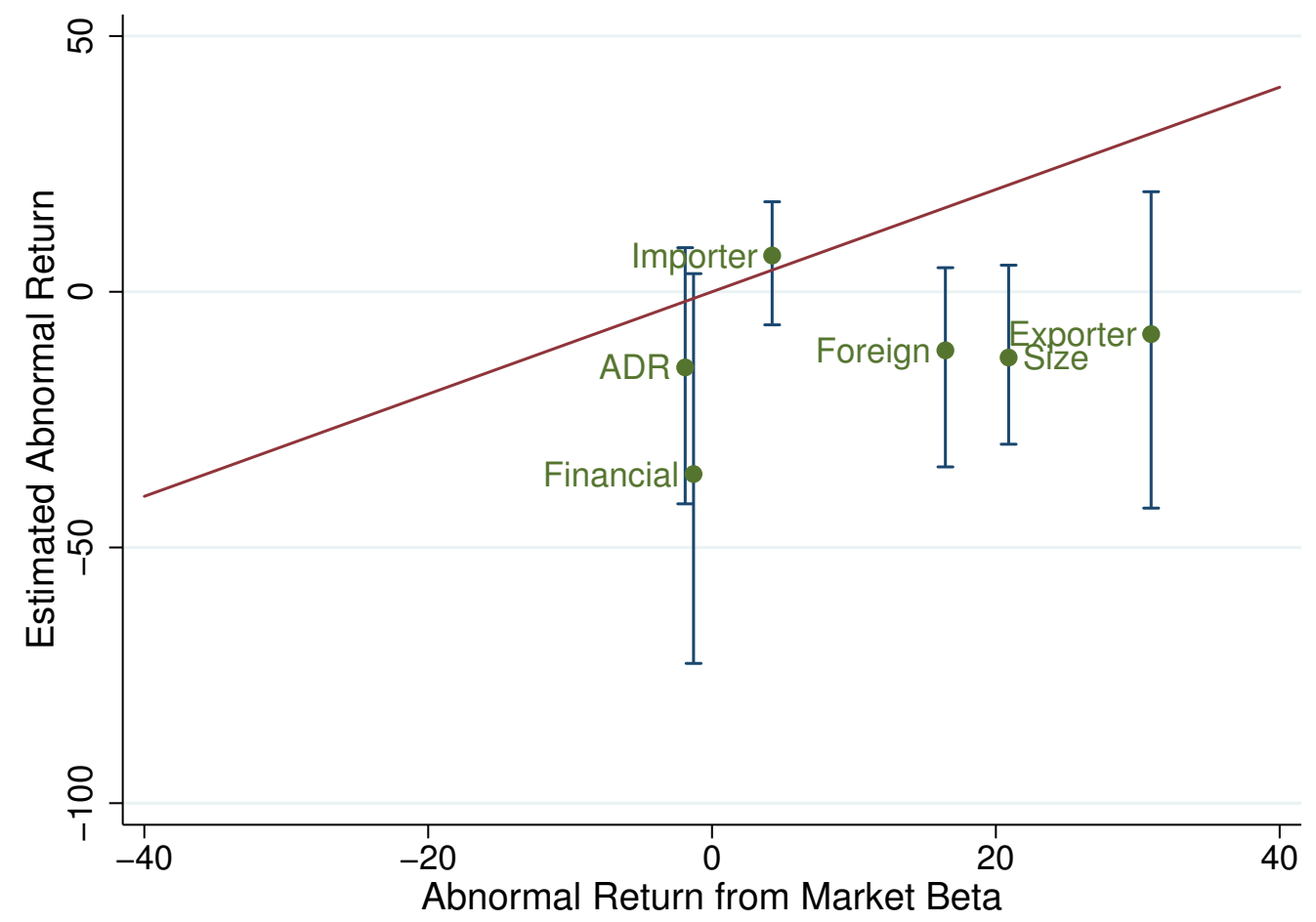

Notes: Each label denotes a zero-cost long short portfolio. "Exporter" is a portfolio going long export-intensive non-financial firms (NFFs) and short non-export-intensive NFFs. "Importer" is defined equivalently for importers. "Financial" goes long banks and short NFFs. "Foreign" goes long firms with a foreign parent and short domestically-owned firms. "Size" goes long firms with above-median market capitalization in 2011, and short firms with below-median market cap. "ADR" goes long firms with an American Depository Receipt and short firms without one. The data sources are described in Section 3.1. On the the x-axis, we plot the expected abnormal return for each portfolio, calculated as the beta of each long-short portfolio on the index times $\alpha_{M}$, the effect of an increase in the probability of default in the index. On the y-axis, we plot the sum of the expected abnormal return and $\left(\alpha_{i}-\beta_{i} \alpha_{M}\right)$, the additional sensitivity of each portfolio to an increase in the probability of default. Values above (below) the line indicates that the portfolio over-performed (under-performed) following increases in the probability of default, relative to the abnormal return implied by the portfolio's market beta. The ranges indicate bootstrapped $90 \%$ confidence intervals. 
Figure 5: Estimated Response to Default Shocks: Industries

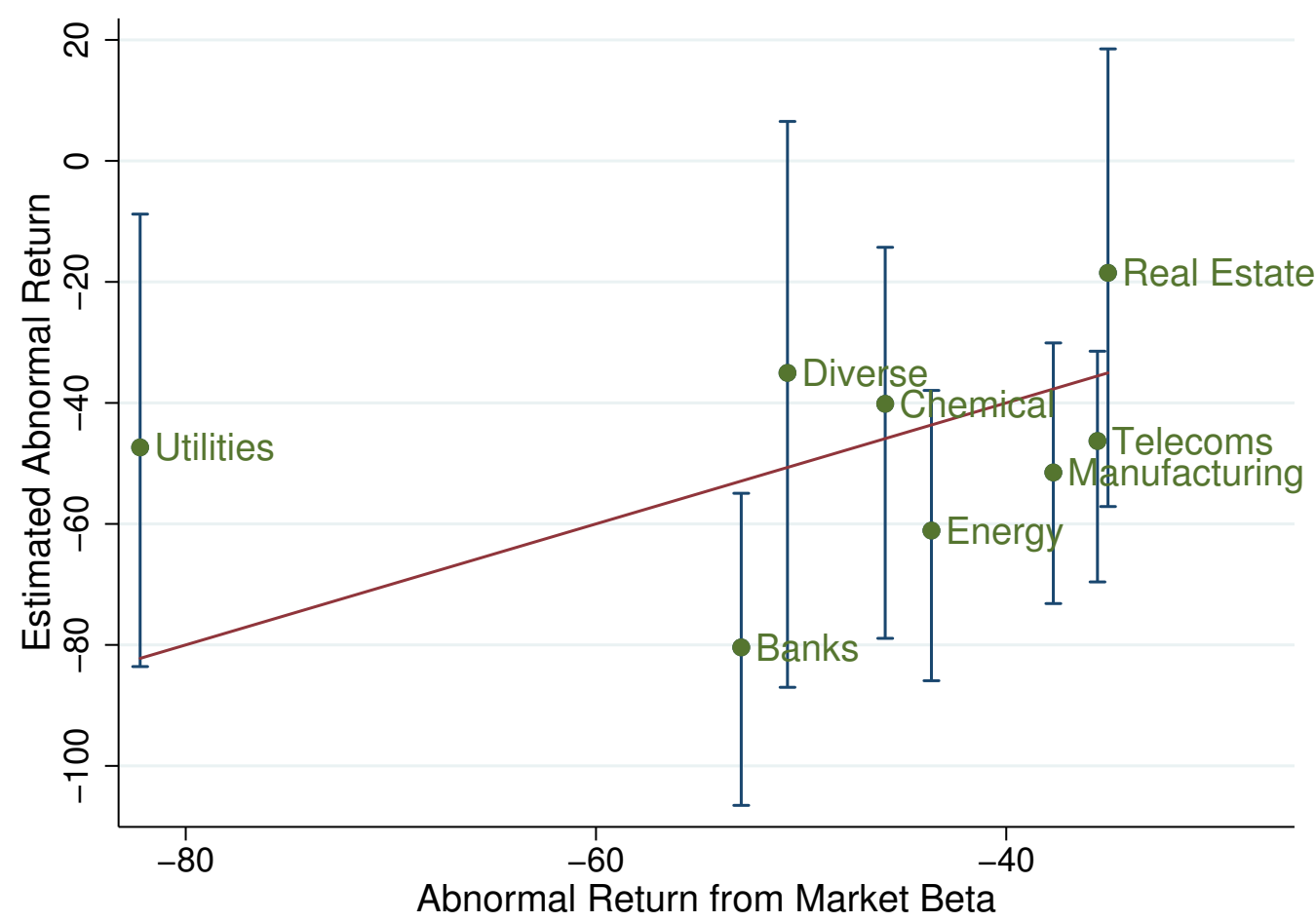

Notes: Industry classifications are based on the Fama-French 12 industry categories with the modifications described in Section 3.1. On the the x-axis, we plot the expected abnormal return for each portfolio, calculated as the beta of each long-short portfolio on the index times $\alpha_{M}$, the effect of an increase in the probability of default in the abnormal return of the index. On the y-axis, we plot the sum of the expected abnormal return and $\left(\alpha_{i}-\beta_{i} \alpha_{M}\right)$, the additional sensitivity of each portfolio to an increase in the probability of default. Values above the line indicates that the portfolio over-performed following increases in the probability of default, relative to what would be implied by the portfolio's market beta. Values below the line indicate underperformance. The ranges indicate bootstrapped $90 \%$ confidence intervals.

\section{Standard Errors and Confidence Intervals}

To construct confidence intervals for our coefficient estimates, we employ the bootstrap procedure advocated by Horowitz (2001). The advantage of this procedure is that it offers "asymptotic refinements" for the coverage probabilities of tests, meaning that it is more likely to achieve the desired rejection probability under the null hypothesis. Our estimators (except for the OLS) are effectively based on a small number of the data points (the events), and therefore these refinements may provide significant improvements over first-order asymptotic approximations. As a practical matter, our confidence intervals are in almost all cases substantially wider than those based on first-order asymptotic approximations. Nevertheless, these "asymptotic refinements" are still based on asymptotic arguments, and there is no guarantee that they are accurate for our data. We also find (in unreported results) that our confidence intervals for our coefficient of interest, $\alpha$, are similar to confidence intervals constructed under normal approximations, using a bootstrapped standard error.

We use 1,000 repetitions of a stratified bootstrap, resampling with replacement from our set of events and non-events, separately, so that each bootstrap replication contains 15 events and 386 non-events. ${ }^{49}$

\footnotetext{
${ }^{49}$ The number of events and non-events listed apply to the ADRs. The exchange rates have a slightly different number of events
} 
In each bootstrap replication, we compute the (asymptotically pivotal) t-statistic $t_{k}=\frac{\hat{\alpha}_{k}-\hat{\alpha}}{\hat{\sigma}_{k}}$, where $\hat{\alpha}$ is the point estimate in our actual data sample, $\hat{\alpha}_{k}$ is the point estimate in bootstrap replication $k$, and $\hat{\sigma}_{k}$ is the heteroskedasticity-robust standard deviation estimate of $\hat{\alpha}-\alpha$ from bootstrap sample $k$. We then determine the 2.5th percentile and 97.5th percentile of $t_{k}$ in the bootstrap replications, denoted $\hat{t}_{2.5}$ and $\hat{t}_{97.5}$, respectively. The reported $95 \%$ confidence interval for $\hat{\alpha}$ is $\left[\hat{t}_{2.5} \hat{\sigma}+\hat{\alpha}, \hat{t}_{97.5} \hat{\sigma}+\hat{\alpha}\right]$, where $\hat{\sigma}$ is the heteroskedasticity-robust standard deviation estimate of $\hat{\alpha}-\alpha$ from our original data sample. We construct $90 \%$ and $99 \%$ confidence intervals in a similar fashion, and use them to assign asterisks in our tables. ${ }^{50}$ In the tables, we report the $95 \%$ confidence interval and the heteroskedasticity-robust standard error from our dataset $(\hat{\sigma})$.

Note that this procedure, like heteroskedasticity-robust standard errors, assumes that the abnormal returns we study are serially uncorrelated.

\section{Event Studies}

\section{D.1 IV-Style Event Study}

We present an "IV-style" event study in this section. This study uses the two-day events and non-events described previously. The second stage equation we wish to estimate is equation (2) in the text. The instrument we use is $1(t \in E) \Delta D_{t}$ (and $1(t \in E)$ ), where $E$ is the set of event days and $\mathbf{1}(\cdot)$ is the indicator function. The first-stage regression is

$$
\Delta D_{t}=\chi 1(t \in E) \Delta D_{t}+\rho 1(t \in E)+\mu_{D}+\omega_{D}^{T} X_{t}+\tau_{t},
$$

where $\tau_{t}$ is a composite of the three unobserved shocks $\left(\varepsilon_{t}, F_{t}, v_{t}\right)$ on the non-event days, and $X_{t}$ are the observable controls. Under the event study assumptions, the unobserved shocks $\varepsilon_{t}$ and $F_{t}$ (in the second stage) are not correlated with the change in the default probability on event days. The standard errors and confidence intervals for this approach are described in section $\mathrm{C}$.

and non-events, due to holidays, missing data, and related issues.

${ }^{50}$ These asterisks represent an "equal-tailed" test that $\alpha \neq 0$. 
Table 3: Equity and Exchange Rate Results, IV-Style Event Study

\begin{tabular}{|cccccc|}
\hline & $(1)$ & $(2)$ & $(3)$ & $(4)$ & $(5)$ \\
& MSCI & Value & Bank & Non-Fin. & YPF \\
\hline$\Delta D$ & $-75.27 * * *$ & $-57.80 * * *$ & $-79.05 * * *$ & $-56.01 * *$ & $-88.14 * * *$ \\
SE & $(14.36)$ & $(11.77)$ & $(11.97)$ & $(17.81)$ & $(19.67)$ \\
$95 \%$ CI & {$[-107.3,-37.0]$} & {$[-86.0,-33.9]$} & {$[-109.8,-56.0]$} & {$[-105.6,-7.7]$} & {$[-136.1,-36.3]$} \\
Events & 15 & 15 & 15 & 15 & 15 \\
Obs. & 401 & 401 & 401 & 401 & 401 \\
\hline & $(6)$ & $(7)$ & $(8)$ & $(9)$ & \\
& Official & Dolar Blue & ADR Blue & BCS & \\
\hline$\Delta D$ & -0.00539 & $10.17 * *$ & 12.39 & 13.95 & \\
SE & $(1.236)$ & $(2.665)$ & $(13.21)$ & $(12.56)$ & \\
$95 \%$ CI & {$[-3.2,2.1]$} & {$[3.3,16.4]$} & {$[-23.7,76.1]$} & {$[-14.7,66.7]$} & \\
Events & 15 & 14 & 14 & 14 & \\
Obs. & 401 & 355 & 353 & 356 & \\
\hline
\end{tabular}

Notes: This table reports the results for the IV-Style Event Study estimator of the effect of changes in the risk-neutral default probability $(\Delta D)$ on several equity indices and exchanges rates. The equity indices are the MSCI Index, the Value-Weighted index, the Value-Weighted Bank Index, the Value-Weighted Non-Financial Index, and YPF. All indices are composed of ADRs. The index weighting is described in the text. For exchange rates, Official is the government's official exchange rate. Dolar Blue is the onshore unofficial exchange rate from dolarblue.net. ADR Blue is the ADR Blue Rate constructed by comparing the ADR share price in dollars with the underlying local stock price in pesos, as described in Section 3. BCS is the Blue-Chip Swap is constructed by comparing the ARS price of domestic Argentine sovereign debt with the dollar price of the same bond, as described in Section 3. The coefficient on $\Delta D$ is the effect on the percentage log returns of an increase in the 5-year risk-neutral default probability from $0 \%$ to $100 \%$, implied by the Argentine CDS curve. Standard errors and confidence intervals are computed using the stratified bootstrap procedure described in the text. The underlying data is based on the two-day event windows and non-events described in the appendix. All regressions contain controls for VIX, S\&P, EEMA, high-yield and investment grade bond indices, oil prices. Significance levels: $* * * \mathrm{p}<0.01, * * \mathrm{p}<0.05, * \mathrm{p}<0.1$.

\section{D.2 Standard Event Studies}

We also present the results of two additional event studies that use the methodology described in Campbell et al. (1997). The first event study uses two-day windows around events.

Let $N$ denote the set of non-event days, and let $L 1=|N|$. We first estimate the factor model on the non-event days,

$$
r_{i, t}=\mu_{i}+\omega_{i}^{T} X_{t}+v_{i, t},
$$

and generate a time series of abnormal returns, $\hat{r}_{i, t}=r_{i, t}-\hat{u}_{i}-\hat{\omega}_{i}^{T} X_{t}$, where $X_{t}$ is the vector of controls discussed in section 3.1. We also estimate the variance of the abnormal returns associated with the factor model (assuming homoskedastic errors), $\hat{\sigma}_{i}^{2}=\frac{1}{L 1} \sum_{t \in N} \hat{v}_{i, t}^{2}$. We next estimate a similar factor model for the change in the probability of default, $\Delta D_{t}$, and create a time series of abnormal default probability changes, $\hat{d}_{t}$. We then classify our event days into three categories, based on the abnormal default probability change during the event window. Let $\sigma_{d}$ denote the standard deviation of the abnormal default probability changes. If the probability increases by at least $\sigma_{d}$, we label that day as an "higher default" event. If the probability decreases by at least $\sigma_{d}$, we label that event as a "lower default" event. If the default probability change is less, in absolute value, than $\sigma_{d}$, we label that as a "no news" event.

For each type of event, we report the cumulative abnormal return and cumulative abnormal default 
probability change over all events of that type (higher default, lower default, no news). We also report two statistics that are described in Campbell et al. (1997). In this event study (but not the next one we discuss), which does not aggregate returns across different ADRs, the two statistics are identical, up to a small sample size correction. Define $E_{\{h, l, n\}}$ as the set of event days of each type. The first statistic, $J 1$, is computed, for event type $j$ and ADR $i$, as

$$
J 1_{i j}=\frac{\sum_{t \in E_{j}} \hat{r}_{i, t}}{\sqrt{\left|E_{j}\right| \hat{\sigma}_{i}^{2}}} .
$$

Under the null hypothesis that the events have no effect on the stock returns, $J 1_{i j}$ is asymptotically distributed as a standard normal. However, because we have so few events in each category, asymptotic normality will be a poor approximation, if the abnormal returns are themselves far from normal. This is one reason we prefer the variance-based estimators.

The second statistic, $J 2$, is nearly identical to $J 1$ for this event study (they will be different in the next event study we describe). For each event, we can define a standardized cumulative abnormal return,

$$
z_{i, t}=\sqrt{\frac{\left|E_{j}\right|-4}{\left|E_{j}\right|-2}} \frac{\hat{r}_{i, t}}{\sqrt{\hat{\sigma}_{i}^{2}}},
$$

where the first term represents a small-sample correction. The statistic $J 2$ is defined as

$$
J 2_{i j}=\frac{\sum_{t \in E_{j}} z_{i, t}}{\sqrt{\left|E_{j}\right|}}
$$

This statistic is also asymptotically standard normal under the null hypothesis, subject to the same caveat about return normality. In the table 4, we present these two statistics for the value-weighted index.

Table 4: Standard Event Study: Index

\begin{tabular}{cccccc}
\hline Shock Type & \# Events & CAR $(\%)$ & $\Delta D(\%)$ & $J_{1}$ & $J_{2}$ \\
\hline Higher Default & 7 & -12.92 & 28.40 & $-2.20^{* *}$ & $-2.19^{* *}$ \\
No News & 3 & -7.65 & -0.51 & $-1.99^{* *}$ & $-1.98^{* *}$ \\
Lower Default & 5 & 23.06 & -29.38 & $4.65^{* * *}$ & $4.63^{* * *}$
\end{tabular}

Notes: CAR indicates cumulative abnormal return over the event windows, $\Delta D$ is the change in the risk-neutral probability of default, and the test statistics $J_{1}$ and $J_{2}$ are described in the text and in Campbell et al. (1997), pp. 162. A shock type of higher default indicates that this event raised the default probability by more than one two-day standard deviation, a shock type of lower default indicates that this event lowered the default probability by more than one two-day standard deviation, and a shock type of no news indicates a day with a legal ruling in which the default probability did not move at least one two-day standard deviation in either direction. The underlying data is based on the two-day event windows and non-events described in the text. The p-values are the $\mathrm{p}$-values for a two-sided hypothesis test assuming normality. Significance levels: *** $\mathrm{p}<0.01, * * \mathrm{p}<0.05, * \mathrm{p}<0.1$.

The results of this event study are broadly similar to the variance-based estimates. In the 7 event days where the default probability significantly increased, the cumulative increase in the default probability was $28.40 \%$ and the stock market experienced a cumulative abnormal return of $-12.92 \%$. Assuming a linear relationship between default probabilities and equity returns, this implies that a $1 \%$ increase in the probability of default causes a $0.45 \%$ fall in the stock market. During the 5 days where the default probability significantly declined, the cumulative fall in the default probability was $29.38 \%$ with a cumulative abnormal return of $23.06 \%$. This implies a $1 \%$ fall in the probability of default causes an $0.78 \%$ rise in the stock market. While the large window sizes used in this study raise concerns about the validity of the identification assumptions, we will see that this estimate is very close to the results we find from our heteroskedasticity-based estimates.

The next event study we present uses four different window sizes. To construct these narrower windows, 
we also use a "sameday" CDS spread from Markit, which is as of 9:30 am EST. We refer to this as the "open," and is it in addition to the "close" defined in the main text. The sameday spread is built under the assumption that the expected recovery rate has not changed from the previous day's close. We convert the open and close CDS spreads into default probabilities ourselves for this analysis, rather than use probabilities provided by Markit, because Markit does not compute "open" default probabilities, only closing ones.

We classify events into several types: close-to-close, open-to-open, close-to-open, and open-to-close. For the Supreme Court ruling on June 16th, 2014, the event occurred in the morning of the 16th, after the U.S. stock market opened. We classify this ruling as "open-to-close" meaning that we will use the CDS spread change from 9:30am EDT on Monday the 16th to roughly 4pm EDT on Monday the 16th, and the ADR returns from 9:30am EDT on Monday the 16th to 4pm EDT on Monday the 16th. If we had instead classified the event as "close-to-close," we would compare the 4pm EDT close on Friday the 13th to the 4pm EDT close on Monday the 16th. The "close-to-open" and "open-to-open" windows are defined in a similar way. We use the narrower window sizes (close-to-open and open-to-close) when possible, and the wider window sizes (close-to-close and open-to-open) when we do not have precise information about the event time.

The heterogenous-window-size event study approach does have one advantage over the heteroskedasticity approach (as we have implemented it). For the heteroskedasticity approach, we use two-day event days, because those are the smallest uniformly-sized windows that all of our events can fit into. If the identification assumptions required for the heterogenous-window-size event study hold, this approach may have more power than the heteroskedasticity-based approach.

Our data set includes one additional event (16 instead of 15), because one of the two-day windows in fact contained two separate legal rulings on consecutive days. Conceptually, the event study is almost identical, except that we must study each type of event (higher default, lower default, no news) for each window size. That is, we separately estimate abnormal returns and abnormal default probability changes for each window size $s \in S$, the set of window sizes. We classify events based on the standard deviation of abnormal default probability changes for the associated window size. Let $E_{j s}$ denote an event of type $j$ (higher default, lower default, no news) with window size $s$ (close-to-close, open-to-open, close-to-open, and open-to-close). The abnormal return $\hat{r}_{i, t, s}$ is the abnormal return for ADR $i$ at time $t$ with window size $s$, and $\hat{\sigma}_{i s}^{2}$ is the variance of the abnormal returns for that window size. The $J 1$ statistic is computed as

$$
J 1_{i j}=\frac{\sum_{s \in S} \sum_{t \in E_{j s}} \hat{r}_{i, t, s}}{\sqrt{\sum_{s \in S}\left|E_{j s}\right| \hat{\sigma}_{i s}^{2}}} .
$$

Asymptotically, subject to the same caveats mentioned previously, this statistic is distributed as a standard normal. The second statistic, $J 2$, is constructed in a similar fashion. However, the standardized cumulative abnormal returns are now defined with respect to the event window size,

$$
z_{i, t, s}=\sqrt{\frac{\left|E_{j s}\right|-4}{\left|E_{j s}\right|-2}} \frac{\hat{r}_{i, t, s}}{\sqrt{\hat{\sigma}_{i s}^{2}}},
$$

and the $J 2$ statistic is

$$
J 2_{i j}=\frac{\sum_{s \in S} \sum_{t \in E_{j s}} z_{i, t, s}}{\sqrt{\sum_{s \in S}\left|E_{j s}\right|}} .
$$

This statistic is also, subject to the same caveats, asymptotically standard normal. It is not the same as the $J 1$ statistic, because of the heterogeneity in window size. If the cumulative abnormal returns occur mostly in narrower windows (which have smaller variance of abnormal returns), the $J 2$ statistic will be larger in absolute value than the $J 1$ statistic. If the reverse is true, the $J 1$ statistic will be larger. The size of 
the window may depend in part on the court releasing the opinion, the urgency with which the opinion was required, and other endogenous factors. It is not obvious whether the $J 1$ or $J 2$ statistic should be preferred. Fortunately, the results presented in table 5 using the two statistics are similar.

Table 5: Heterogenous-Window Event Study: Index

\begin{tabular}{cccccc}
\hline Shock Type & \# Events & CAR $(\%)$ & $\Delta D(\%)$ & $J_{1}$ & $J_{2}$ \\
\hline Higher Default & 5 & -10.81 & 14.73 & $-3.45^{* * *}$ & $-3.06^{* * *}$ \\
No News & 6 & -0.35 & 3.91 & -0.12 & -0.09 \\
Lower Default & 5 & 11.90 & -28.40 & $4.12^{* * *}$ & $3.47^{* * *}$ \\
\hline
\end{tabular}

Notes: CAR indicates cumulative abnormal return over the event window, $\Delta D$ is the change in the risk-neutral probability of default, and the test statistics $J_{1}$ and $J_{2}$ are described in the text and in Campbell et al. (1997), pp. 162. This study pools events across different window sizes (open-open, open-close, close-open, close-close). A shock type of higher default indicates that this event raised the default probability by more than one standard deviation, where the standard deviation is defined for non-events with the same window size. A shock type of lower default indicates that this event lowered the default probability by more than one standard deviation, and a shock type of no news indicates a day with a legal ruling in which the default probability did not move at least one standard deviation in either direction. The underlying data is based on the event windows and non-events described in the text, and uses the narrowest windows possible with our data and uncertainty about event times. The p-values are the p-values for a two-sided hypothesis test assuming normality. Significance levels: $* * * \mathrm{p}<0.01, * * \mathrm{p}<0.05, * \mathrm{p}<0.1$.

In the 5 event days where the default probability significantly increased, the cumulative probability of default rose $14.7 \%$ and the stock market had a cumulative abnormal return of $-10.8 \%$. This estimate implies that a $1 \%$ increase in the probability of default causes a $0.73 \%$ fall in equity returns. During the 5 days where the default probability significantly declined, the cumulative fall in the default probability was $28.4 \%$ with a cumulative abnormal equity return of $11.9 \%$. This implies a $1 \%$ fall in the probability of default causes an $0.42 \%$ rise in the stock market. When we again treat up and down movements symmetrically, we find that a $1 \%$ increase in the probability of default causes a $0.53 \%$ fall in the equity market.

Compared with these event studies, the IV-style event study described previously has the advantage of offering an interpretable coefficient, $\hat{\alpha}$, that estimates the change in stock prices given a change in the default probability. It also takes into account the magnitude of the default probability changes on each event day, whereas the event studies discussed above treat each event in a category equally. However, it is not a priori clear that the impact of the default probability on stock returns should be linear, and therefore not obvious that this approach is superior to the two-day event study. The similarity of the two results suggests linearity is not a bad assumption. Additionally, because the IV-style event study uses two-day event windows, it requires stronger identification assumptions than the heterogenous-window event study.

\section{E Alternative Specifications}

\section{E.1 Alternative Event Windows for the CDS-IV Estimator}

In this subsection, we present results for the CDS-IV estimator that use alternative event windows. The "alternative 2-day window" results we present refer to events for which there are two possible 2-day windows that could encompass the event. For example, if we are certain the event occurred during trading hours on Wednesday, and believe there are no other events, statements by politicians, or the like on any adjacent day, then we can use either the Monday close to Wednesday close two day window or the Tuesday close to Thursday close two day window. In our main analysis, as discussed in the text, we place the event on the first day; in this example, that would mean that we use the Tuesday to Thursday closes. In these results, 
we place the event on the second day; in this example, the Monday to Wednesday close. The five two-day windows that move one day earlier in these results are Dec. 5, 2012, Dec. 7, 2012, Aug. 26, 2013, Jan. 13, 2014, and Jun. 27, 2014.

The "1-Day Window" results use a different approach. For these results, each 1-day return is a data point; our analysis now has 816 data points, instead of 401. We also gain an additional event (in the two-day analysis, two events fell within the same window). When we are certain that an event occurred during a one-day window, we use only that window as the event. When we are not certain which of the two possible one-day windows contains the event, we call both of those one-day windows a single event.

In effect, we are including some non-event days as events in our 1-day window analysis. For the heteroskedasticity-based estimator, this does not bias the results; it is still true that the variance on our "event" days is higher than on our non-event days, even though a few of our events did not actually contain a legal ruling. If we knew which days actually contained the release of our legal rulings, we could improve the power of our analysis by removing the non-events from our event sample; of course, we do not know which days to remove.

For the purposes of bootstrapping the standard errors in this analysis, we bootstrap events, not "event days." That is, we draw (with replacement) 16 events from our event sample, which could contain anywhere from 16 to 32 one-day windows. We have experimented with the alternative approach of drawing 20 eventdays; the results seem qualitatively similar, but the latter approach could construct bootstrap replication samples in which there are no actual events. 


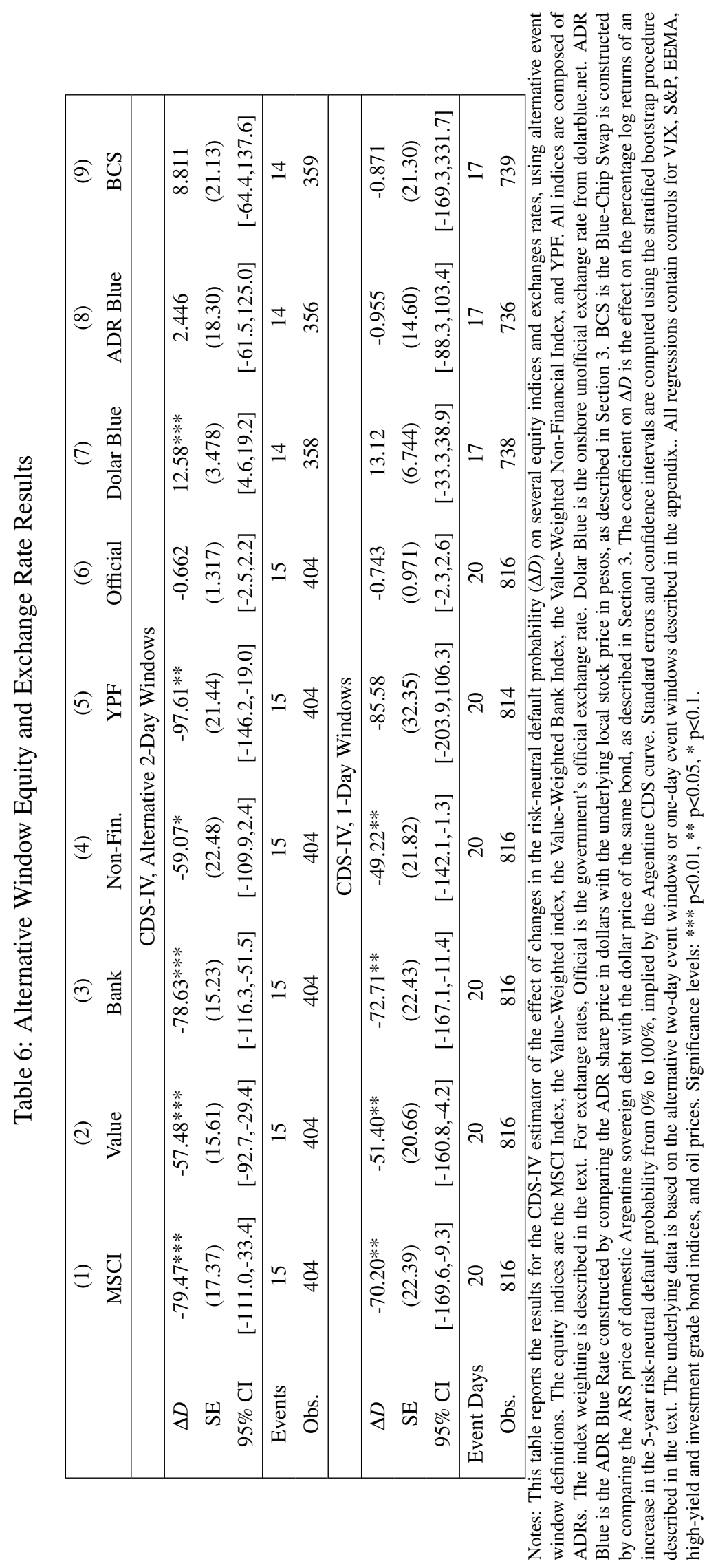




\section{E.2 Alternate Measures of Default Probability}

In this section, we discuss how our results are affected by using different measures for the probability of default. In particular, we change two features of our baseline default probability: the horizon and the assumed recovery rate. In our baseline specification we look at the cumulative default probability over five years, and here we will also consider the one and three year horizons. While we have data on CDS spreads out to 30 years, we are reluctant to use them because these longer tenors tend to be traded much less frequently. These are the first set of "Markit" results in Table 7.

The second change we will consider concerns the recovery rate. In our baseline specification, we use the average dealer-reported recovery rate. While this series does vary, and in particular increases towards the eventual actual recovery rate as Argentina approached its eventual default, we cannot be sure how representative the earlier reported quotes are of market expectations. Therefore, as an alternative to the dealer reported recovery rates, we set the recovery rate equal to $39.5 \%$, the rate at which the CDS auction eventually settled. We estimate the risk-neutral default probability under this assumption using the Matlab command CDS bootstrap and use the U.S. Treasury zero coupon curve as the discounting curve. These results are labeled "Constant Recovery" in table 7.

We will also consider the raw par spreads and points upfront as alternative measures of the default probability. This approach has the drawback that the coefficients are more difficult to interpret, but does come with the benefit that it uses market prices directly rather than relying on a model. The results are labeled "Par Spread" in Table 7. The final set of results we include looks at the effect of changes in the quoted Points Upfront. The way that CDS generally trade today is not actually with the par spread. Instead, the buyer agrees to pay the seller a fixed coupon (5\% for Argentine CDS) and "Points Upfront", the percentage of the notional that the buyer pays the seller upon initiation of the CDS. There is a one-to-one mapping between the par spread and points upfront. The results are labeled "Points Upfront" in Table 7.

We also use measures of the risk-neutral probability of default computed using CDS data from Bloomberg and Datastream. For reasons discussed in appendix section A.1, we have much less confidence in these data sources than Markit and therefore restrict ourselves to only using the 5-year spread. Therefore, rather than bootstrapping the risk-neutral probability of default using the ISDA Standard Model, we use the credit triangle approximation as described in appendix section A.4. We also use the realized recovery rate of 39.5\%, and so these results should be compared to the results using Markit data and a 5-year credit triangle approximation with a constant recovery assumption. These calculations are labels "Markit CT, Constant Recovery", "Bloomberg CT, Constant Recovery", and "Datastream CT, Constant Recovery", with credit triangle abbreviated CT.

Finally, we consider a specification that does not use any CDS data at all. Instead of CDS spreads or risk-neutral default probability measures imputed from CDS spreads, we instead use the log bond price and yield spread of a restructured bond. In particular, we use the log price and yield spread for a discount USDdenominated bond issued as part of the 2010 restructuring that matures in 2033 (ISIN XS0501194756). We choose this bond because it has the best pricing data of the restructured bonds in Bloomberg. This has the drawback that it is a longer tenor instrument than the CDS spreads and default probability we look at. We define the yield spread as the yield to maturity on the bond over the over the 20 -year U.S. Treasury par yield from Gürkaynak et al. (2007). We find very similar qualitative results using these alternative measures, although the magnitudes are difficult to compare given the difference in tenor. 
Table 7: Alternate Default Probability Measures

\begin{tabular}{|c|c|c|c|c|c|c|c|}
\hline \multirow{2}{*}{\multicolumn{2}{|c|}{ Measure }} & \multicolumn{3}{|c|}{ Indices } & \multicolumn{3}{|c|}{ Exchange Rates } \\
\hline & & Value & Banks & Non-Fin. & Blue & ADR & BCS \\
\hline Markit & $1 \mathrm{Y}$ & $-30.49 * * *$ & $-42.45 * * *$ & $-30.42 * *$ & $5.716 * * *$ & 0.910 & 1.025 \\
\hline Markit & $3 \mathrm{Y}$ & $-48.95 * * *$ & $-67.40 * * *$ & $-47.51 * *$ & $8.580 * *$ & 8.245 & 8.336 \\
\hline Markit & $5 Y$ & $-60.43 * * *$ & $-83.16 * * *$ & $-58.63 * *$ & $10.37 * *$ & 10.71 & 11.01 \\
\hline Constant Recovery & $1 \mathrm{Y}$ & $-28.96 * * *$ & $-40.63 * * *$ & $-28.84 * * *$ & $5.701 * * *$ & 0.283 & 0.209 \\
\hline Constant Recovery & $3 \mathrm{Y}$ & $-51.67 * * *$ & $-71.16 * * *$ & $-50.04 * *$ & $9.044 * *$ & 9.387 & 8.942 \\
\hline Constant Recovery & $5 \mathrm{Y}$ & $-68.20 * * *$ & $-93.80 * * *$ & $-66.24 * *$ & $11.67 * *$ & 13.02 & 12.56 \\
\hline Par Spread & $1 \mathrm{Y}$ & $-0.135 * *$ & $-0.199 * * *$ & $-0.134 *$ & $0.0283^{* *}$ & 0.00817 & 0.0151 \\
\hline Par Spread & $3 \mathrm{Y}$ & $-0.301 * *$ & $-0.441 * * *$ & -0.295 & $0.0606^{* *}$ & 0.0448 & 0.0631 \\
\hline Par Spread & $5 \mathrm{Y}$ & $-0.397 * *$ & $-0.579 * * *$ & -0.391 & $0.0790 * *$ & 0.0643 & 0.0911 \\
\hline Points Upfront & $1 \mathrm{Y}$ & $-0.350 * * *$ & $-0.494 * * *$ & $-0.350 * *$ & $0.0668 * * *$ & 0.00744 & 0.0121 \\
\hline Points Upfront & $3 \mathrm{Y}$ & $-0.458 * * *$ & $-0.645^{* * *}$ & $-0.448 * *$ & $0.0832 * *$ & 0.0637 & 0.0697 \\
\hline Points Upfront & $5 \mathrm{Y}$ & $-0.477 * * *$ & $-0.671 * * *$ & $-0.466^{* *}$ & $0.0852 * *$ & 0.0688 & 0.0759 \\
\hline Markit CT, CR & $5 \mathrm{Y}$ & $-48.83 * * *$ & $-66.54 * * *$ & $-47.58 * * *$ & $8.497 * *$ & 5.799 & 4.019 \\
\hline Bloomberg CT, CR & $5 \mathrm{Y}$ & $-44.00 * * *$ & $-66.30 * *$ & $-40.14 * *$ & $12.04 * *$ & $19.19 *$ & 17.86 \\
\hline Datastream CT, CR & $5 \mathrm{Y}$ & $-41.36 * * *$ & $-58.07 *$ & -33.40 & 4.416 & $30.09 *$ & 15.42 \\
\hline Log Bond Price & $5 \mathrm{Y}$ & $51.11 * * *$ & $70.70 * *$ & $47.41 * * *$ & $-11.61 * *$ & -14.37 & -12.34 \\
\hline Bond Spread & $5 \mathrm{Y}$ & $-3.299 * * *$ & $-4.761 * * *$ & $-2.952 * * *$ & $0.755^{*}$ & 0.969 & 0.863 \\
\hline
\end{tabular}

Notes: Measure "Markit" indicates that these are the risk-neutral default probabilities computed by Markit. "Constant Recovery" uses our estimation of the risk-neutral default probability under the assumption that the recovery rate is equal to its realized rate of 39.\%. "Par Spread" directly uses the Composite par spread from Markit and "Points Upfront" uses the points upfront data from Markit. The next three entries use the credit triangle (CT) approximation using Markit, Bloomberg, and Datastream CDS data assuming a constant recovery rate. "Log Bond Price" uses the log of the price a USD-denominated restructured discount bond issue (ISIN XS0501194756) that matures in 2033. "Bond Spread" uses the yield to maturity of this restructure bond over the 20-year U.S. Treasury par yield from Gürkaynak et al. (2007). Dolar Blue is the onshore unofficial exchange rate from dolarblue.net. ADR Blue is the ADR Blue Rate constructed by comparing the ADR share price in dollars with the underlying local stock price in pesos, as described in Section 3. Blue-Chip Swap is constructed by comparing the ARS price of domestic Argentine sovereign debt with the dollar price of the same bond, as described in Section 3. The Value-Weighted index, the Value-Weighted Bank Index and the Value-Weighted Non-Financial Index are referred to as "Value," "Banks", and "Non-Fin.", respectively, and are included in their standard form and delevered. Standard errors and confidence intervals are computed using the stratified bootstrap procedure described in the text. The underlying data is based on the two-day event windows and non-events described in the text. All regressions contain controls for VIX, S\&P, EEMA, high-yield and investment grade bond indices, soybean and oil prices. Significance levels: *** $\mathrm{p}<0.01,{ }^{*} \mathrm{p}<0.05,{ }^{*} \mathrm{p}<0.1$

\section{F Issues Regarding Weak/Irrelevant Instruments}

In this section, we discuss two issues related to weak instruments problems. First, as noted in the text, the CDS-IV estimator is relevant if there is a difference in the variance of the default probability changes on event and non-event days. If the difference in this variance is small, issues relating to weak instruments can arise (see Nakamura and Steinsson (2013) for a discussion of this issue). We formally test that difference between the variances on event and non-event days is large.

Second, as noted in the text, there are other possible estimators of $\alpha$ that can be constructed from the difference of the covariance matrix on event and non-event days. These estimators, however, use an "irrelevant instrument" under the null hypothesis that $\alpha=0$, and therefore are not appropriate for our problem. 


\section{F.1 Tests of Differences in Variances}

We conduct two tests to verify that the variance of the default probability changes during our event windows is significantly higher than the variance during non-event windows. Following Foley-Fisher and Guimaraes (2013), we conduct a formal test of hypothesis that $\left(\Omega_{E}\right)_{22}=\left(\Omega_{N}\right)_{22}$ using the method developed by Brown and Forsythe (1974) and Levene (1960). We use the sample associated with our value index (recall that for the exchange rates, the sample is slightly smaller). We strongly reject the hypothesis of equal variances. We also report the first-stage F-statistic of the CDS-IV estimator for the value index, as advocated by Stock and Yogo (2005). For the CDS-IV estimator, this first-stage F-statistic is closely related to the difference in the variance of the default probability during the event and non-event windows.

Table 8: Tests of Differences in Variance

\begin{tabular}{ccc}
\hline Test & F-statistic & $\mathrm{p}$-value \\
\hline Levene & $53.7^{* * *}$ & 0.0000 \\
Brown-Forsythe trimmed mean & $53.0^{* * *}$ & 0.0000 \\
Brown-Forsythe median & $52.6^{* * *}$ & 0.0000 \\
First-Stage F-stat & 338.3 &
\end{tabular}

Notes: "Test" describe the F-statistic being computed. The Levene test for unequal variances is described in Levene (1960). The Brown-Forsythe tests are described in Brown and Forsythe (1974). These tests all formally test the hypothesis that the variance of the changes in the 5-year cumulative default probability is equal on event days and non-event days. The sample associated with these tests is the sample we used to compute the results for our value index, and involves 15 events and 386 non-events. The first-stage F-stat is the first-stage F-statistic from the two-stage least squares IV implementation of the CDS-IV estimator, on the same sample. Significance levels: $* * * \mathrm{p}<0.01$, $* *$ $\mathrm{p}<0.05, * \mathrm{p}<0.1$.

An alternative to pre-testing for differences in variance is weak-identification-robust inference. A procedure for this type of inference in a similar context is described and implemented by Nakamura and Steinsson (2013). The strength of our rejection of the hypothesis of equal variances suggests that this approach is unnecessary for our application.

\section{F.2 Irrelevant Instruments}

We use the CDS-IV estimator because the alternative estimators use an "irrelevant instrument" under the null hypothesis that $\alpha=0$. As can be seen in equation (3), the coefficient of interest can be identified as the ratio of the first element of the matrix to an off-diagonal:

$$
\hat{\alpha}_{R I V}=\frac{\Delta \Omega_{1,1}}{\Delta \Omega_{1,2}}=\frac{\operatorname{var}_{E}\left(r_{t}\right)-\operatorname{var}_{N}\left(r_{t}\right)}{\operatorname{cov}_{E}\left(\Delta D_{t}, r_{t}\right)-\operatorname{cov}_{N}\left(\Delta D_{t}, r_{t}\right)}
$$

The estimator $\hat{\alpha}_{R I V}$ is the ratio of the sample estimates of $\Delta \Omega_{1,1}$ and $\Delta \Omega_{1,2}$. The denominator, $\Delta \Omega_{1,2}$, is the covariance between the default probability, which is the variable being instrumented for, and the instrument. Under the null hypothesis, this covariance is zero, meaning that the instrument is irrelevant. As a result, the behavior of the $\hat{\alpha}_{R I V}$ estimator under the null hypothesis is not characterized by the standard IV asymptotics, and our confidence intervals will not have the correct coverage probabilities. ${ }^{51}$

\footnotetext{
${ }^{51}$ Under a different null hypothesis, that $\alpha$ is near, but not equal, to zero, weak identification asymptotics may be a better characterization of the sample distribution of $\hat{\alpha}_{R I V}$.
} 
The CDS-IV estimator does not suffer from this issue. The estimator $\hat{\alpha}_{C I V}$ is based on the ratio of the sample estimates of $\Delta \Omega_{1,2}$ and $\Delta \Omega_{2,2}$. Under the null hypothesis that $\alpha=0$ and $\lambda>0$, the CDSIV instrument is still relevant, and the standard asymptotics for $\hat{\alpha}_{C I V}$ apply. The GMM estimator, which uses all three moments, can be thought of as a sort of average of the CDS-IV and Returns-IV estimators. When $\alpha \neq 0$, using all three moments is helpful because it takes advantage of all available information and makes over-identifying tests possible. However, under the null hypothesis that $\alpha=0$, using the Returns-IV

estimator in any way is problematic. More formally, the Jacobian of the moment conditions with respect to the parameters does not have full column rank when $\alpha=0$, and the identification assumption used to derive the standard GMM asymptotics does not hold. The two-step GMM procedure, implemented using standard asymptotics to estimate the optimal weighting matrix, would generally not correctly estimate the variances, because of the irrelevant instrument. As a result, the weight matrix might effectively place excessive weight on the Returns-IV estimator, relative to the CDS-IV estimator, and end up providing problematic results.

\section{G Additional Results}

\section{G.1 Mexico, Brazil, and Other Countries}

In this section, we present the results of OLS and CDS-IV regressions for non-Argentine countries' equity indices and default probabilities. With OLS, we find that the Argentine risk-neutral default probability comoves with other emerging market equity indices and sovereign default probabilities (as measured by those countries' CDS). With the CDS-IV estimator, we find no significant causal effect. We interpret these results as suggesting that there are common factors in the pricing of emerging market debt and equity, consistent with the findings of Pan and Singleton (2008), but the legal rulings we study did not affect these common factors. Moreover, our results suggest that the legal rulings did not have significant effects on other sovereign debtors. We interpret these results as consistent with the uniqueness of Argentina's circumstances, and the limited applicability of these legal rulings to future cases. 
Table 9: Default Probability, Other Countries

(a) OLS

\begin{tabular}{|cc|cc|cc|}
\hline Country & $\Delta D$ & Country & $\Delta D$ & Country & $\Delta D$ \\
\hline Argentina & $1.199 * * *$ & Iceland & -0.00515 & Philippines & 0.0178 \\
Austria & 0.00829 & Indonesia & 0.0194 & Portugal & 0.00369 \\
Belgium & 0.0154 & Ireland & -0.00555 & Romania & $0.0249 * *$ \\
Bahrain & 0.00776 & Italy & -0.00231 & Russia & $0.0558 * * *$ \\
Brazil & $0.0427 * * *$ & Japan & 0.00616 & South Africa & $0.0364 * * *$ \\
Chile & $0.0235 * * *$ & Kazakhstan & $0.0358 * * *$ & Spain & -0.00267 \\
China & 0.00941 & South Korea & 0.00425 & Thailand & 0.00681 \\
Colombia & $0.0349 * * *$ & Malaysia & 0.00123 & Turkey & $0.0500 * * *$ \\
Croatia & $0.0290 * *$ & Mexico & $0.0367 * * *$ & Ukraine & $0.105 * *$ \\
Cyprus & 0.0729 & Morocco & -0.00643 & Venezuela & $0.172 * * *$ \\
Egypt & 0.0158 & Panama & $0.0335 * * *$ & Vietnam & -0.00470 \\
France & $0.0224 * *$ & Peru & $0.0333 * * *$ & & \\
\hline
\end{tabular}

(b) CDS-IV

\begin{tabular}{|cc|cc|cc|}
\hline Country & $\Delta D$ & Country & $\Delta D$ & Country & $\Delta D$ \\
\hline Argentina & $1.384 * * *$ & Iceland & 0.0171 & Philippines & -0.0122 \\
Austria & -0.00547 & Indonesia & -0.0158 & Portugal & 0.00355 \\
Belgium & 0.0108 & Ireland & -0.0238 & Romania & -0.00370 \\
Bahrain & -0.00337 & Italy & -0.0271 & Russia & 0.0331 \\
Brazil & 0.00191 & Japan & -0.00399 & South Africa & 0.0197 \\
Chile & -0.00376 & Kazakhstan & 0.0151 & Spain & -0.0162 \\
China & -0.00752 & South Korea & -0.0170 & Thailand & -0.0136 \\
Colombia & 0.00157 & Malaysia & $-0.0220 *$ & Turkey & 0.0112 \\
Croatia & -0.0239 & Mexico & -0.000665 & Ukraine & 0.128 \\
Cyprus & 0.119 & Morocco & -0.0156 & Venezuela & 0.0240 \\
Egypt & -0.0227 & Panama & -0.00605 & Vietnam & -0.0646 \\
France & -0.00211 & Peru & -0.00359 & & \\
\hline
\end{tabular}

Notes: This table reports the results for the OLS (a) and CDS-IV (b) estimators of the effect of changes in the five-year risk-neutral Argentine default probability on the five-year risk-neutral default probability for the country listed. The default probability measure used for the outcome variable is derived from the credit triangle approximation described in appendix A.4, which explains why the coefficient on Argentina is not exactly one. The coefficient is the effect on the other country's five-year risk neutral default probability of an increase in the 5-year risk-neutral default probability from $0 \%$ to $100 \%$, implied by the Argentine CDS curve. Standard errors and confidence intervals are computed using the stratified bootstrap procedure described in the text. The underlying data is based on the two-day event windows and non-events described in the text. All regressions contain controls for VIX, S\&P, EEMA, high-yield and investment grade bond indices, soybean and oil prices. Significance levels: $* * *$ $\mathrm{p}<0.01, * * \mathrm{p}<0.05, * \mathrm{p}<0.1$ 
Table 10: Regressions for Brazil and Mexico

\begin{tabular}{ccc}
\hline & $(2)$ & $(4)$ \\
& Brazil MSCI Index & Mexico MSCI Index \\
\hline OLS $\Delta D$ & $-11.40^{* * *}$ & $-6.646^{* *}$ \\
Robust SE & $(3.464)$ & $(2.857)$ \\
95\% CI & {$[-17.5,-4.6]$} & {$[-12.7,-1.1]$} \\
\hline Event IV $\Delta D$ & 1.967 & 1.932 \\
Robust SE & $(5.360)$ & $(3.655)$ \\
95\% CI & {$[-11.5,13.8]$} & {$[-8.1,7.6]$} \\
\hline CDS-IV $\Delta D$ & 3.989 & 3.286 \\
Robust SE & $(4.941)$ & $(4.258)$ \\
95\% CI & {$[-8.4,11.5]$} & {$[-10.6,9.3]$} \\
\hline
\end{tabular}

Notes: This table reports the results for the OLS, IV-style event study, and CDS-IV estimators of the effect of changes in the risk-neutral default probability $(\Delta D)$ on the stock market indices of Brazil and Mexico. The coefficient on $\Delta D$ is the effect on the percentage log returns (of stocks) and change in the 5-year CDS spread (in bps) of an increase in the 5-year risk-neutral default probability from $0 \%$ to $100 \%$, implied by the Argentine CDS curve. Standard errors and confidence intervals are computed using the stratified bootstrap procedure described in the text. The underlying data is based on the two-day event windows and non-events described in the text. Significance levels: $* * * \mathrm{p}<0.01, * * \mathrm{p}<0.05, * \mathrm{p}<0.1$.

\section{G.2 Multinational Firms}

In this section, we discuss several firms that could be considered Argentine, but were excluded from our analysis. Techint is a privately held multinational conglomerate that controls, among other companies, Tenaris and Ternium. Tenaris is a steel pipe company, headquartered in Luxembourg, that conducts most of its business outside of Argentina. Tenaris is listed on the Buenos Aires stock exchange and has an ADR on the NYSE. Ternium is a steel company, also headquartered in Luxembourg, that is listed only on the NYSE, but owns a subsidiary, Siderar, that is listed on the Buenos Aires stock exchange, and that subsidiary conducts a substantial part of its business in Argentina. We include Siderar (ticker ERAR) in our data for local stocks, and do not include Tenaris in either our local stock or ADR datasets. Petróleo Brasileiro (Petrobras) is the state oil company of Brazil. The Argentine subsidiary of Petrobras, Petrobras Argentina (ticker PESA) is included in our dataset, but its parent is not. We also exclude Arcos Dorados ("Golden Arches"), an Argentina-headquartered McDonald's franchisee that has operations across Latin America and is listed only on the NYSE, and not in Argentina. We present results for the ADRs of Tenaris and Petrobras, and the stock of Arcos Dorados, below. 
Table 11: Regressions for Tenaris, Petrobras, and Arcos Dorados

\begin{tabular}{cccc}
\hline & $(1)$ & $(2)$ & $(3)$ \\
& Tenaris ADR & Petrobras ADR & Arcos Dorados \\
\hline OLS $\Delta D$ & -5.620 & $-14.44 * *$ & -11.27 \\
Robust SE & $(5.163)$ & $(7.191)$ & $(7.775)$ \\
95\% CI & {$[-15.3,6.1]$} & {$[-30.6,-0.5]$} & {$[-24.9,7.0]$} \\
\hline Event IV $\Delta D$ & -0.404 & 4.271 & 12.13 \\
Robust SE & $(6.775)$ & $(9.612)$ & $(10.20)$ \\
95\% CI & {$[-18.5,12.9]$} & {$[-26.4,27.5]$} & {$[-25.4,44.1]$} \\
\hline CDS-IV $\Delta D$ & 0.621 & 7.457 & 16.68 \\
Robust SE & $(7.314)$ & $(10.86)$ & $(13.75)$ \\
95\% CI & {$[-18.9,12.7]$} & {$[-27.3,33.0]$} & {$[-26.9,45.8]$} \\
\hline
\end{tabular}

Notes: This table reports the results for the OLS, IV-style event study, and CDS-IV estimators of the effect of changes in the risk-neutral default probability $(\Delta D)$ on the ADRs of Tenaris and Petrobras, and the stock of Arcos Dorados. These companies are multinationals that conduct a small portion of their business in Argentina, but are listed on the Argentine stock exchange (Tenaris and Petrobras) or headquartered in Argentina but listed on the NYSE (Arcos Dorados). The coefficient on $\Delta D$ is the effect on the percentage log returns of an increase in the 5-year risk-neutral default probability from $0 \%$ to $100 \%$, implied by the Argentine CDS curve. Standard errors and confidence intervals are computed using the stratified bootstrap procedure described in the text. The underlying data is based on the two-day event windows and non-events described in the text. Significance levels: $* * * \mathrm{p}<0.01, * *$ $\mathrm{p}<0.05, * \mathrm{p}<0.1$.

\section{G.3 Delevered Portfolios}

In table 12 below, we present results with a "crude" deleveraging. We form an index composed of firm's ADRs and U.S. treasury bills. We weight each firm by the previous year's book value of assets, and then assume that the firm has debt equal to the difference between that book value of assets and the previous quarter's market value of common equity. For each firm, we include in the index a mixture of treasury bills and ADRs, in proportion to the firms' mix of debt and equity. We then apply the CDS-IV estimation procedure to these indices.

Table 12: Delevered Indices, CDS-IV

\begin{tabular}{cccc}
\hline & $(1)$ & $(2)$ & $(3)$ \\
& Value Index & Bank Index & Non-Financial Index \\
\hline$\Delta D$ & $-16.00^{* *}$ & $-10.79^{* * *}$ & $-27.98^{*}$ \\
$\mathrm{SE}$ & $(4.253)$ & $(2.259)$ & $(10.18)$ \\
$95 \% \mathrm{CI}$ & {$[-31.5,-4.2]$} & {$[-16.2,-4.4]$} & {$[-57.0,3.5]$} \\
Events & 15 & 15 & 15 \\
Obs. & 401 & 401 & 401
\end{tabular}

All regressions have controls for VIX, S\&P, EEMA, oil prices, and CDX indices. Confidence intervals for value index and FX calculated using a stratified bootstrap following Horowitz (2001). Confidence intervals for the tracking portfolios calculated using a hybrid bootstrap method, in which the coefficients for the portfolio weights are sampled from their asymptotic distribution, then the high frequency data is bootstrapped using the stratified bootstrap procedure described in the text. 


\section{G.4 Local Stock Results}

In this section, we show the response of equal- and value-weighted local stock portfolios to the default shocks. We also show the response of industry portfolios to default shocks, controlling for the response of the Argentine market. We group these firms into equal-weighted industry portfolios, using the industry definitions described in section 3.1. We also construct an equal-weighted index of all of the firms in our sample, which is restricted to firms passing a data quality test also described in section 3.1. We use this equal-weighted index as our measure of the Argentine market return. All of the returns we study in this section are dollar returns, converted at the ADR blue rate. In Figure 5 and Table 13 below, we display estimates of the excess sensitivity of the industry portfolios to the default shock, using the CDS-IV estimator and the bootstrapped confidence intervals described in the previous sections.

Table 13: Cross-Section: Industry Returns, CDS-IV

\begin{tabular}{ccccccc}
\hline & $(1)$ & $(2)$ & $(3)$ & $(4)$ & $(5)$ & $(6)$ \\
& Equal-Weighted & Value-Weighted & Banks & Chemicals & Diverse & Energy \\
\hline$\Delta D$ & $-51.23^{*}$ & $-53.74^{* *}$ & $-27.49^{*}$ & 5.756 & 15.63 & -17.45 \\
& $(13.61)$ & $(14.31)$ & $(12.45)$ & $(16.78)$ & $(18.69)$ & $(12.96)$ \\
$95 \%$ CI & {$[-92.2,0.4]$} & {$[-125.9,-9.2]$} & {$[-61.0,4.7]$} & {$[-38.3,37.2]$} & 0.989 & 0.852 \\
Index $\beta$ & - & - & 1.033 & 0.896 & {$[-45.2,66.5]$} & {$[-47.4,15.7]$} \\
Events & 14 & 14 & 14 & 14 & 14 & 14 \\
Obs. & 353 & 353 & 353 & 351 & 353 & 353 \\
\hline \hline & $(7)$ & $(8)$ & $(9)$ & $(10)$ & $(11)$ & $(12)$ \\
& Manufacturing & Non-Durables & Non-Financial & Real Estate & Telecoms & Utilities \\
\hline$\Delta D$ & -13.79 & -5.701 & 6.438 & 16.54 & -10.74 & 34.87 \\
& $(10.02)$ & $(7.501)$ & $(4.336)$ & $(18.03)$ & $(10.27)$ & $(15.79)$ \\
$95 \%$ CI & 0.736 & 0.750 & 1.015 & 0.684 & 0.694 & 1.605 \\
Index $\beta$ & {$[-42.1,11.1]$} & {$[-23.1,6.0]$} & {$[-10.3,20.3]$} & {$[-28.1,71.6]$} & {$[-37.9,6.7]$} & {$[-13.7,88.8]$} \\
Events & 14 & 14 & 14 & 14 & 14 & 14 \\
Obs. & 353 & 353 & 353 & 338 & 353 & 353 \\
\hline
\end{tabular}

Notes: This table reports the results for the "CDS-IV" estimator. The column headings denote the outcome variable. "EqualWeighted" is an equal-weighted index of local equities in Table 2 and "Value-Weighted" is a value-weighted index of those same stocks, excluding YPF. The returns are expressed as dollar returns, converted from peso returns using the ADR blue rate. The industry classifications are based on Fama-French with modifications described in Section 3.1. The coefficient on $\Delta D$ is the effect on the percentage returns of an increase in the 5-year risk-neutral default probability from $0 \%$ to $100 \%$, implied by the Argentine CDS curve. Index beta is the coefficient on the equal-weighted index of Argentine local equities, as described in Section 5. Standard errors and confidence intervals are computed using the stratified bootstrap procedure described in the text. The underlying data is based on the two-day event windows and non-events described in the text. Significance levels: *** $\mathrm{p}<0.01, * * \mathrm{p}<0.05, * \mathrm{p}<0.1$.

\section{G.5 Individual Bond Prices}

As discussed in section 6, one potential complication in interpreting our results is the RUFO clause in the restructured bond contracts. In particular, one might be concerned that as the probability of default increases, the expected payout on the restructured bonds also increases, raising the amount Argentina is expected to repay creditors. In this case, the effect of the legal rulings on bond prices is ambiguous. The effect on CDS-implied probability of default is not ambiguous; if the recovery assumption is updated correctly, then 
the default probability is correct.

In the table below, we observe that increases in the CDS-implied default probability lead to significant declines in the value of the restructured bonds. If the default probability is measured correctly, this is not consistent with the story that increases in the default probability coincided with increases in the probability of a settlement that offered improved terms to restructured bondholders. That is, either the RUFO clause would be circumvented, or the RUFO clause was binding and a settlement was not likely.

We also investigate the performance of the holdout bonds around the legal rulings. The bonds owned by the holdouts are very illiquid, but we were able to find some prices from Bloomberg. We are uncertain as to the quality of these prices and therefore interpret the results cautiously. Consistent with this, we find large standard errors in our estimation. This could reflect the poor quality of the data, but also has another interpretation. Several rulings coincided with significant increases in the holdout bond prices, while others did not. One possible interpretation of this fact is that some rulings raised the probability of a settlement, while others lowered that probability, but this was largely uncorrelated with whether the rulings raised or lowered the probability of default.

The restructured bond we examine in the table below is a dollar-denominated discount bond issued as part of the 2010 restructuring. The holdout bond we examine is a dollar-denominated bond maturing in 2030 that court documents show NML Capital owned in 2003. For completeness, we also show a domestic-law fixed coupon dollar bond maturing in 2017.

Table 14: Bond Level Analysis: CDS-IV

\begin{tabular}{cccc}
\hline & $(1)$ & $(2)$ & $(3)$ \\
& Restructured & Holdout & Domestic \\
\hline$\Delta D$ & $-124.8^{* * *}$ & 1.206 & $-48.56^{*}$ \\
$\mathrm{SE}$ & $(11.93)$ & $(40.35)$ & $(10.68)$ \\
$95 \% \mathrm{CI}$ & {$[-146.2,-93.5]$} & {$[-63.3,103.1]$} & {$[-75.0,2.0]$} \\
Events & 15 & 15 & 15 \\
Obs. & 397 & 258 & 401
\end{tabular}

Notes: This table reports the effect of changes in the five-year risk-neutral Argentine default probability $(\Delta D)$ on the price (percentage log price return) of Argentine government bonds. The coefficient on $\Delta D$ is the effect on the bond price of an increase in the 5-year risk-neutral default probability from $0 \%$ to $100 \%$, implied by the Argentine CDS curve. "Holdout" is a USD-denominated bond maturing in 2030. "Restructured" is a dollar-denominated discount bond issued as part of the 2010 restructuring with an ISIN of XS0501194756 that matures in 2033. "Domestic" is domestic-law fixed coupon dollar debt maturing in 2017 with an ISIN ARARGE03F441.

\section{Holdings and Liquidity Data}

In this section, we provide additional background on the likely holders of the ADRs we study. We also provide information about the relative liquidity of the ADRs and local stocks, and information on the liquidity of Argentine sovereign CDS relative to other CDS. 


\section{H.1 ADR Holdings Data}

In this section, we use 13-F filings to document that the ADRs we study are owned in significant quantities by large, diversified financial institutions headquartered in the U.S. and other developed countries. 13-F filings are quarterly filings mandated by the SEC for financial institutions that control more than \$100mm USD of financial assets. These institutions must disclose their ownership of certain assets, including ADRs that trade on the NYSE and NASDAQ. We collect quarterly data from Thompson Reuters, which is available via WRDS, on all 13-F reported holdings of the ADRs we study, by financial institution. There are no Argentine financial institutions that both manage over \$100mm USD and own any shares of the ADRs, during any quarter between 2011q1 to 2014q2. We list the top ten holders of the ADRs we study, by average market value, for the 2011-2014 period. We note that these institutions are sophisticated, mostly-US-based financial institutions that are unlikely to be significantly affected by Argentina's default.

Table 15: Top Institutional Holders of ADRs

\begin{tabular}{|c|c|c|c|}
\hline Rank & Institution & Country & Avg. Holdings (\$MM USD) \\
\hline \hline 1 & LAZARD CAPITAL MARKETS LLC & USA & 413 \\
\hline 2 & MASON CAPITAL MANAGEMENT & USA & 293 \\
\hline 3 & ETON PARK CAPITAL MGMT, L.P. & USA & 256 \\
\hline 4 & CAPITAL INTL INC. (SINGAPORE) & Singapore & 158 \\
\hline 5 & BLACKSTONE GROUP & USA & 143 \\
\hline 6 & SOROS FUND MANAGEMENT, L.L.C. & USA & 128 \\
\hline 7 & MSDW \& COMPANY & USA & 126 \\
\hline 8 & HIGHFIELDS CAPITAL MGMT, L.P. & USA & 112 \\
\hline 9 & WELLINGTON MANAGEMENT CO, LLP & USA & 109 \\
\hline 10 & THIRD POINT LLC & USA & 87 \\
\hline
\end{tabular}

Notes: This table reports the ten institutions that file 13-F reports with the largest dollar value of average holdings of the twelve exchange-traded ADRs we study, over the period of 2011 quarter 1 to 2014 quarter 2. Institutions are required to file 13-F reports if they manage more than $\$ 100 \mathrm{~mm}$ USD of eligible securities (a set that includes exchange-traded stocks and other assets).

"Country" is the the country of incorporation, the nationality of the legal vehicle that manages the assets, not its ultimate parent. "Avg. Holdings" is the mean dollar amount of holdings of the twelve ADRs, in millions of U.S. dollars.

\section{H.2 ADR and Equity Liquidity Data}

In this section, we compare the average monthly turnover of ADRs with the average monthly turnover of the underlying equities traded on the local stock exchange. Local turnover comes from Bolsar.com, the website of the Bolsa de Comercio de Buenos Aires (BCBA) and ADR Turnover is from CRSP, accessed via WRDS. During the sample period, all of the ADRs we studied had higher turnover in the ADR market than their respective underlying on the local exchange, often by an order of magnitude. 
Table 16: Average Monthly Turnover of ADRs and Local Equities

\begin{tabular}{|c|ccc|}
\hline Ticker & Turnover - ADR, \$M & Turnover - Local, \$M & ADR/Local Turnover \\
\hline BFR & 81.1 & 18.0 & 4.5 \\
BMA & 232.0 & 33.9 & 6.8 \\
CRESY & 67.8 & 1.5 & 44.5 \\
EDN & 23.3 & 15.3 & 1.5 \\
GGAL & 207.6 & 95.2 & 2.2 \\
IRCP & 2.0 & 0.2 & 11.8 \\
IRS & 32.1 & 2.5 & 12.8 \\
PAM & 56.4 & 29.7 & 1.9 \\
PZE & 71.8 & 13.8 & 5.2 \\
TEO & 259.7 & 42.1 & 6.2 \\
TGS & 16.1 & 1.7 & 9.2 \\
YPF & 1512.8 & 80.5 & 18.8 \\
\hline
\end{tabular}

Notes: Ticker is the Ticker of ADR. Turnovers for the ADRs and Local equities are reported in millions of U.S. Dollars. The daily dollar value of the turnover of local equities is calculated by dividing the ARS turnover by the ADR Blue Rate. The ratio of ADR/Local Turnover first sums all turnover from January 2011 - July 31, 2014 and then computes the ratios.

\section{H.3 CDS Liquidity}

In this section, we use data from the Depository Trust and Clearing Corporation (DTCC) to compare the liquidity of Argentine CDS to that of other sovereigns, financial corporations, and non-financial corporations. ${ }^{52}$ For each category, we report one entity that trades more than Argentina, one roughly the same amount, and one less. We also report the daily notional traded in millions of USD. Argentine CDS are actively traded, with CDS as liquid as other emerging markets, major financial corporates, and several of the most actively traded non-financial corporates. During our sample period, Argentina was on average the 15 th most commonly traded sovereign CDS.

Table 17: Trading Volume of CDS

\begin{tabular}{|ccc|}
\hline & Average Trades/Day & Average Daily Notional (\$m) \\
\hline Argentine Republic & 18.2 & 146.4 \\
\hline Republic Of Korea & 26.7 & 282.1 \\
Republic Of Indonesia & 18.3 & 153.6 \\
Republic Of The Philippines & 13.6 & 130.4 \\
\hline Bank Of America Corporation & 23.5 & 214.3 \\
The Goldman Sachs Group, Inc. & 18.2 & 173.2 \\
Citigroup Inc. & 15.5 & 139.3 \\
\hline Eastman Kodak Company & 27.0 & 81.3 \\
Radioshack Corporation & 18.1 & 76.8 \\
Fiat S.P.A. & 13.4 & 82.1 \\
\hline
\end{tabular}

Notes: This data from the DTCC runs from 2011Q1 to 2014Q2. The sovereign, financial, and non-financial corporate reference entities displayed in this table were chosen to represent entities that experienced somewhat higher, equivalent, and somewhat lower CDS volume, in terms of trades per day.

\footnotetext{
${ }^{52}$ We thank Andreas Stathopoulos for this suggestion.
} 


\section{Econometric Model}

The model we use is

$$
\begin{aligned}
\Delta D_{t} & =\mu_{d}+\omega_{D}^{T} X_{t}+\gamma^{T} r_{t}+\beta_{D} F_{t}+\varepsilon_{t} \\
r_{t} & =\mu+\Omega X_{t}+\alpha \Delta D_{t}+\beta F_{t}+\eta_{t},
\end{aligned}
$$

where $r_{t}$ is a vector of returns, $\Delta D_{t}$ is the change in the default probability, $X_{t}$ is a set of global factors (S\&P 500, etc...), $F_{t}$ is an unobserved factor, and $\varepsilon_{t}$ is the idiosyncratic default probability shock, and $\eta_{t}$ is a vector of return shocks that do not directly affect the probability of default. Through some algebra, we show that this is equivalent to the systems described in equations 1 and 2, used in most of our analysis, and the equations used in the cross-sectional analysis.

We begin by separating the equation governing the vector of returns $r_{t}$ into the return of asset $i, r_{i, t}$, which is the asset of interest, and the returns of some other assets, denoted $r_{-i, t}$. We separate the various coefficient vectors and matrices, $\mu, \Omega, \alpha, \beta, \gamma$, and shocks $\eta_{t}$, into versions for asset $i, \mu_{i}, \omega_{i}^{T}$, etc..., and versions for the other assets, $\mu_{-i}, \Omega_{-i}$, etc... This system can be written as

$$
\begin{aligned}
\Delta D_{t} & =\mu_{d}+\omega_{D}^{T} X_{t}+\gamma_{i}^{T} r_{i, t}+\gamma_{-i}^{T} r_{-i, t}+\beta_{D} F_{t}+\varepsilon_{t} \\
r_{i, t} & =\mu_{i}+\omega_{i}^{T} X_{t}+\alpha_{i} \Delta D_{t}+\beta_{i} F_{t}+\eta_{i, t} \\
r_{-i, t} & =\mu_{-i}+\Omega_{-i} X_{t}+\alpha_{-i} \Delta D_{t}+\beta_{-i} F_{t}+\eta_{-i, t} .
\end{aligned}
$$

Most of our analysis considers only a single asset, $r_{i, t}$, and the default probably change $\Delta D_{t}$. Substituting the returns $r_{-i, t}$ into the $\Delta D_{t}$ equation,

$$
\begin{aligned}
\Delta D_{t}= & \frac{\mu_{d}+\gamma_{-i}^{T} \mu_{-i}}{1-\gamma_{-i}^{T} \alpha_{-i}}+\frac{\omega_{D}^{T}+\beta_{-i}^{T} \Omega_{-i}}{1-\gamma_{-i}^{T} \alpha_{-i}} X_{t}+\frac{\gamma_{i}^{T} r_{i, t}}{1-\gamma_{-i}^{T} \alpha_{-i}}+ \\
& \frac{\beta_{D}+\gamma_{-i}^{T} \beta_{-i}}{1-\gamma_{-i}^{T} \alpha_{-i}} F_{t}+\frac{1}{1-\gamma_{-i}^{T} \alpha_{-i}}\left(\gamma_{-i}^{T} \eta_{-i, t}+\varepsilon_{t}\right) \\
r_{i, t}= & \mu_{i}+\omega_{i}^{T} X_{t}+\alpha_{i} \Delta D_{t}+\beta_{i} F_{t}+\eta_{i, t} .
\end{aligned}
$$

This system, for the two assets, is equivalent to the one in equations 1 and 2, except that is has two shocks, $\gamma_{-i}^{T} \eta_{-i, t}$ and $\varepsilon_{t}$, that directly affect $\Delta D_{t}$ without affecting $r_{i, t}$, and includes constants and observable controls $X_{t}$. Neither of these differences substantially alter the identification assumptions or analysis. The event study and Rigobon (2003) approach both identify the coefficient $\alpha_{i}$, under their identifying assumptions, which is the coefficient of interest.

Next, we discuss a version of this system with the market return. Let the market return be a weighted version of the return vector, $r_{m, t}=w^{T} r_{t}$. Separating the vectorized version of the system into four equations,

$$
\begin{aligned}
\Delta D_{t} & =\mu_{d}+\omega_{D}^{T} X_{t}+\gamma_{i}^{T} r_{i, t}+\gamma_{-i}^{T} r_{-i, t}+\beta_{D} F_{t}+\varepsilon_{t} \\
r_{i, t} & =\mu_{i}+\omega_{i}^{T} X_{t}+\alpha_{i} \Delta D_{t}+\beta_{i} F_{t}+\eta_{i, t} \\
r_{-i, t} & =\mu_{-i}+\Omega_{-i} X_{t}+\alpha_{-i} \Delta D_{t}+\beta_{-i} F_{t}+\eta_{-i, t} \\
r_{m, t} & =\mu_{m}+\omega_{m}^{T} X_{t}+\alpha_{m} \Delta D_{t}+F_{t}+w^{T} \eta_{t},
\end{aligned}
$$

where $\mu_{m}=w^{T} \mu, \omega_{m}^{T}=w^{T} \Omega$, and so on. We have assumed that $w^{T} \beta=1$, which is a normalization. 
Substituting out $r_{-i, t}$,

$$
\begin{aligned}
\Delta D_{t}= & \frac{\mu_{d}+\gamma_{-i}^{T} \mu_{-i}}{1-\gamma_{-i}^{T} \alpha_{-i}}+\frac{\omega_{D}^{T}+\beta_{-i}^{T} \Omega_{-i}}{1-\gamma_{-i}^{T} \alpha_{-i}} X_{t}+\frac{\gamma_{i}^{T} r_{i, t}}{1-\gamma_{-i}^{T} \alpha_{-i}}+ \\
& \frac{\beta_{D}+\gamma_{-i}^{T} \beta_{-i}}{1-\gamma_{-i}^{T} \alpha_{-i}} F_{t}+\frac{1}{1-\gamma_{-i}^{T} \alpha_{-i}}\left(\gamma_{-i}^{T} \eta_{-i, t}+\varepsilon_{t}\right) \\
r_{i, t}= & \mu_{i}+\omega_{i}^{T} X_{t}+\alpha_{i} \Delta D_{t}+\beta_{i} F_{t}+\eta_{i, t} \\
r_{m, t}= & \mu_{m}+\omega_{m}^{T} X_{t}+\alpha_{m} \Delta D_{t}+F_{t}+w^{T} \eta_{t}
\end{aligned}
$$

as above. Next, we solve for $F_{t}$ using the market return equation:

$$
F_{t}=r_{m, t}-\mu_{m}-\omega_{m}^{T} X_{t}-\alpha_{m} \Delta D_{t}-w^{T} \eta_{t}
$$

Plugging this into our system of equations,

$$
\begin{aligned}
\left(1+\alpha_{m} \frac{\beta_{D}+\gamma_{-i}^{T} \beta_{-i}}{1-\gamma_{-i}^{T} \alpha_{-i}}\right) \Delta D_{t}= & \left(\frac{\mu_{d}+\gamma_{-i}^{T} \mu_{-i}}{1-\gamma_{-i}^{T} \alpha_{-i}}-\frac{\beta_{D}+\gamma_{-i}^{T} \beta_{-i}}{1-\gamma_{-i}^{T} \alpha_{-i}} \mu_{m}\right)+\left(\frac{\omega_{D}^{T}+\beta_{-i}^{T} \Omega_{-i}}{1-\gamma_{-i}^{T} \alpha_{-i}}-\frac{\beta_{D}+\gamma_{-i}^{T} \beta_{-i}}{1-\gamma_{-i}^{T} \alpha_{-i}} \omega_{m}^{T}\right) X_{t}+ \\
& \frac{\gamma_{i}^{T} r_{i, t}}{1-\gamma_{-i}^{T} \alpha_{-i}}+\frac{\beta_{D}+\gamma_{-i}^{T} \beta_{-i}}{1-\gamma_{-i}^{T} \alpha_{-i}} r_{m, t}+\left(\frac{\gamma_{-i}^{T}}{1-\gamma_{-i}^{T} \alpha_{-i}}-\frac{\beta_{D}+\gamma_{-i}^{T} \beta_{-i}}{1-\gamma_{-i}^{T} \alpha_{-i}} w_{-i}^{T}\right) \eta_{-i, t}+ \\
& \frac{\beta_{D}+\gamma_{-i}^{T} \beta_{-i}}{1-\gamma_{-i}^{T} \alpha_{-i}} w_{i} \eta_{i, t}+\frac{1}{1-\gamma_{-i}^{T} \alpha_{-i}} \varepsilon_{t} \\
r_{i, t}= & \left(\mu_{i}-\beta_{i} \mu_{m}\right)+\left(\omega_{i}^{T}-\beta_{i} \omega_{m}^{T}\right) X_{t}+\left(\alpha_{i}-\beta_{i} \alpha_{m}\right) \Delta D_{t} \\
& +\beta_{i} r_{m, t}+\left(1-w_{i} \beta_{i}\right) \eta_{i, t}+w_{-i}^{T} \eta_{-i, t}
\end{aligned}
$$

From these equations, it follows that the event study approach and Rigobon (2003) approach both identify the coefficient $\left(\alpha_{i}-\beta_{i} \alpha_{m}\right)$, under their identifying assumptions, which is the coefficient of interest. 


\section{J Event and Excluded Dates}

Table 18: Default Probability Changes and Returns during Event Windows

\begin{tabular}{cccc}
\hline Event Number & Two-Day Window End Date & $\Delta D(\%)$ & Equity Return $(\%)$ \\
\hline 1 & November 27, 2012 & 4.40 & 3.90 \\
2 & November 29, 2012 & -10.61 & 6.75 \\
3 & December 5, 2012 & -6.40 & 2.84 \\
4 & December 7, 2012 & -0.58 & 0.10 \\
5 & January 11, 2013 & 3.44 & 0.08 \\
6 & March 4, 2013 & -5.41 & 7.44 \\
7 & March 27, 2013 & 2.59 & -2.07 \\
8 & August 26, 2013 & 2.35 & -3.21 \\
9 & October 4, 2013 & 0.05 & -2.64 \\
10 & October 8, 2013 & -1.56 & 2.60 \\
11 & November 19, 2013 & -0.04 & -3.99 \\
12 & January 13, 2014 & 2.38 & -0.95 \\
13 & June 16, 2014 & 7.72 & -6.50 \\
14 & June 24, 2014 & -5.56 & 2.92 \\
15 & June 27, 2014 & 5.83 & -2.73
\end{tabular}

Notes: $\Delta D$ refers to the percent change in the risk-neutral probability of default and Equity Return refers to the log return on the value-weighted index of ADRs. 


\begin{tabular}{|c|c|c|c|c|c|c|}
\hline 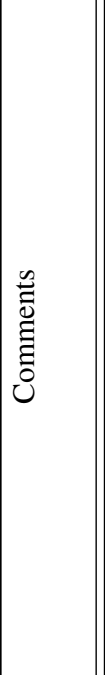 & 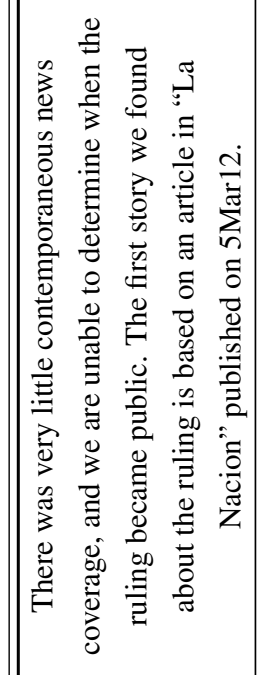 & 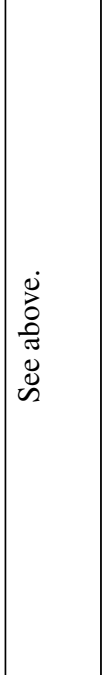 & 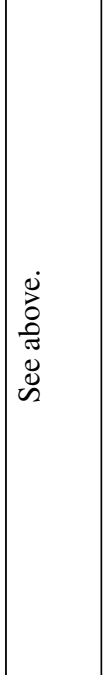 & 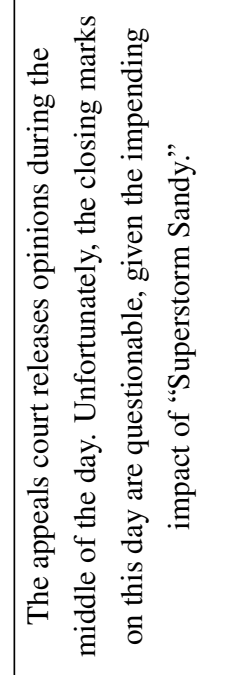 & 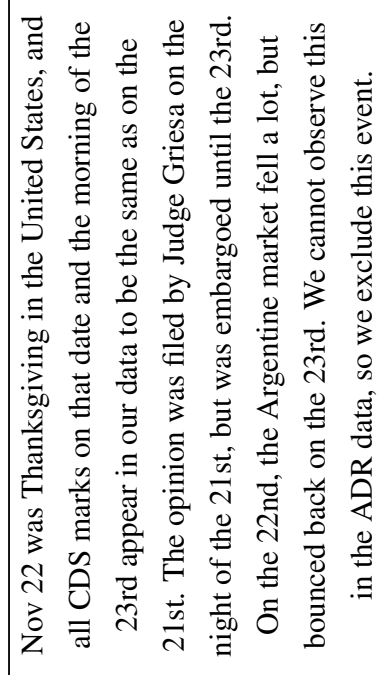 & 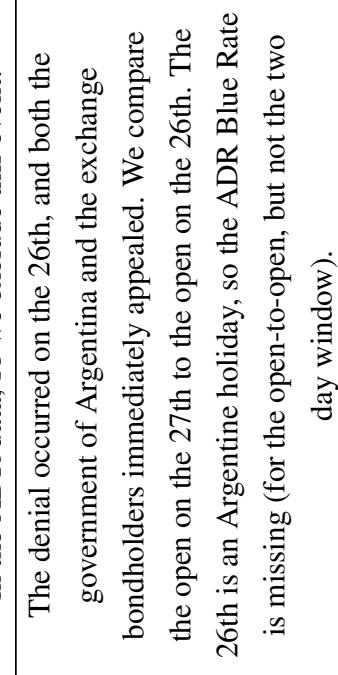 \\
\hline & 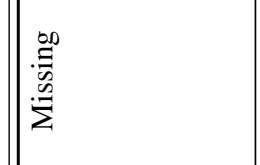 & 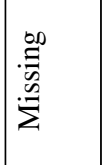 & 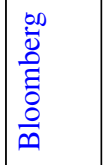 & 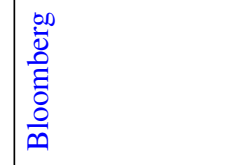 & 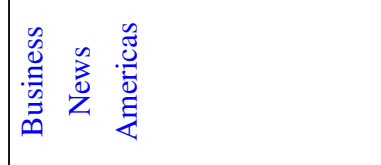 & 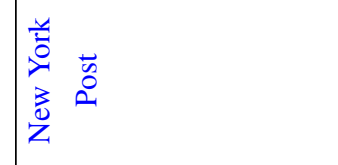 \\
\hline 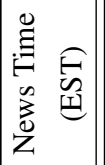 & 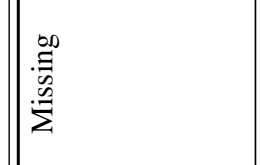 & 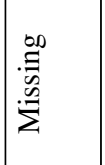 & 竞竞 & 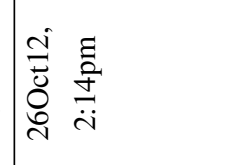 & 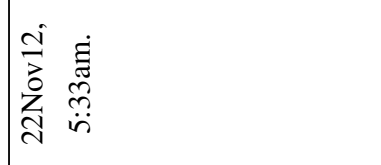 & 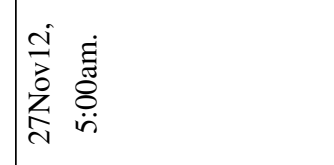 \\
\hline 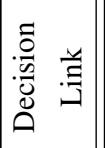 & 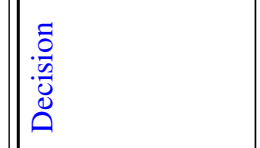 & $\begin{array}{l}\frac{\vec{g}}{0} \\
\overline{0}\end{array}$ & 蛋 & 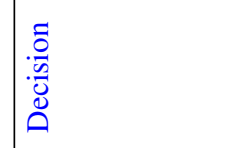 & 离 & 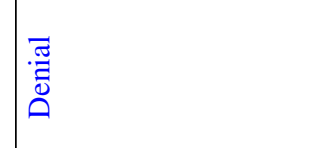 \\
\hline 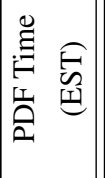 & |udscs:zi imara & 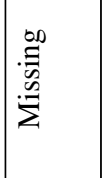 & 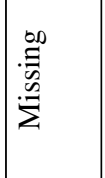 & 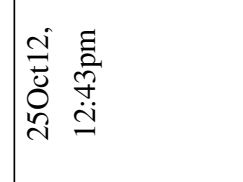 & 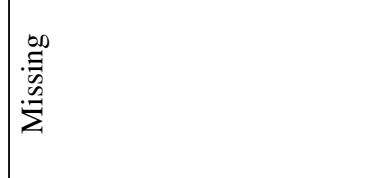 & 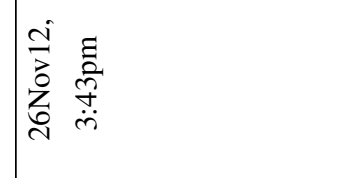 \\
\hline & 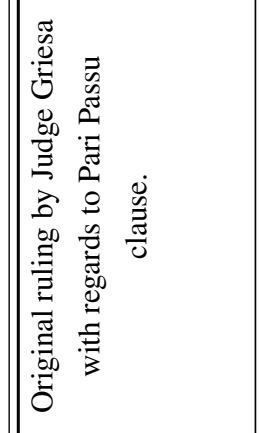 & 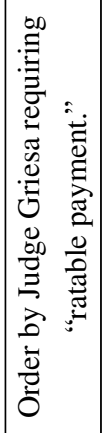 & 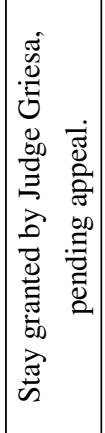 & 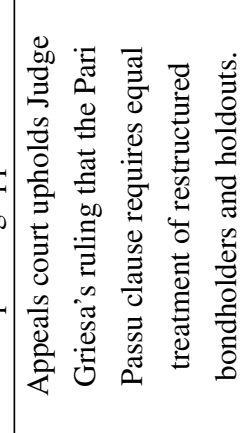 & 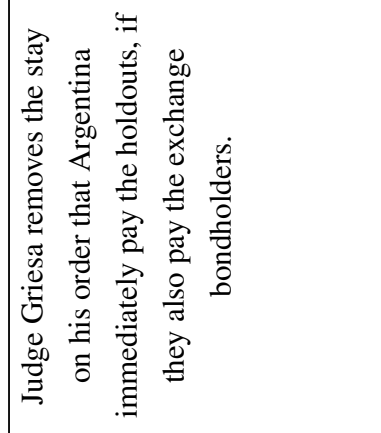 & 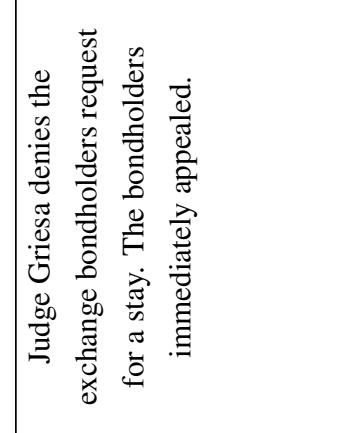 \\
\hline 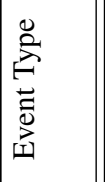 & 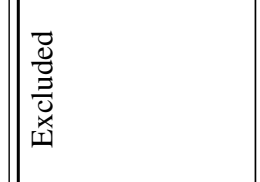 & 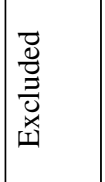 & 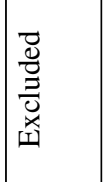 & 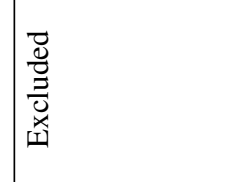 & 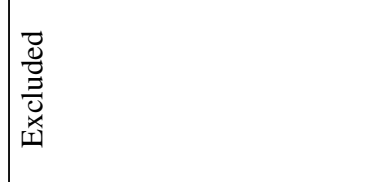 & 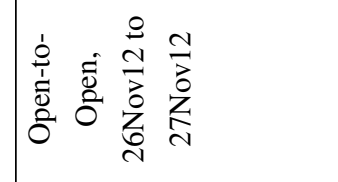 \\
\hline 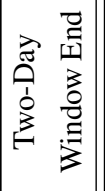 & $\mid \begin{array}{l}\overrightarrow{\tilde{u}} \\
\stackrel{\Delta}{2}\end{array}$ & 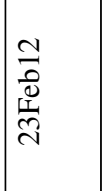 & 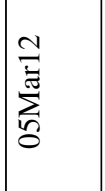 & 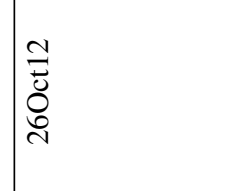 & $\mid$ & 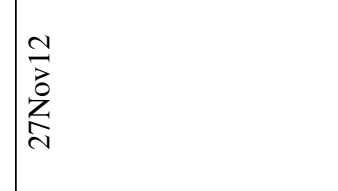 \\
\hline
\end{tabular}




\begin{tabular}{|c|c|c|c|c|c|c|}
\hline Dे & & & & 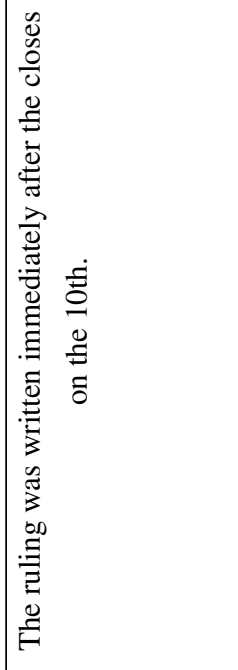 & 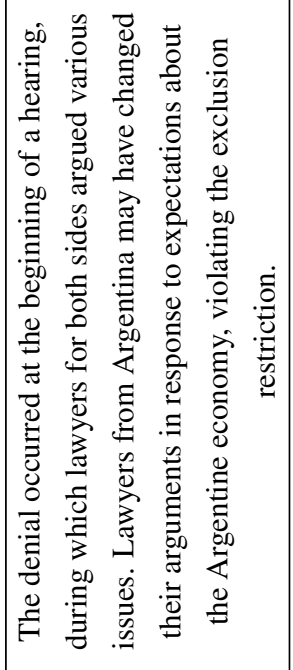 & 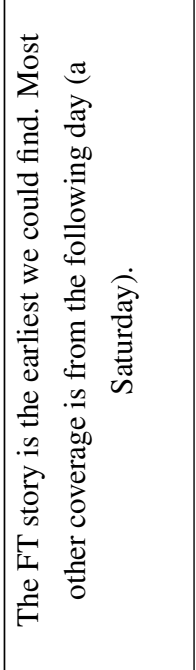 \\
\hline & 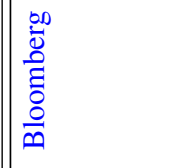 & 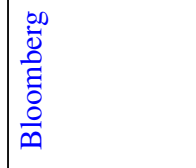 & 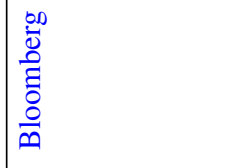 & 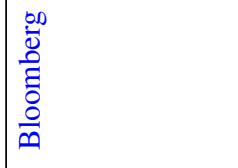 & 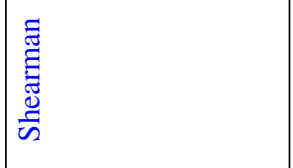 & 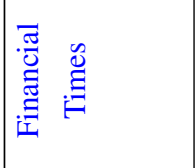 \\
\hline 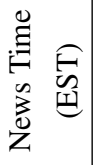 & 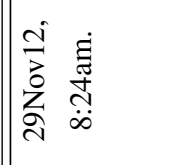 & 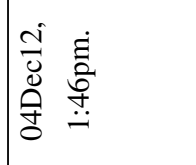 & 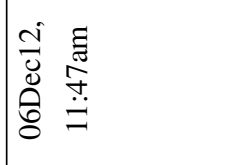 & 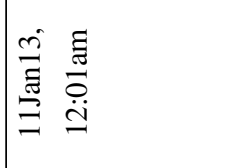 & 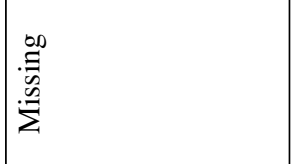 & 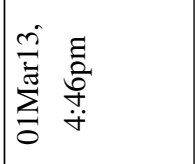 \\
\hline 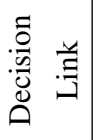 & 宓 & 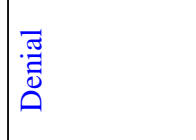 & $\frac{\dot{v}}{\tilde{g}}$ & $\frac{\dot{\bar{v}}}{\dot{0}}$ & 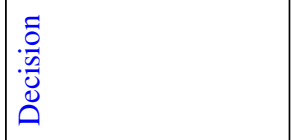 & 离 \\
\hline 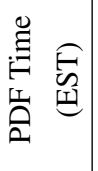 & 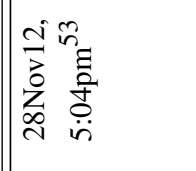 & 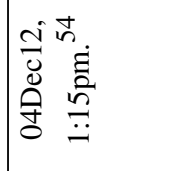 & 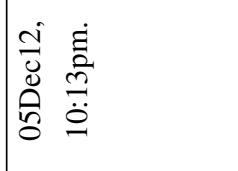 & 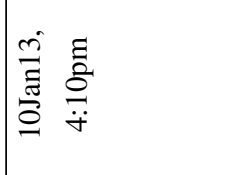 & 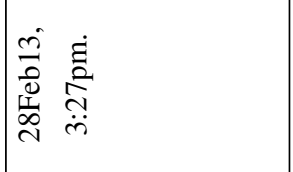 & 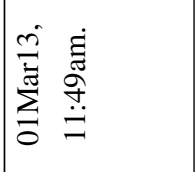 \\
\hline 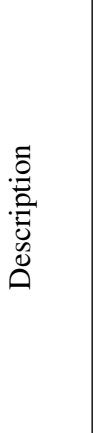 & 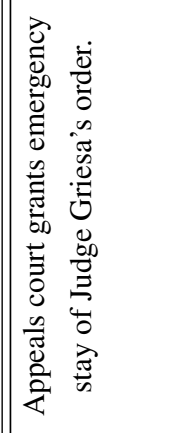 & 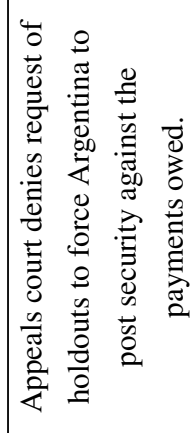 & 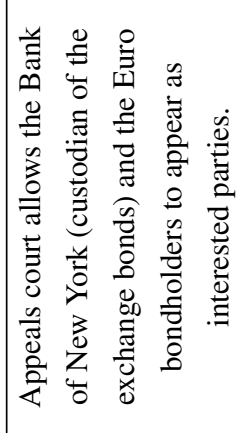 & 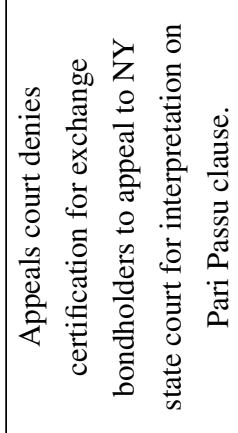 & 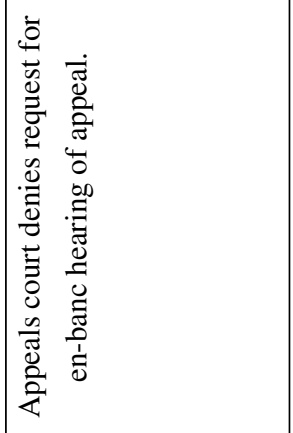 & 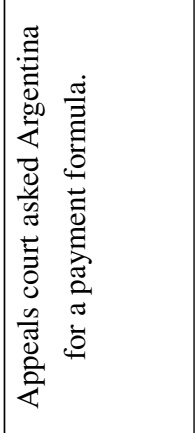 \\
\hline 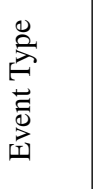 & 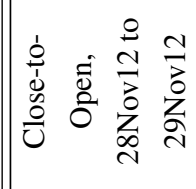 & 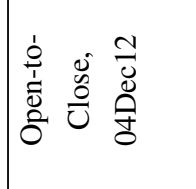 & 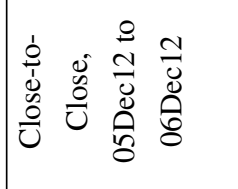 & 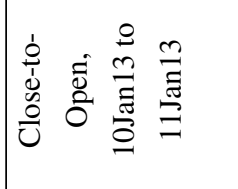 & 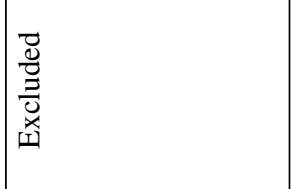 & 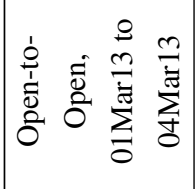 \\
\hline 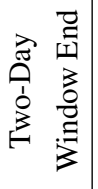 & 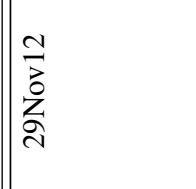 & 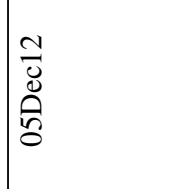 & 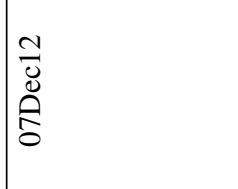 & $\underset{\stackrel{M}{\Xi}}{\stackrel{M}{\Xi}}$ & 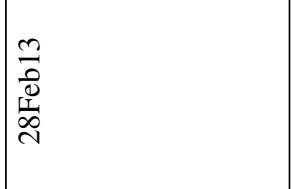 & 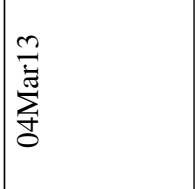 \\
\hline
\end{tabular}




\begin{tabular}{|c|c|c|c|c|c|c|c|}
\hline 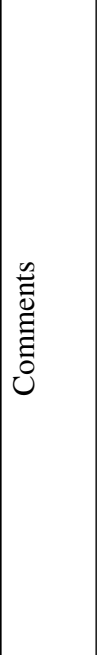 & 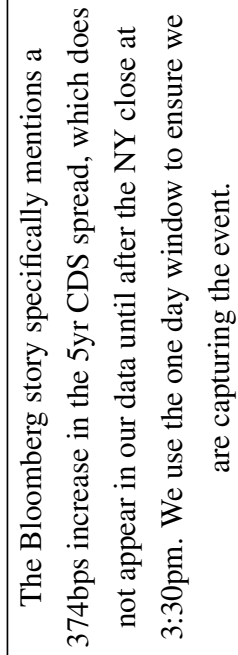 & 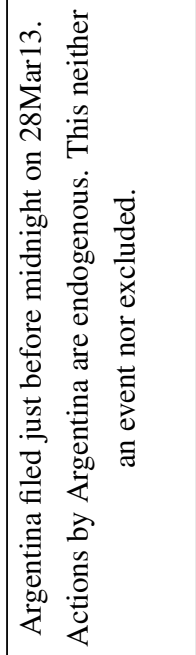 & 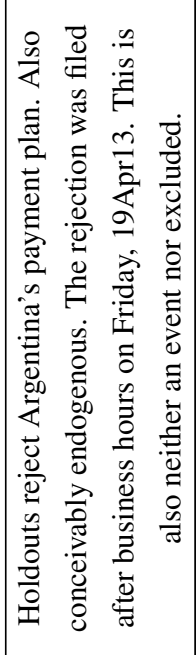 & 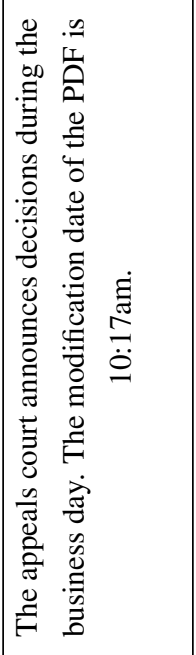 & 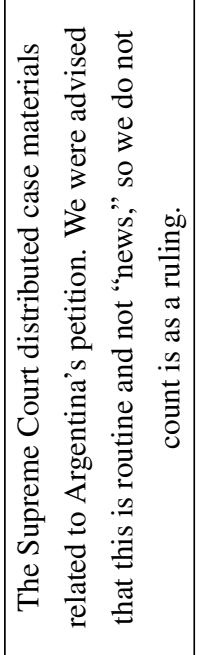 & 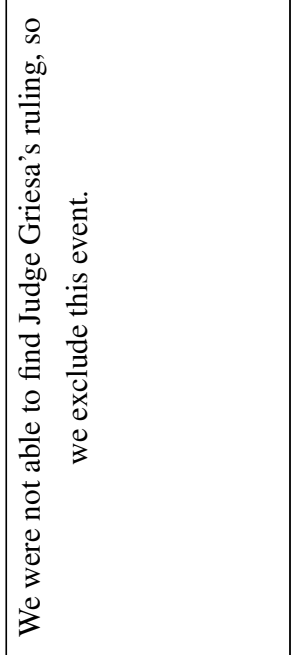 & \\
\hline 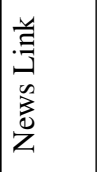 & 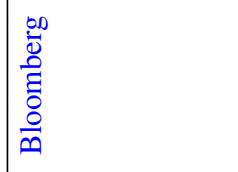 & 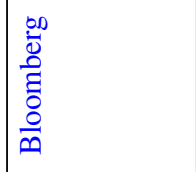 & 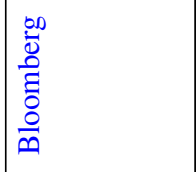 & 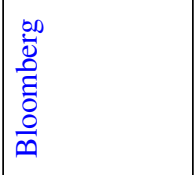 & 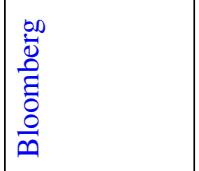 & 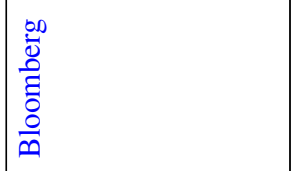 & 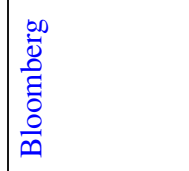 \\
\hline 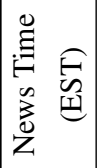 & 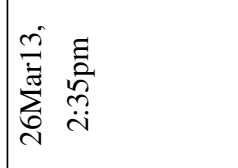 & 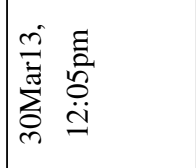 & 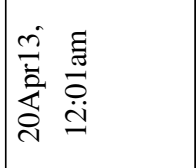 & 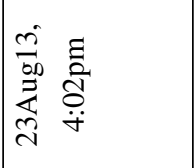 & 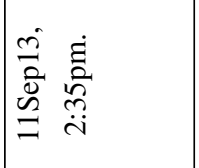 & 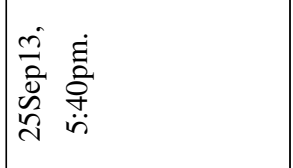 & 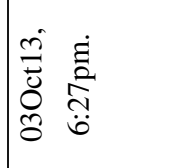 \\
\hline 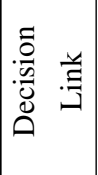 & $\frac{\bar{\Xi}}{\tilde{0}}$ & $\overleftrightarrow{\measuredangle}$ & $\frac{\vec{\lambda}}{\stackrel{\overrightarrow{2}}{\ddot{2}}}$ & 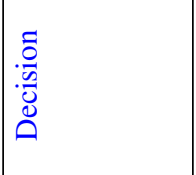 & 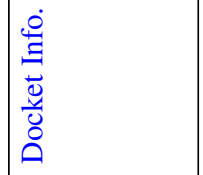 & 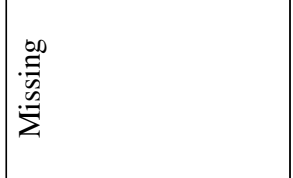 & 离 \\
\hline 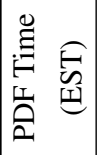 & 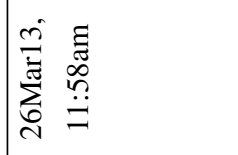 & 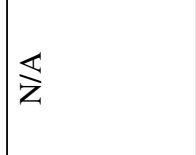 & 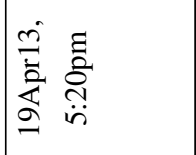 & 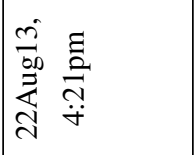 & 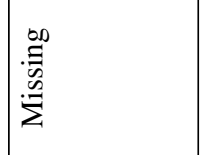 & 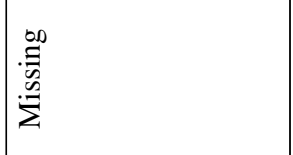 & 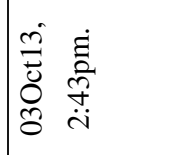 \\
\hline 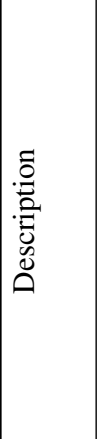 & 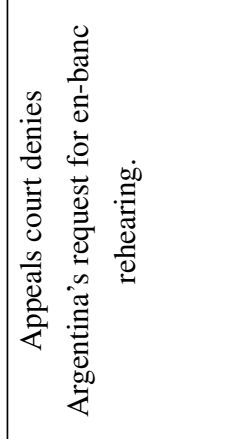 & 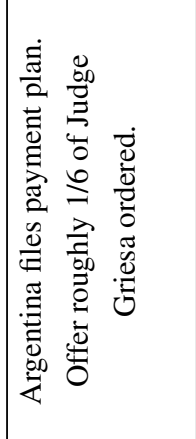 & 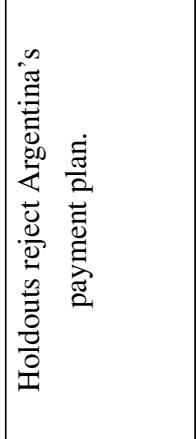 & 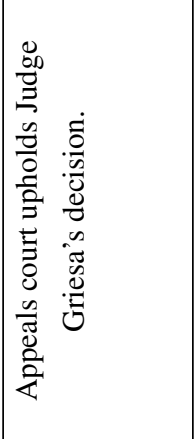 & 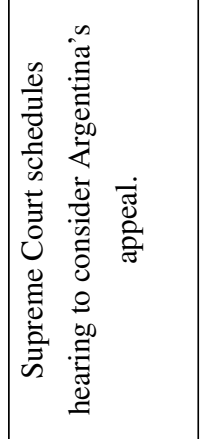 & 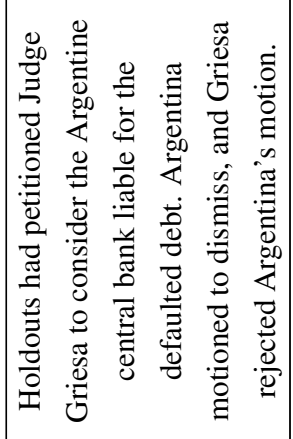 & 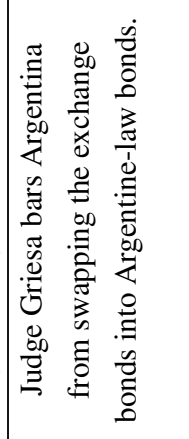 \\
\hline 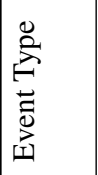 & 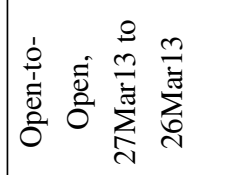 & 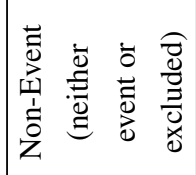 & 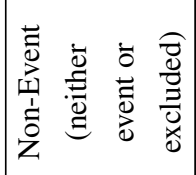 & 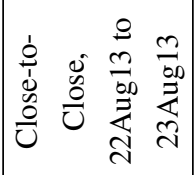 & 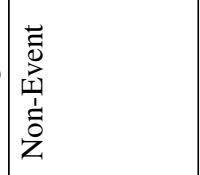 & 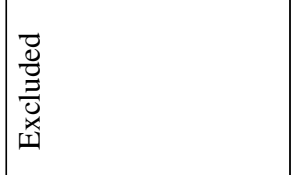 & 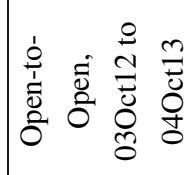 \\
\hline 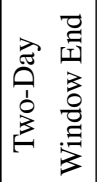 & 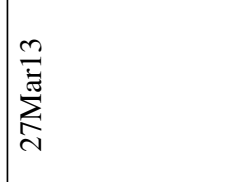 & $\frac{m}{\bar{c}}$ & 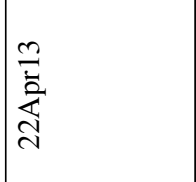 & 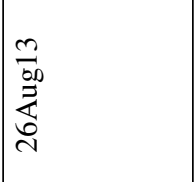 & 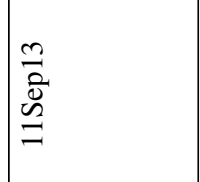 & $\begin{array}{l}m \\
\frac{m}{0} \\
0 \\
0 \\
0 \\
i\end{array}$ & $\begin{array}{l}\frac{9}{\tilde{U}} \\
\dot{0} \\
\\
0\end{array}$ \\
\hline
\end{tabular}




\begin{tabular}{|c|c|c|c|c|c|c|c|c|}
\hline Uू. & 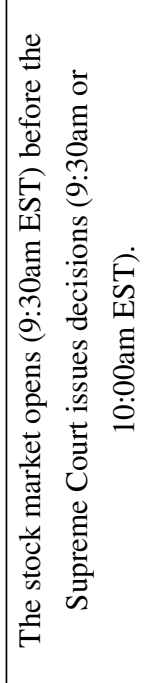 & 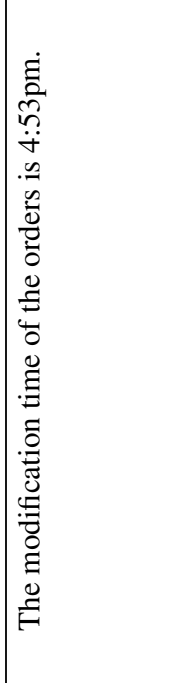 & 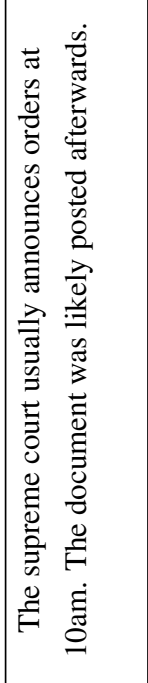 & 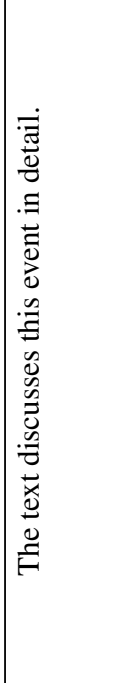 & 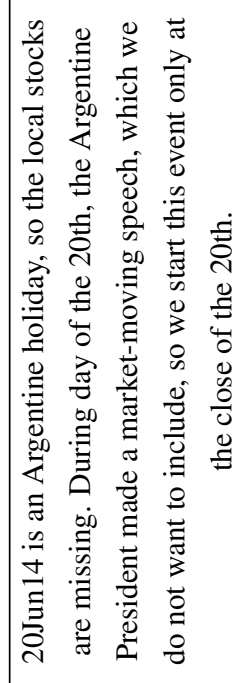 & 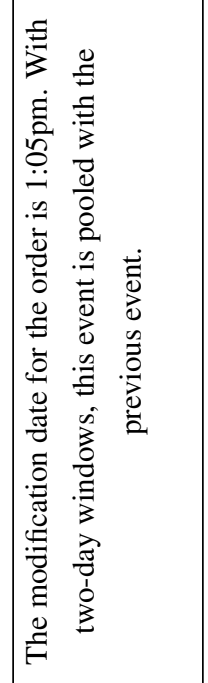 & & \\
\hline 羔 & $\underbrace{}_{\substack{n \\
0}}$ & 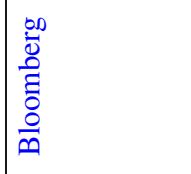 & 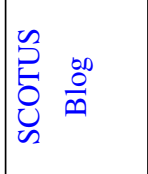 & 象 & & 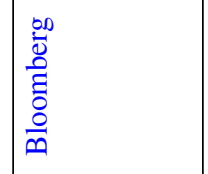 & 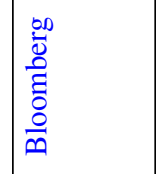 & \\
\hline 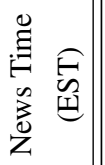 & 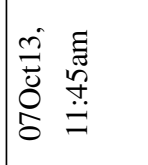 & 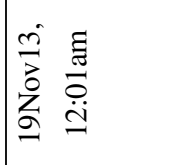 & 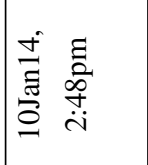 & 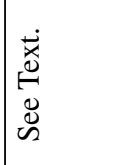 & & 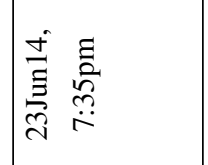 & 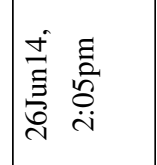 & \\
\hline 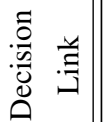 & 离 & 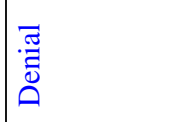 & 离 & $\mid$ & 离 & 离 & 产 & \\
\hline 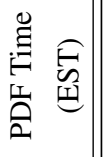 & $\overleftrightarrow{z}$ & 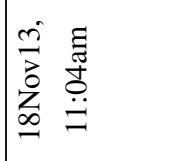 & 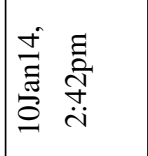 & 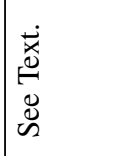 & 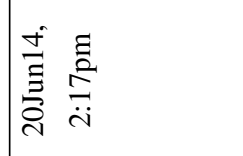 & 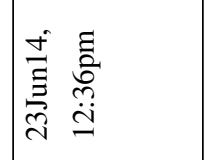 & 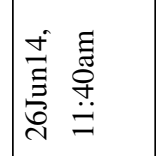 & \\
\hline & 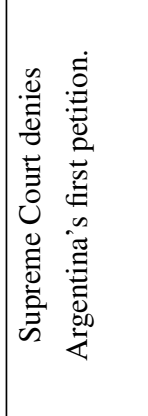 & 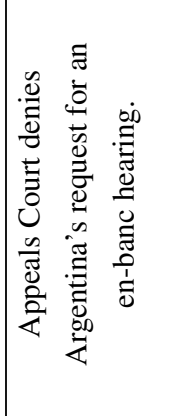 & 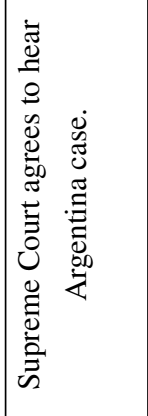 & 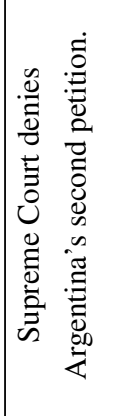 & 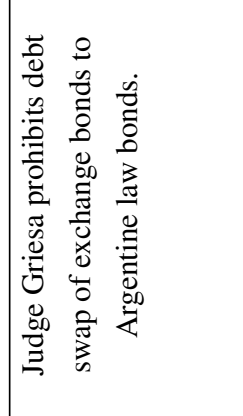 & 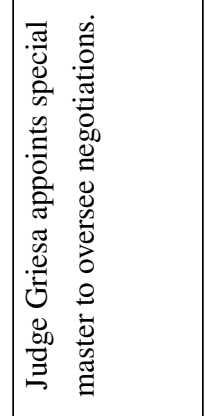 & 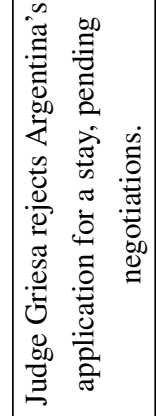 & 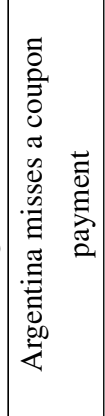 \\
\hline 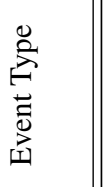 & 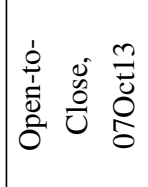 & 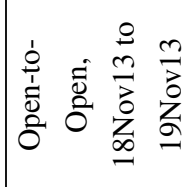 & 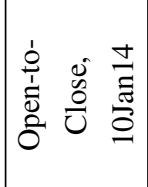 & 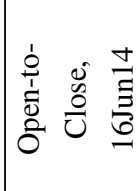 & 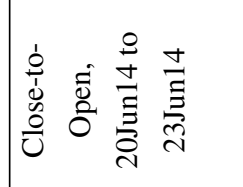 & 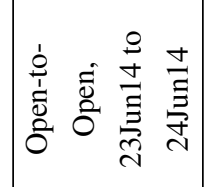 & 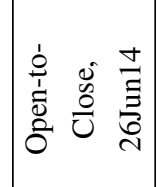 & 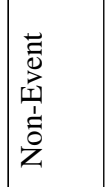 \\
\hline 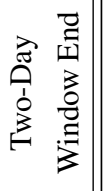 & $\begin{array}{l}m \\
\bar{z} \\
\dot{0} \\
\ddot{0}\end{array}$ & $\begin{array}{l}m \\
\frac{m}{a} \\
\vdots \\
2\end{array}$ & 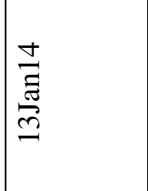 & 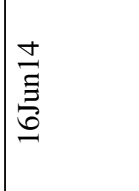 & 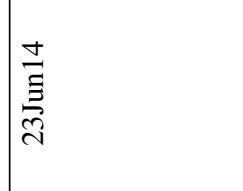 & 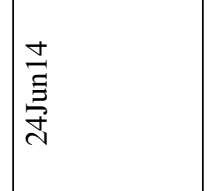 & 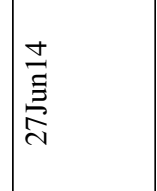 & 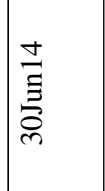 \\
\hline
\end{tabular}




\begin{tabular}{|c|c|c|}
\hline : & 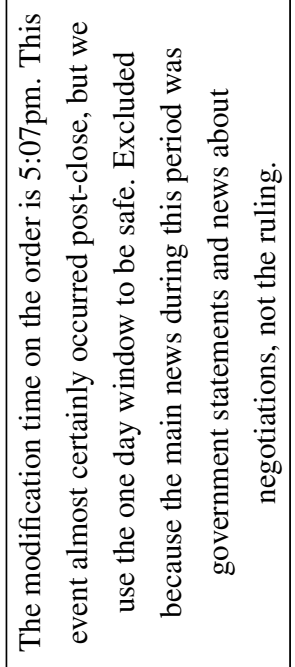 & 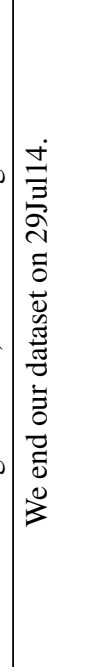 \\
\hline 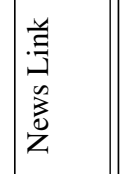 & 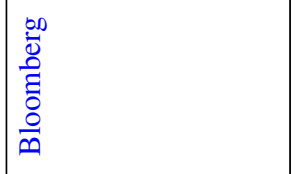 & 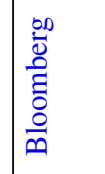 \\
\hline 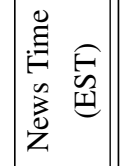 & 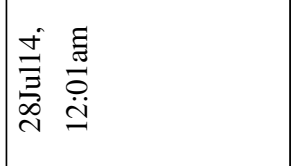 & \\
\hline 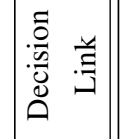 & 离 & \\
\hline 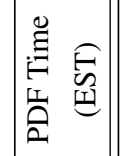 & 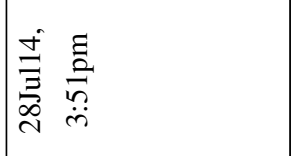 & \\
\hline & 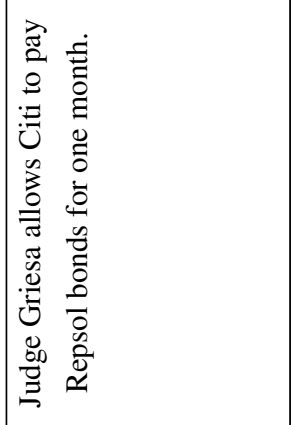 & 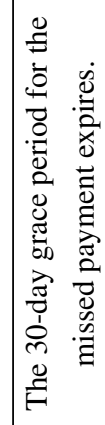 \\
\hline 总 & 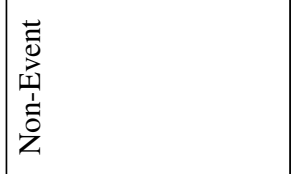 & \\
\hline 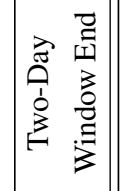 & 离 & 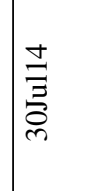 \\
\hline
\end{tabular}




\section{Appendix References}

Brown, Morton B. and Alan B. Forsythe, "Robust tests for the equality of variances," Journal of the American Statistical Association, 1974, 69 (346), 364-367.

Campbell, John Y., Andrew W. Lo, and Craig MacKinlay, The Econometrics of Financial Markets, Princeton University press, 1997.

Chodos, Daniel and Igor Arsenin, "Argentina: NDFs are a good hedge for the Blue Chip swap (only) in "blow-up" scenarios," Credit Suisse Fixed Income Research, April 2012.

Cotterill, Joseph, "Bonar turns into subpoena," FT Alphaville April 2015. http://ftalphaville.ft. com/2015/02/26/2120454/bonar-turns-into-subpoena/ [Accessed: 5/1/2016].

_ , "The great Bonar caper," FT Alphaville April 2015. http://ftalphaville.ft.com/2015/04/23/ 2127218/the-great-bonar-caper/ [Accessed: 5/1/2016].

Dolarblue.net, "Como adquirir (o vender) dólares legalmente a través de la Bolsa," September 2014. http://web.archive.org/web/20150323065949/http://blog.dolarblue.net/2014/09/ como-adquirir-o-vender-dolares .html [Accessed: 5/1/2016].

_, "Cálculo," 2016. http://web.archive.org/web/20150926023011/http://blog.dolarblue. net/p/calculo.html [Accessed: 5/1/2016].

Foley-Fisher, Nathan and Bernardo Guimaraes, "US real interest rates and default risk in emerging economies," Journal of Money, Credit and Banking, 2013, 45 (5), 967-975.

Gopinath, Gita and Brent Neiman, "Trade Adjustment and Productivity in Large Crises," American Economic Review, 2014, 104 (3), 793-831.

Gürkaynak, Refet S., Brian Sack, and Jonathan H. Wright, "The US Treasury Yield Curve: 1961 to the Present," Journal of Monetary Economics, 2007, 54 (8), 2291-2304.

Horowitz, Joel L., “The Bootstrap,” Handbook of Econometrics, 2001, 5, 3159-3228.

Infodolar, "COTIZACIÓN DÓLAR CONTADO CON LIQUIDACIÓN,” 2016.

Levene, Howard, "Robust tests for equality of variances," Contributions to probability and statistics: Essays in honor of Harold Hotelling, 1960, 2, 278-292.

Longstaff, Francis A., Jun Pan, Lasse Heje Pedersen, and Kenneth J. Singleton, "How Sovereign Is Sovereign Credit Risk?," American Economic Journal: Macroeconomics, 2011, 3 (2), 75-103.

Markit, "Markit CDS Sensitivities Methodology,” January 2012.

Nakamura, Emi and Jón Steinsson, "High frequency identification of monetary non-neutrality," Technical Report, National Bureau of Economic Research 2013.

Pan, Jun and Kenneth J. Singleton, "Default and Recovery Implicit in the Term Structure of Sovereign CDS Spreads,” The Journal of Finance, 2008, 63 (5), 2345-2384.

Rigobon, Roberto, "Identification through Heteroskedasticity," Review of Economics and Statistics, 2003, 85 (4), 777-792.

Stock, James H. and Motohiro Yogo, “Testing for Weak Instruments in Linear IV Regression,” Identification and Inference for Econometric Models: Essays in honor of Thomas Rothenberg, 2005, 1.

White, Richard, "The Pricing and Risk Management of Credit Default Swaps, with a Focus on the ISDA Model," OpenGamma Quantitative Research, 2013, (16). 